\title{
Catalytic Neutralization of Water Pollutants Mediated by Den- dritic Polymers
}

\author{
Michael Arkas ${ }^{1, *}$, Ioannis Anastopoulos ${ }^{2}$ Dimitrios A. Giannakoudakis ${ }^{3}$, Ioannis Pashalidis ${ }^{4}$, Theodora Katsika ${ }^{1}$, \\ Eleni Nikoli 1, Rafael Panagiotopoulos ${ }^{1}$ Anna Fotopoulou ${ }^{1}$, Michail Vardavoulias ${ }^{5}$, and Marilina Douloudi 1,*
}

1 Demokritos National Centre for Scientific Research, Institute of Nanoscience and Nanotechnology, Athens, Greece.; m.arkas@inn.demokritos.gr (M.A.); theodorakatsika@gmail.com (T.K.); h.nikoli@inn.demokritos.gr (E.N.); rafail.panagiotopoulos@hotmail.gr (R.P); a.fotopoulou99@hotmail.com (A.F.); marilina.douloudi@gmail.com (M.D.).

2 Department of Agriculture, University of Ioannina, UoI Kostakii Campus, 47040 Arta, Greece.; anastopoulos_ioannis@windowslive.com

3 Department of Chemistry, Aristotle University of Thessaloniki, 54124, Thessaloniki, Greece; dagchem@gmail.com

4 Environmental \& Radioanalytical Chemistry Lab, Department of Chemistry, University of Cyprus, P.O. Box 20537, 1678 Nicosia, Cyprus; pspasch@ucy.ac.cy

5 PYROGENESIS S.A., Technological Park 1, Athinon Avenue, 19500 Attica, Greece.; mvardavoulias@pyrogenesis-sa.gr (M.V.)

* Correspondence: m.arkas@inn.demokritos.gr; (M.A.); Tel.: +30-210-650-3669 (M.A.); marilina.douloudi@gmail.com (M.D.)

\begin{abstract}
Radially polymerized dendritic compounds are nowadays an established polymer category next to their linear, branched and cross-linked counterparts. Their uncommon tree-like architecture is characterized by adjustable internal cavities and external groups. They are therefore exceptional absorbents and this attainment of high concentrations into their interior renders them ideal reaction media. In this framework they are applied in many environmentally benign implementations. One of the most important among them is water purification though pollutant decomposition. Simple and composite catalysts and photo-catalysts containing dendritic polymers and applied in water remediation will be discussed jointly with some unconventional solutions and future prospects.
\end{abstract}

Keywords: Dendritic Polymers; Dendrimers; Metal Nanoparticles; Photocatalysis; Water Purification; dye discoloration; pollutant degradation; nanoparticle catalysis; decomposition; semicoductors

\section{Introduction}

The field of Nanoscience has noticed particular research attention and growth the last two decades thanks to its vast applicability in several areas, including catalysis, optoelectronics, sensing, drug delivery, energy storage and water decontamination [1-6]. Water pollution is a serious global environmental phenomenon and poses a major threat for both the maintenance of aquatic ecosystem and human health and welfare. Among all different water pollution sources, the industrial sector takes the leading place, producing the highest amount of organic and inorganic waste water, most of which are toxic and non-biodegradable and can produce carcinogenic or mutagenic effects in tissues of living organisms through ingestion, inhalation and skin contact [7-8]. Specifically, industrial phenolic byproducts, dyes and pigments constitute some representative examples of such water contaminants, while their increased solubility in water, along with their high resistance to common degradation practices, make their removal from water environments a rather complex, costly and time-consuming process [9-11]. Some of the most popular techniques for eradicating these color substances from water are adsorption [12], catalysis 
[13], membrane technology [14], chemical oxidation [15], biological degradation and coagulation [16-17]. The first and second categories are the mostly employed methods due to their operational easiness and non-toxic nature. However, the limited recyclability, low stability and high solubility of the adsorbent/catalyst decrease their water remediation performance and necessitate the development of novel, more efficient methods for water treatment purposes [18].

The introduction of dendritic molecules revolutionized the field of nanoscale materials and polymer technology. Representing separate class after linear, branched and crosslinked counterparts they constitute the most extensively utilized, for the fabrication of nanoscale composites with adjustable architecture and controlled physicochemical properties [19,20-22]. Dendritic architectures can be classified into five main categories based on their special structural and dispersity characteristics: a) monodispersed symmetric dendrimers, b) asymmetric hyperbranched polymers, c) dendrons, fragments of dendrimers and hyperbranched polymers emanating from a focal point, d) dendronized polymers, deriving by chemical binding of dendrons to linear polymers, and e) dendrigrafts, a mixed category of hyperbranched polymers with repeated units of linear polymers and branched architecture [23-27] (Figure 1). Interestingly, the characteristic branched treelike morphology of these macromolecules, inspired the choice of their name, which comes

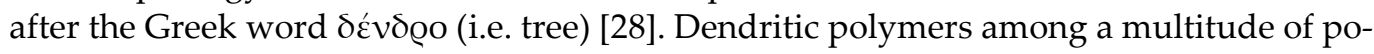
tential applications are considered novel candidates for use in water remediation treatments [14], [29], [30]. They can be synthesized through two main mechanisms: the divergent and the convergent [31-33]. In the divergent method, dendrimers' synthesis initiates from a focal point of a reactive core, whereas in the convergent method, independently synthesized dendrons are assembled to produce the final dendritic structure [34,35] (Figures 2 a, b).
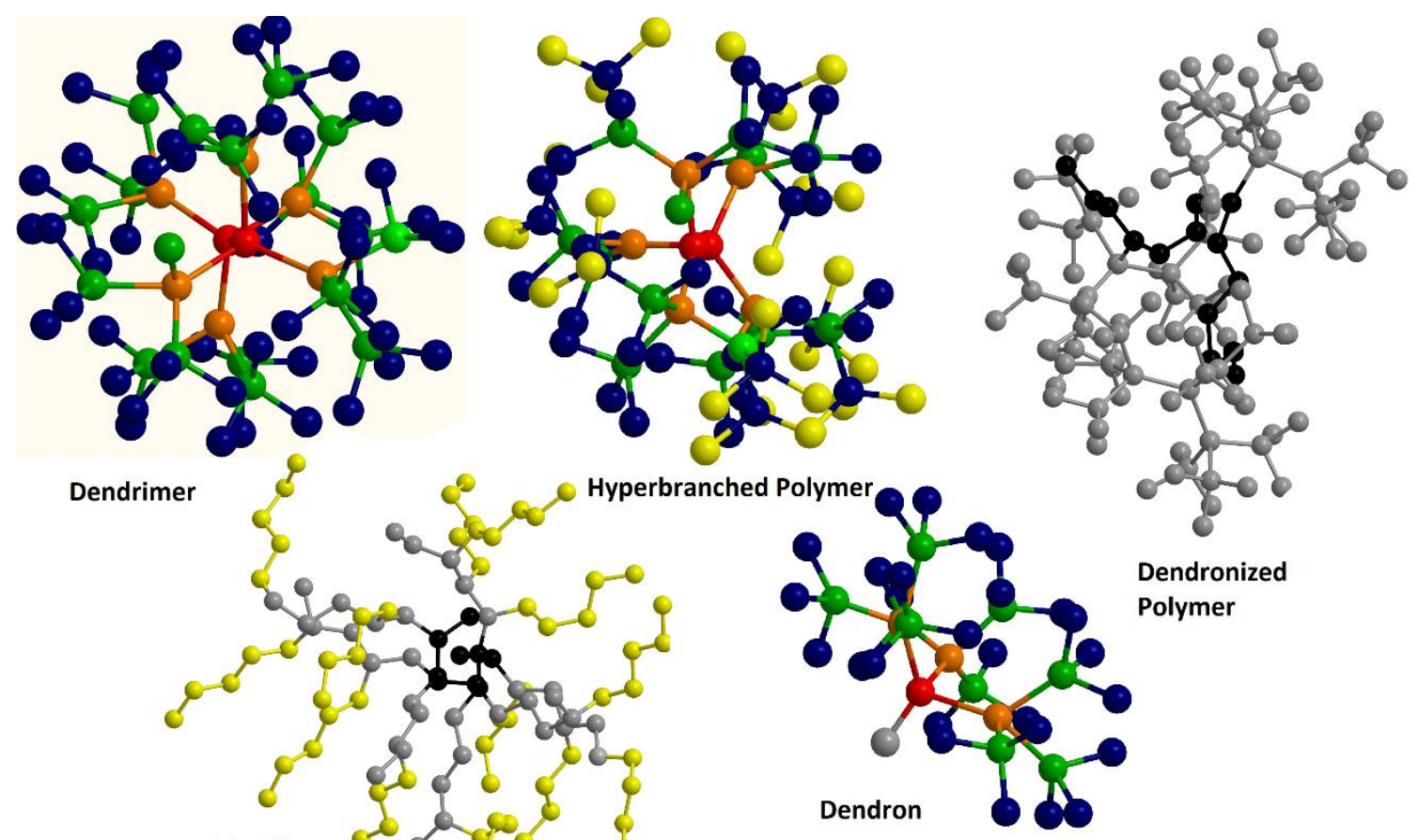

Dendrigraft
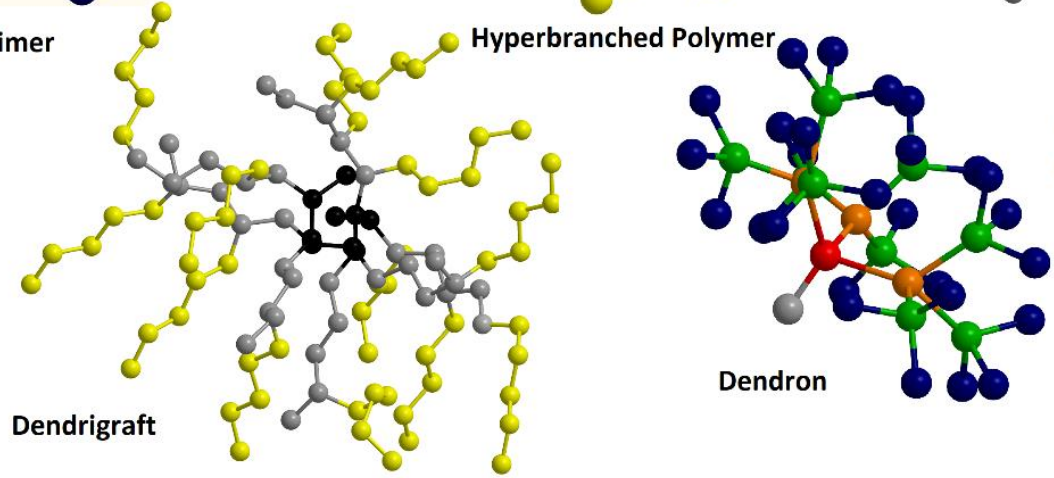

Figure 1. Schematic representation of the categories of dendritic polymers. Each sphere represents a monomer. Different colors depict the different polymerization generations. 


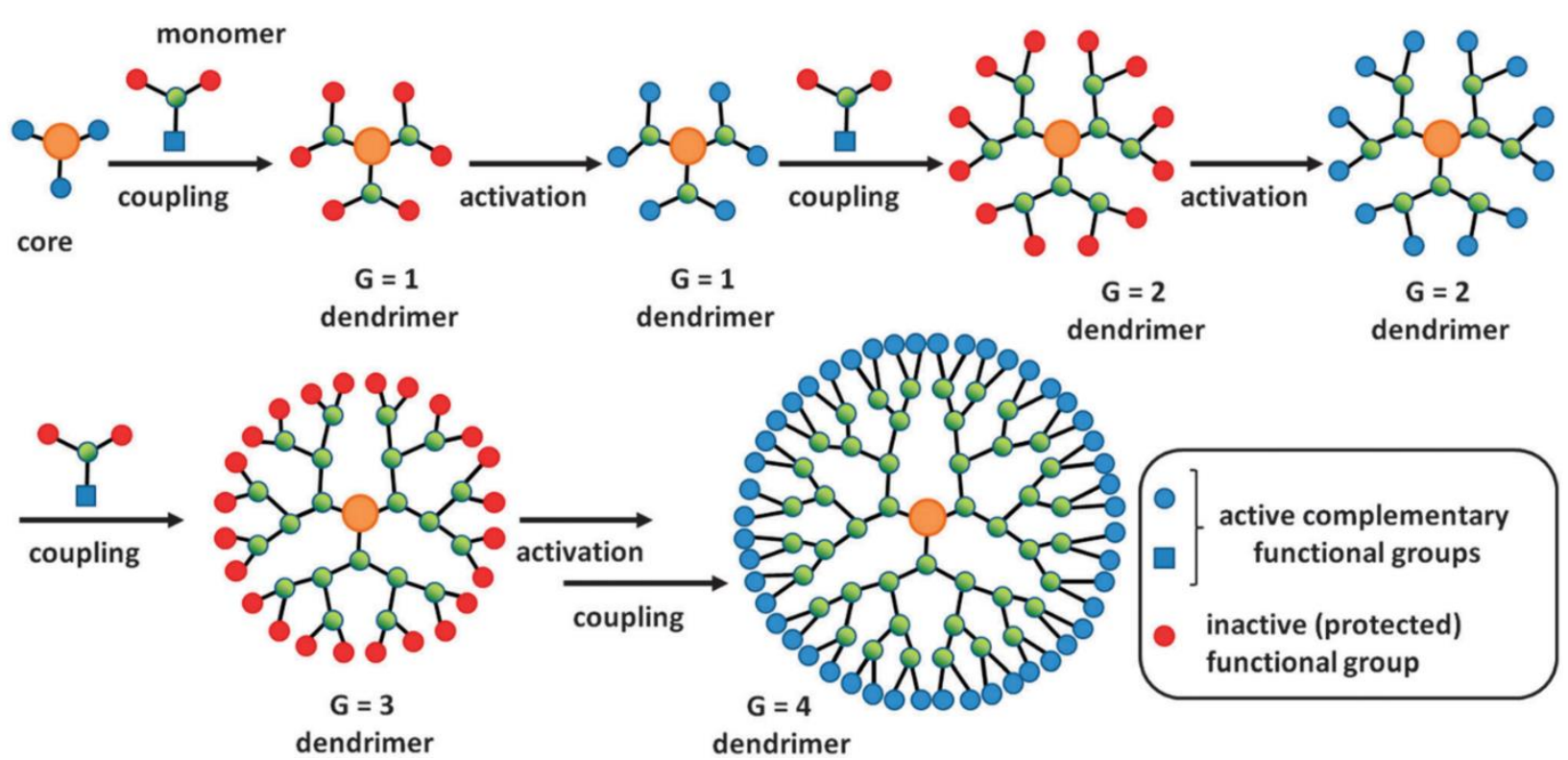

(a)
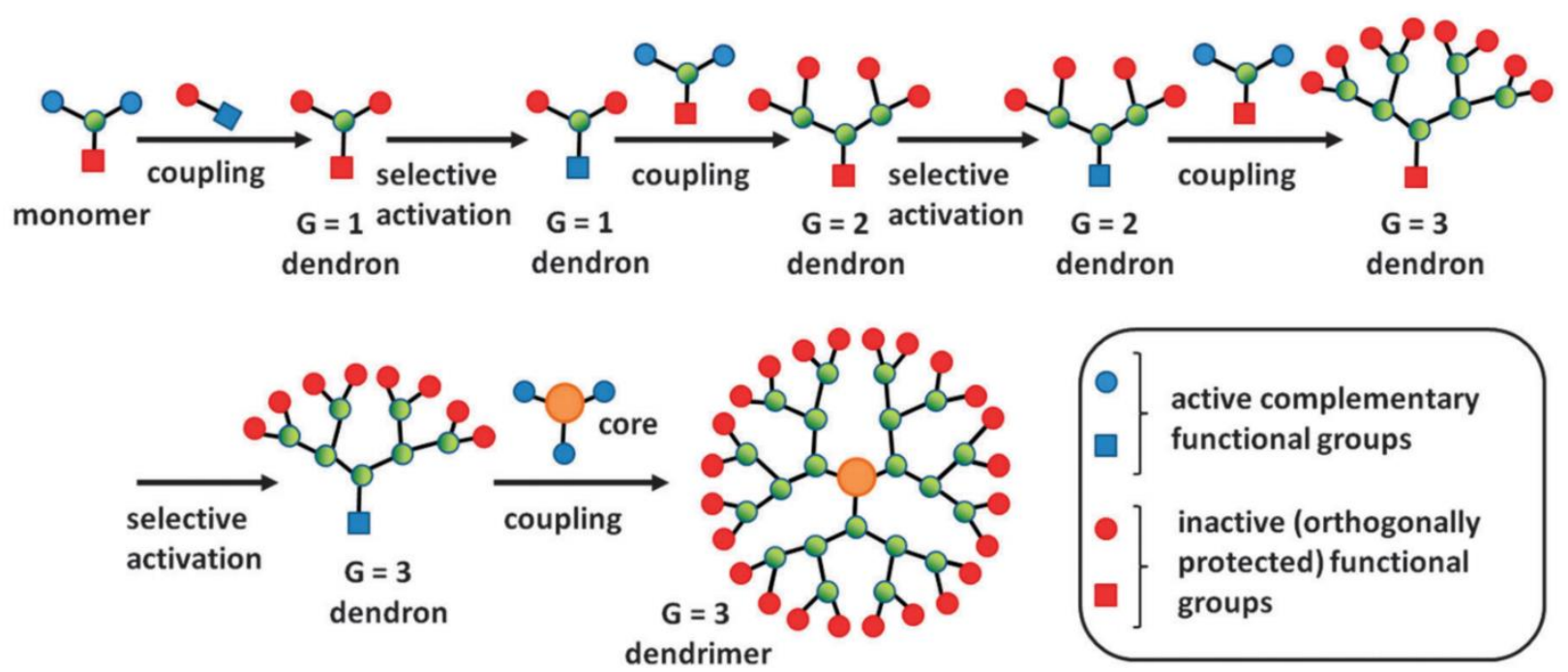

(b)

Figure 2. (a) Synthesis of dendrimers according to the divergent method. (b) Synthesis of dendrimers according to the convergent method. (Reproduced with permission from [37]; Copyright Royal Society of Chemistry).

The predominant advantage of dendritic materials is the hosting environment that they offer, which originates from the completely manageable synthetical procedure of their building blocks (e. g. functional groups of the interior branches and the exterior surface). The fabrication of hybrid nanoparticles with desired shapes and physicochemical and biological functionalities $[23,38,39]$ is thus facilitated. More particularly, tailored dendritic-metal nanocomposites can be produced, when guest metal ions can either be encapsulated in the internal "branches" of dendrimers or be stabilized with their peripheral functional end-groups. In the same way semiconductors, and other active substances of nanosized dimensions can be incorporated that combine the properties of both the dendrimer and the hosting material [26, 40]. Some of the most known and widely used dendrimers in the field of hosting technology are diamino butane poly (propylene imine) DAB/PPI and poly(amidoamine) PAMAM. The most common non-symmetric hyperbranched counterparts are poly (ethylene glycol), polyglycerol PG and poly (ethylene imine) PEI [41, 42] (Figure 3). Dendrimers as individual entities may be employed in a multitude of applications. Interestingly, their ability to act as biomimetic materials attracted many medicinal fields to use them for applied research purposes as drug delivery carriers, diagnostical and imaging tools, anticancer and gene therapy [43-46]. 


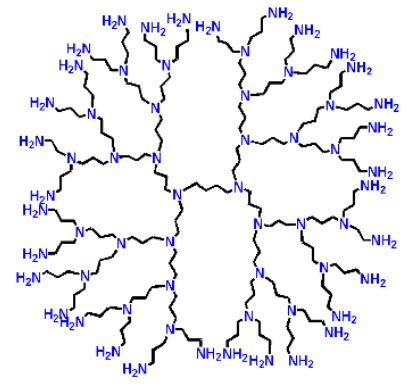

PPI

Additionally, fine-tuning of their guest-host interrelations, favors their use in separation technology as homogeneous catalysts and interestingly as inexpensive, water insoluble adsorbents of organic and inorganic water contaminants [47-49].

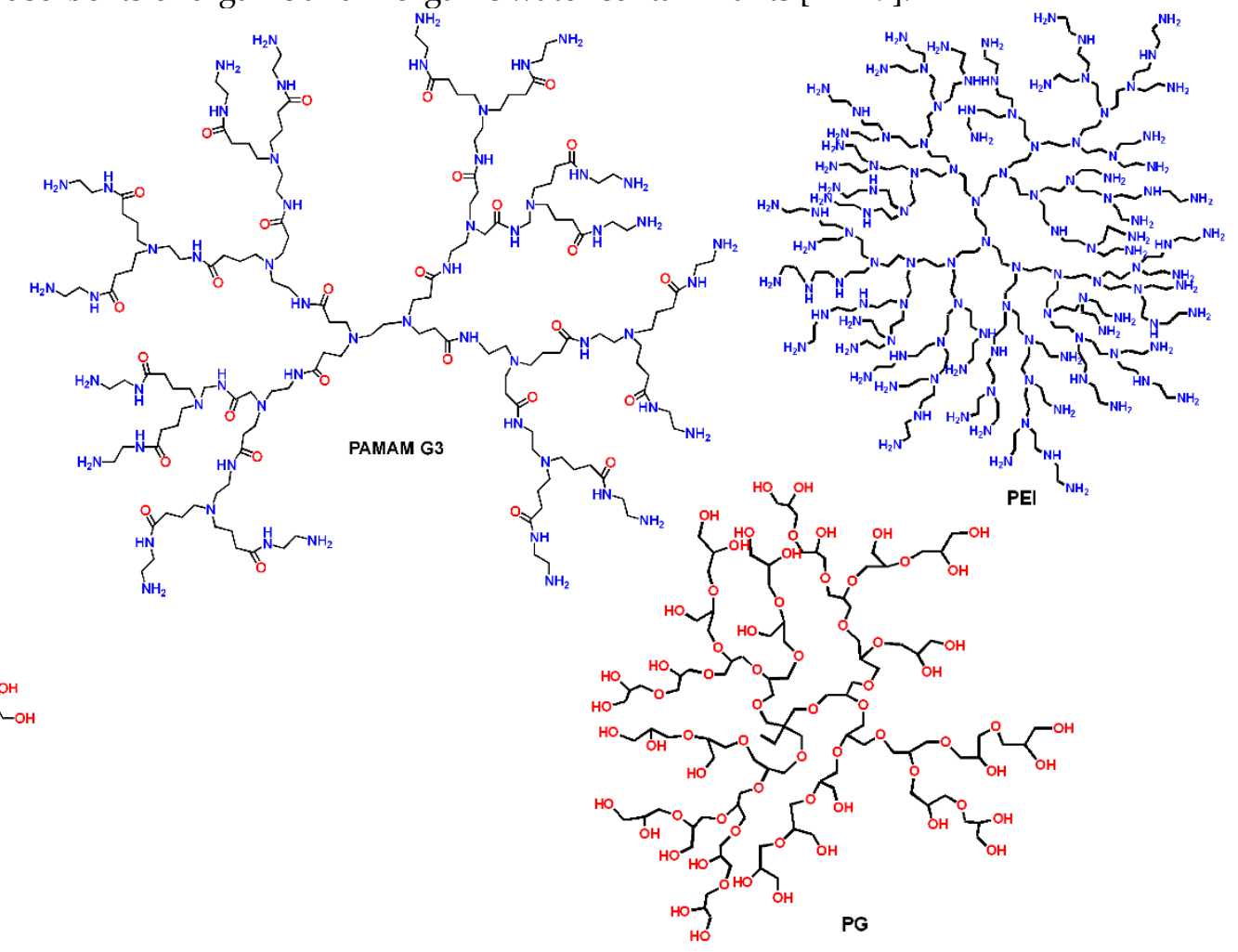

Figure 3. Chemical formulas of the most common dendritic polymers.

Transition metal nanoparticles are great candidates for use in catalytic reactions while their oxides and sulfides are suitable for photocatalysis. Owning to their special electromagnetic properties, electroconductivity and wide reactive surface area, which promotes the interfacial interaction between the active substrate and the reactants, these nano-catalysts turned out to be particularly useful in degradation processes of organic contaminants for water purification. However, their increased susceptibility towards agglomeration and oxidation, both of which significantly downgrade their catalytic potential, propelled the discovery of novel matrices and protective stabilizers that prevent the occurrence of such phenomena during catalytic procedures [50,51]. Among the various encapsulating nano-agents that can be employed as passivators, including carbon, clay, silica, zeolites and organic polymers, the latter are the most established and widely used ones. Specifically, thanks to their ability to envelop molecules, dendritic polymers have been proved to be ideal supports for the fabrication of colloidal solutions imparting higher chemical stability, increased solubility and thus enhanced catalytic properties [6]. In fact, grafting of dendrimers on soluble nanoparticles surfaces is markedly advantageous, since it enables to control size and site of the interfacial reaction, [52-54]. Current literature proves the successful formation of several metal nanoparticles, such as $\mathrm{Pt}, \mathrm{Pd}, \mathrm{Ag}, \mathrm{Cu}, \mathrm{Au}$, $\mathrm{Ru}$ and $\mathrm{Rh}$, encapsulated in dendrimers by following the colloid template synthetical method $[55,56]$. Bimetallic nanocomposites contained in dendrimers can also be achieved through three different reaction methods: the partial displacement, the co-complexation and the sequential loading method. Semiconductor oxides, sulfites are also governed by the same nucleation concepts. These nano-catalysts with dendrimers as templates have been repeatedly utilized in the past for numerous catalytic and photocatalytic reactions, including oxidations, reductions, hydrogenations, and covalent bond cleavages that all aim at the biodegradation of toxic wastewater substances, avoidance of secondary wastes 
formation and recyclability of materials used for targeted water purification applications $[12,13,16,17,57]$.

The present review will characterize in great detail the methods used for the synthesis of catalysts that are based on nanoparticles encapsulated in dendrimers, and compare their efficacy specifically in water decontamination processes. Some special cases involving dendritic polymers but not necessarily anticipated guests (e.g., ions or enzymes) will be presented as well. Future prospects of these materials will also be included in an attempt to optimize their properties and expand their applicability in other pollutant categories.

\section{Conventional Homogenous Catalysis by Metal Nanoparticles}

\subsection{Reduction of Aromatic Nitro-compounds}

\subsubsection{The Benchmark Reaction of p-nitrophenol}

The reduction of nitro-compounds to their amino counterparts in general, transforms highly toxic compounds to less toxic amino-analogues that may be recovered and are usually useful in pharmaceutical antipyretic and analgesic preparations. Specifically, p-nitrophenol is mutagenic [58] cyto- and embryotoxic [59] and for this reason it constitutes one of the most burdensome compounds in industrial and agricultural wastewater. This explains the fact that it is the most common standard used for the initial catalytic evaluation of metal NPs formed by dendritic polymers. Furthermore, it provides many insights about basic nucleation principles and the overall NPs properties that affect pollutant transformation processes.

The earliest attempt to exploit the potential of these dendritic polymer metal nanocomposites to p-nitrophenol hydrogenation was implemented in 2003 by Hayakawa et al. [60]. The group introduced laser irradiation for the production of gold NPs with PAMAM G3, G5 and PPI G3, G4. They observed a general tendency of the NPs average diameters to decrease by dendrimer concentration and most importantly suggested that the dendritic macromolecules form monolayers around the metal cores. Esumi expanded the scope to silver, platinum and palladium [61] and Bingwa performed kinetic analysis and the determination of the Langmuir-Hinshelwood parameters for the particular p-nitrophenol reduction catalyzed by Ag and Au NPs [62]. In all these works, NP size was independent to dendrimer generation and PPI nanocomposites exhibited the best reduction rates. The interest for this novelty was so high that as soon as 2009, 4-nitrophenol reduction by PAMAM-Cu combined NPs was proposed as laboratory experiment suitable for first-year University students [63].

In contrast, to the previous experiments in the case of Pd incorporation to PAMAM G4 and PAMAM-OH G4, G6 cavities Johnson et al reported the synthesis of agglomerates with numbers of atoms approximately equivalent to dendrimer $/ \mathrm{Pd}^{2+}$ ratio. The authors correlated their activity to their size indicating that for clusters up to $50 \mathrm{Pd}$ atoms there is a positive linear dependency to the reaction rate. They also established the steric hindrance of the larger generation dendrimers to the accessibility to the catalysts [64] which was confirmed by Nemanashi et al. for Ag, $\mathrm{Cu}$ and $\mathrm{Au}$ NPs [65]. PAMAM-OH G6 though exhibited lower activation enthalpy (Hł) [66] activation energy (EA) [66-67] and effectively inhibited reoxidation of $\mathrm{Cu}^{0} \mathrm{NPs}$ to $\mathrm{Cu}^{2+}$ [68]. A direct comparison of $\mathrm{Pt}$ and Pd NPs formed by sodium dietylhexyl sulfosuccinate reverse microemulsions in an isooctane/water system with their respective counterparts templated by PAMAM-OH G4-G6 revealed that the latter have about half average diameters, narrower dispersity and superior catalytic performance and established the potential of the dendritic scaffolds method [69].

The first silver core/gold shell alloy particles with size 3-4 $\mathrm{nm}$ were obtained by sequential incorporation of $\mathrm{Ag}+$ and $\mathrm{AuCl}_{4}$ - ions into the cavities of amine terminated G3, 
G5 and carboxyl-terminated G3.5 5.5 half generations poly(amidoamine) dendrimers [70]. Hydroxyl functionalized G6 additionally stabilized $\mathrm{Au}, \mathrm{Cu}, \mathrm{Pd}, \mathrm{Pt}$, and $\mathrm{AuCu}, \mathrm{PdCu}$, $\mathrm{PtCu}$ bimetallic NPs with smaller diameters in the range of 1 to 3 nanometers and established the beneficial synergistic effect of $\mathrm{Ag}$ or $\mathrm{Cu}$ combination with a more expensive noble metal to the reaction rate [71]. Analogous outcome was created when PAMAM-OH G4-G6 were employed in order to generate Ru NPs with mean diameters ranging from 1.1 to $2.2 \mathrm{~nm}$ [72] and to amalgamate $\mathrm{Ru}$ and $\mathrm{Ni}$ with the bimetallic combination manifesting superior performance that single metal equivalents [73].

4-nitrophenol hydrogenation process model was followed further in order to evaluate most of the newly synthesized dendritic matrices. These are being designed in order to compose task specific metal nano-catalysts. 1,2,3-Triazolyl click dendrimers containing silicon and external pentose groups (Figure 4a) were conceived in order to secure stoichiometric coordination of $\mathrm{Au}$ [74] and $\mathrm{Pd}$ [75] ions to the internal triazole groups. This set ratio led to the nucleation of smaller metal cores and larger overall active surfaces that were also able to catalyze Suzuki-Miyaura coupling of 4-bromoacetophenone with phenylboronic acid. Replacement of the pentose groups by nona-PEG-chains (Figure $4 \mathbf{b}$ ) afforded gold NPs of diameters 1.8 and $12 \mathrm{~nm}$ depending directly on the $\mathrm{HAuCl}_{4} / \mathrm{star}$ polymer analogy. Furthermore, longer PEG chains (PEG2000 instead if PEG550) favor smaller metal particles [76]. Further alternative substitution by 9 arene cores and 27 triethylene glycol chains (Figure 4c) led to a matrix capable to agglomerate wide variety of transition metals (Fe, Ru, Co, Rh, Ir, Ni, Pd, Pt, Cu, Ag and $\mathrm{Au}$ ) from simple commercially available salts. All reaction rates were slower in comparison to analogous composites stabilized by simple triazoles due to the stereochemical restrictions of p-nitrophenol diffusion though the bulky periphery of the nano-catalyst. Pd Nps were the smallest, the most effective and did not require induction time [77].

Interaction of four different generations (G1-G4) of similar triazolyl glycodendrimers (Figure 4d) with gold cations revealed strong evidences towards the support of the theory of two nucleation mechanisms first noticed by Tanaka for Pd [78] and further described by Noh [66] (Figure 5a). Stabilization of metal NPs into an organic cluster was observed for the 2 smallest dendrimers while in the case of the larger analogues' incorporation occurred into their cavities [79]. Related amphiphilic Janus dendrimers bearing benzotriazole units and hydrophilic oligo (ethylene glycol) (OEG) chain on one side and a hydrophobic benzyl ether dendron functionalized by two long aliphatic chains formed micelles as well and incorporated Ag and Cu NPs [80] (Figure 5b). In a final most recent variant a 1,2,3-triazolyl dendronized polymer formed micellar catalytic nanoreactors when decorated by Au NPs (Figure 5c) [81] Random copolymerization [82] and controlled di-block polymer formation [83] with ferrocene-containing dendrons, by ring-opening metathesis, afforded mixed dendronized polymers that self-assemble into spherical micelles (Figures 5 d, e), are capable of Ag and Au NP stabilization and the composites may perform 4nitrophenol reduction with extremely high turnover number up to 25000 . 

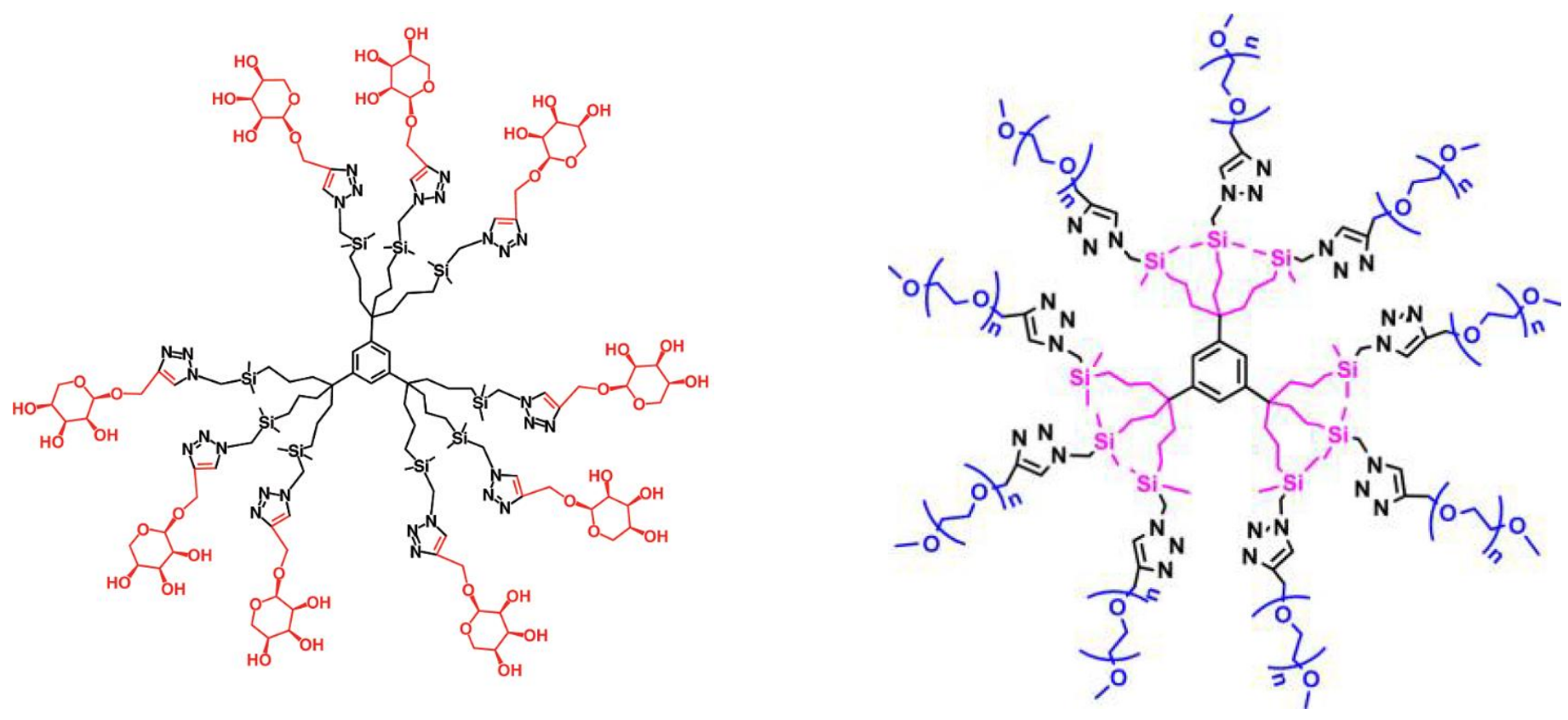

(a)

(b)

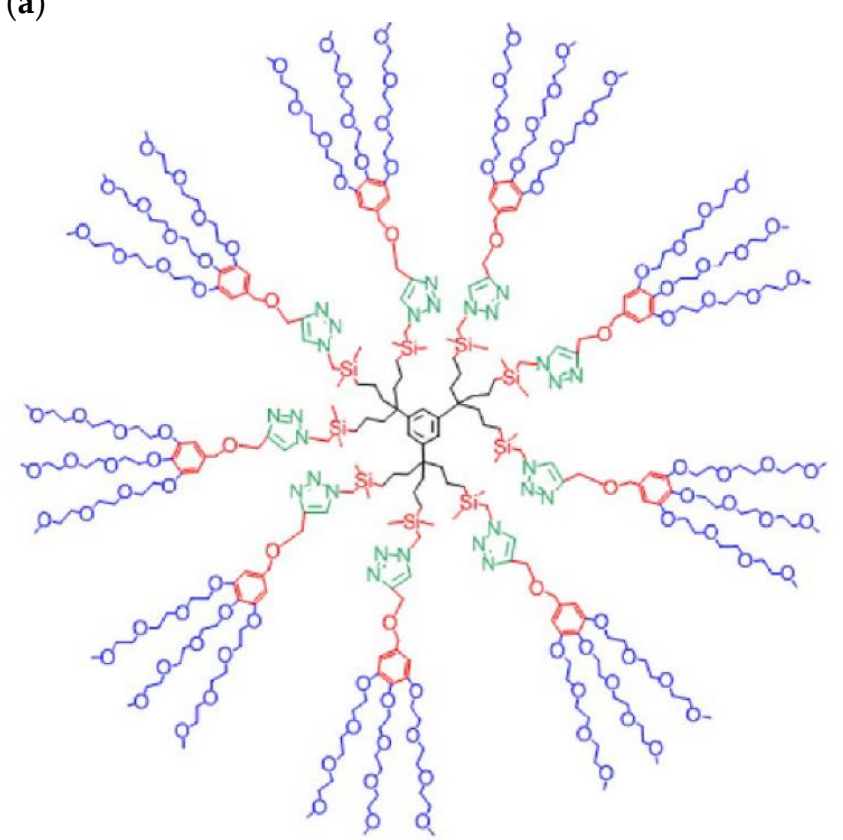

(c)

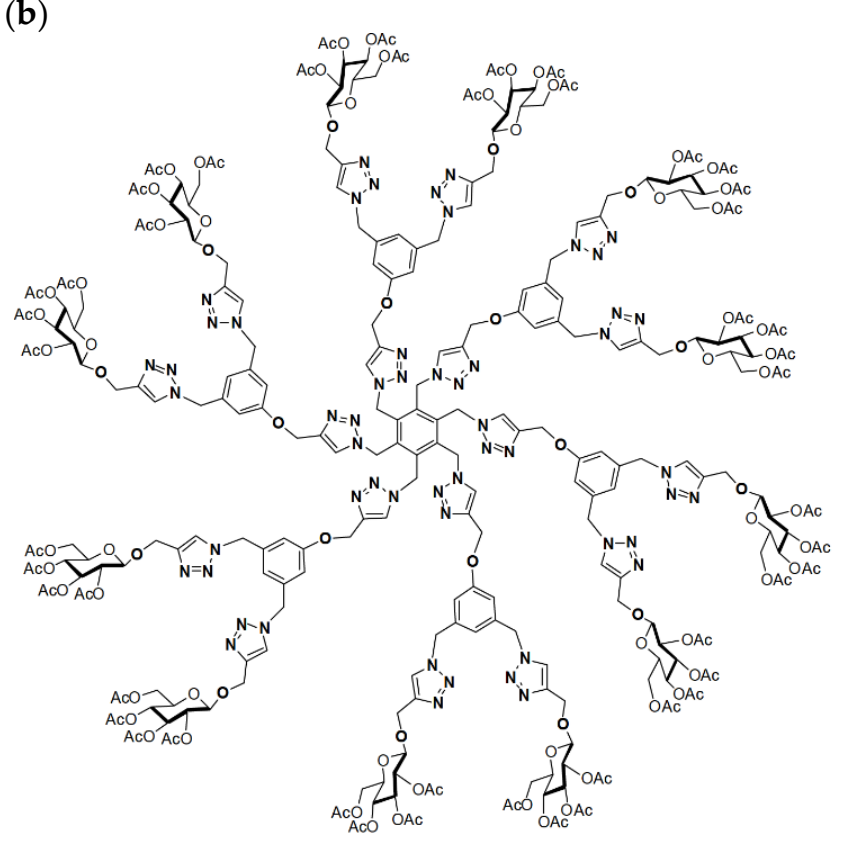

(d)

Figure 4. (a) Triazolyl Pentose-Terminated click dendrimer. Reproduced with permission from [74]; (b)Triazolyl nona-PEG click dendrimer. Reproduced with permission from [76] (c) Triethylene glycol nona-arene triazolyl click dendrimer Reproduced with permission from [77] (d) Triazolyl glycodendrimers. Reproduced with permission from [79]. 


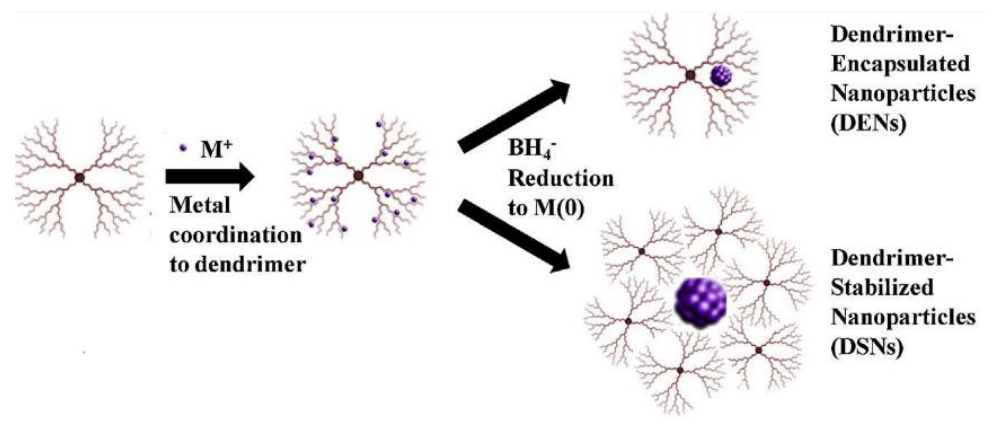

(a)
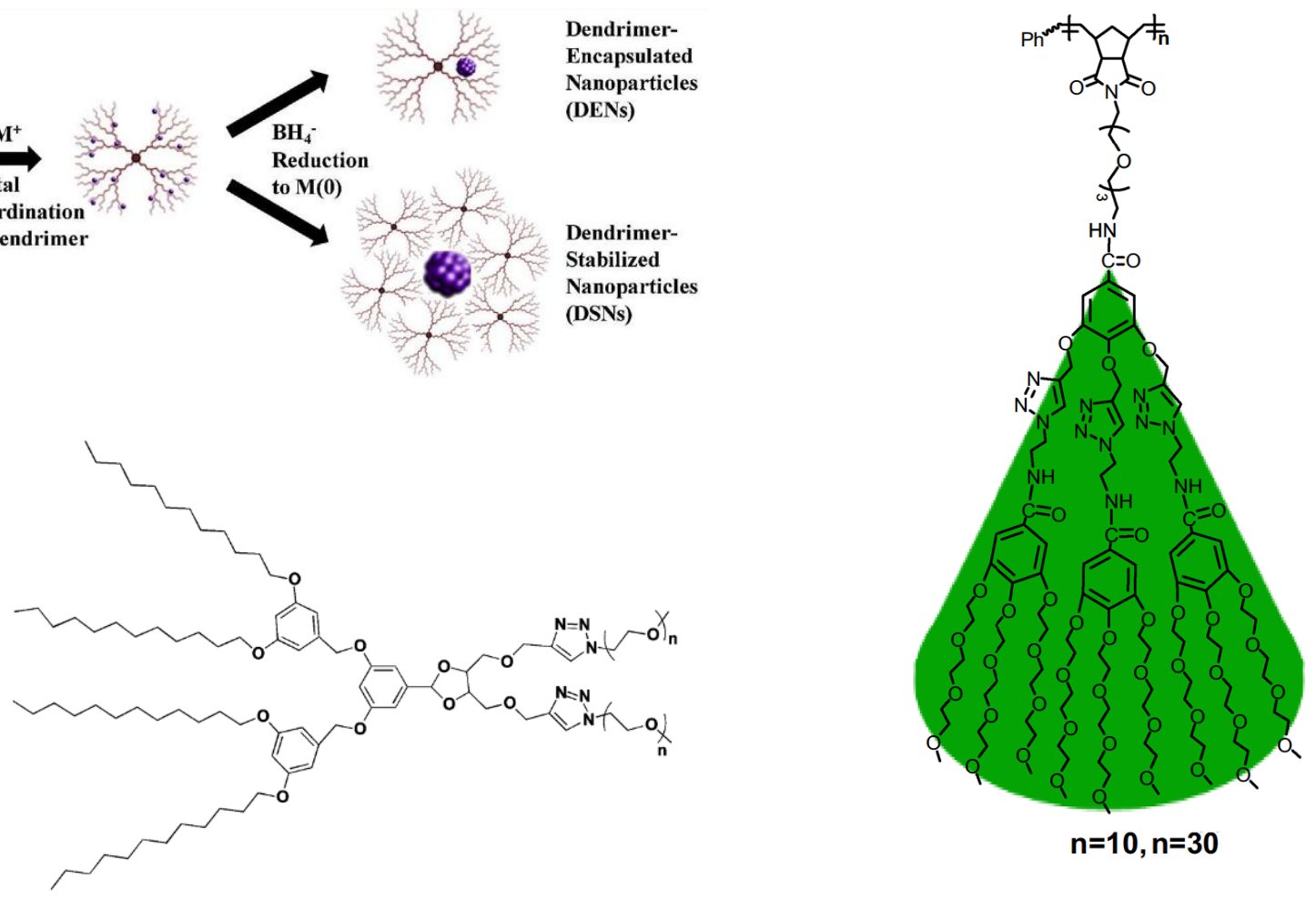

(b)

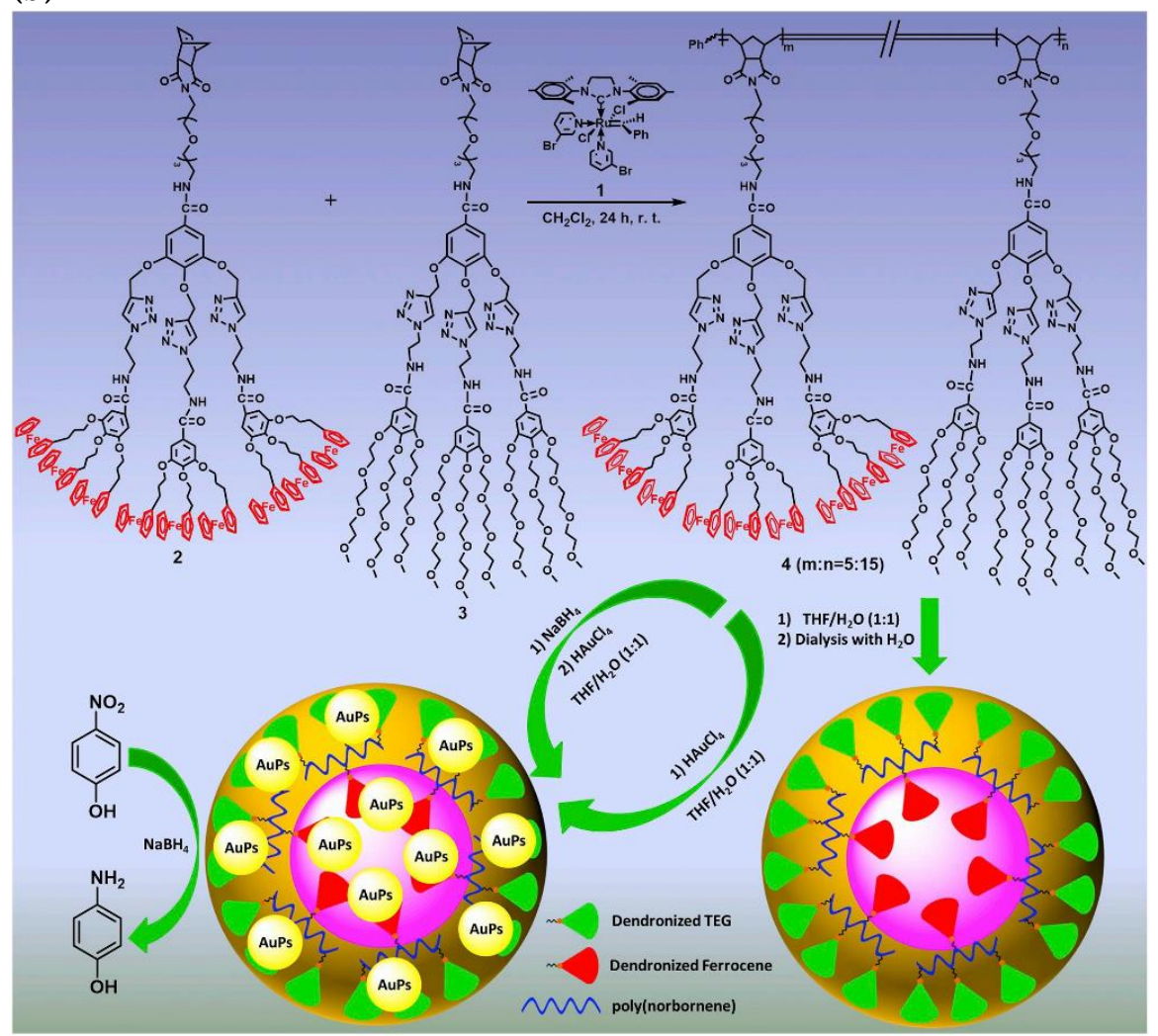

(d) (c)
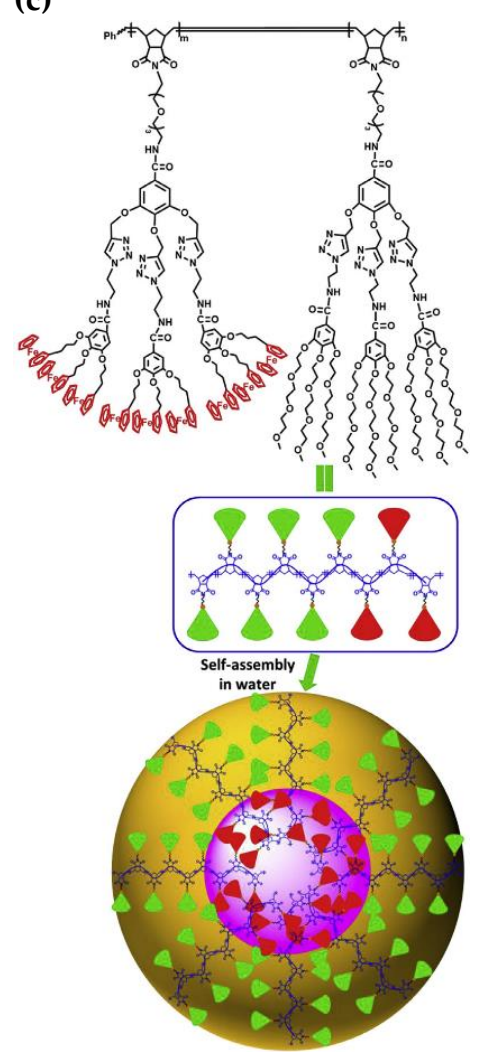

(e)

Figure 5. (a) Schematic illustration of the two dendrimer templated metal NPs nucleation mechanisms. Reproduced with permission from [66]; (b) Chemical Structure of dendritic Janus amphiphiles benzotriazole. Reproduced with permission from [80] (c) 1,2,3-triazolyl dendronized polymer. Provided by the Springer Nature SharedIt content-sharing initiative from [81]. (d) Synthesis and self-assembly of mixed dendronized triethylene glycol - ferrocene random copolymer. Reproduced with permission from [82] and (e) diblock copolymer. Reproduced with permission from [83]. 
In between some more efforts worth mentioning Asharani and Thirumalai reported the synthesis of PEG-G1-(3,5-DHB-OH)16 (Figure 6a) a poly(ethylene glycol core) dendrimer bearing hydroxyl terminal groups and paired it with silver cations [84]. Analogous successful catalytic Ag NPs combination was implemented with Polyetheramine (Jeffamine) core PAMAM dendrimer [85]. Functionalization of PPI G2 by 1,2-epoxyhexane afforded an amphiphilic template (Figure $6 \mathbf{b}$ ) for the aggregation of extremely small-sized $\mathrm{Ru}$ NPs in the range between 0.5 to $1 \mathrm{~nm}$ [86]. Similar core shell architecture was produced by the hyperbranched analogue PEI as the core and linear or dendritic hydrophobic shells. These copolymers were designed in order to increase the stability of AuNPs of average diameters $3 \mathrm{~nm}$ (Figure 7a). The branched architecture of the latter offered higher catalytic rates and an "unprecedented" maximal turnover of approximately 23000. [87] When ammonium salts of hyperbranched polystyrene were employed even smaller gold nanoparticles ( $1 \mathrm{~nm}$ in size) were achieved and were related to the observed "unique" reduction rates. Apart from the conventional p-nitrophenol transformation testing, aerobic oxidation of alcohols, and homocoupling of phenylboronic acid were successfully attained [88]. Another series of amphiphilic (PEI) core and acetic amide, propionic amide, butyric amide and isobutyric amide shells containing Au NPs established the superiority of the branched shells as optimal catalytic activity and reaction rates were achieved by the isobutyric amide functionalized derivative. The linear shells followed the rule of stereochemical diffusion limitations with the less bulky acetic amide/PEI/Au NPs nano-catalyst exhibiting the second-best results [89]. The most recent homogenous reduction catalysis implementation is by far the most unconventional. A mechanochemical method of blending solid powders of metal precursors [ $\mathrm{Ir}$ (cyclooctadiene) $\mathrm{Cl}_{2}$ and $\mathrm{PtCl}_{2}$, with triazine dendritic hosts (Figure 7b) and $\mathrm{NaBH}_{4}$ milling and then extracting of the water-soluble impurities from a $\mathrm{H}_{2} \mathrm{O} / \mathrm{CH}_{2} \mathrm{Cl}_{2}$ biphasic system was proposed for obtaining Ir and Pt NPs [90].

In order to enhance the biocompatibility of PAMAM G5/Au NPs coupling of the dendrimer with maleic anhydride and then with cysteamine was performed. Reduction of the metal ions took place in a solution of chloroauric acid sodium borohydride. The resulting materials retain the catalytic properties of the unmodified parent compounds. Furthermore, due to a zwitterionic layer consisting of amine and carboxyl groups they did not form aggregates neither in fibrinogen nor in phosphate-buffered saline solutions and they were also far less toxic [91]. In the same framework attempt to reduce PAMAM toxicity by coupling with 4-carbomethoxypyrrolidone resulted to biocompatible scaffolds that hosted smaller than 5nm silver NPs and exhibited improved performance as well [92].

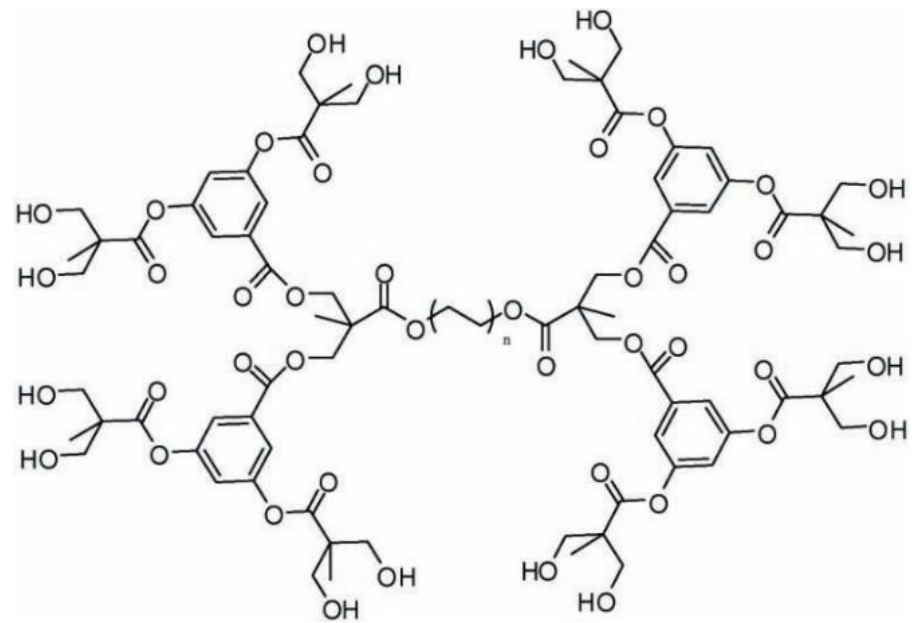

(a)

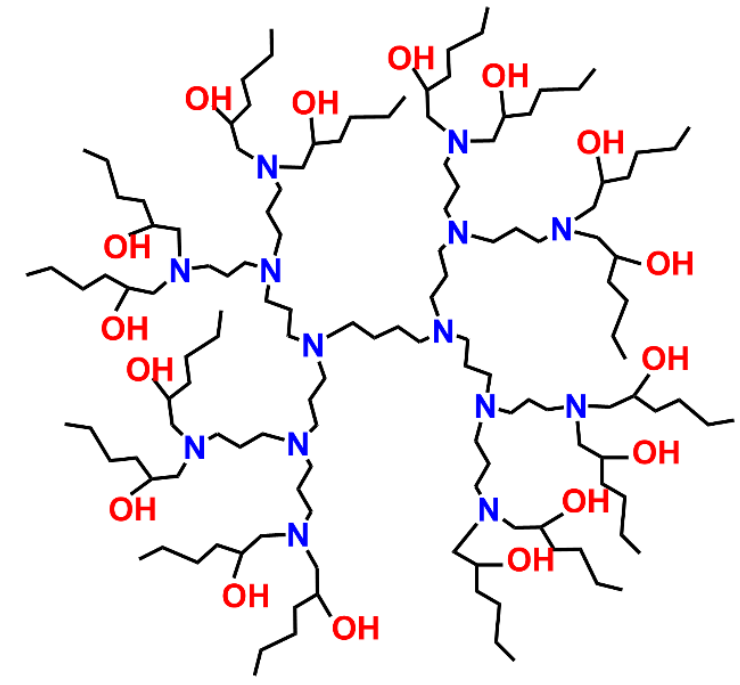

(b)

Figure 6. (a) Chemical Structures of PEG-G1-(3,5-DHB-OH)16 dendrimer. Reproduced with permission from [84].; (b) Structure of amphiphilic PPI G2 dendrimer. 


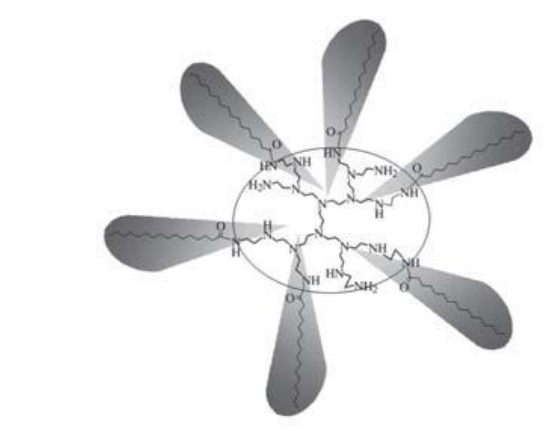

PEI-C16

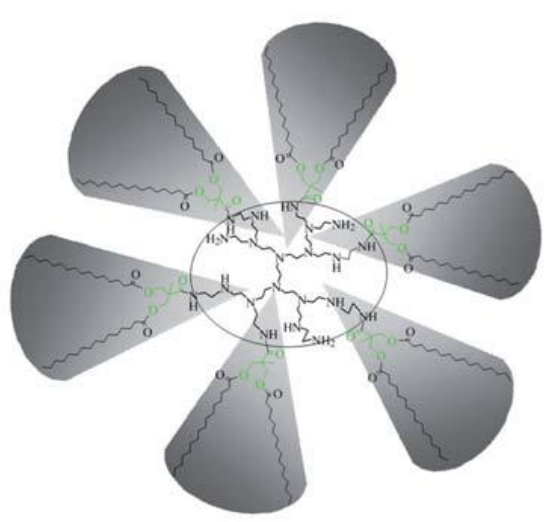

PEI-D1-C16

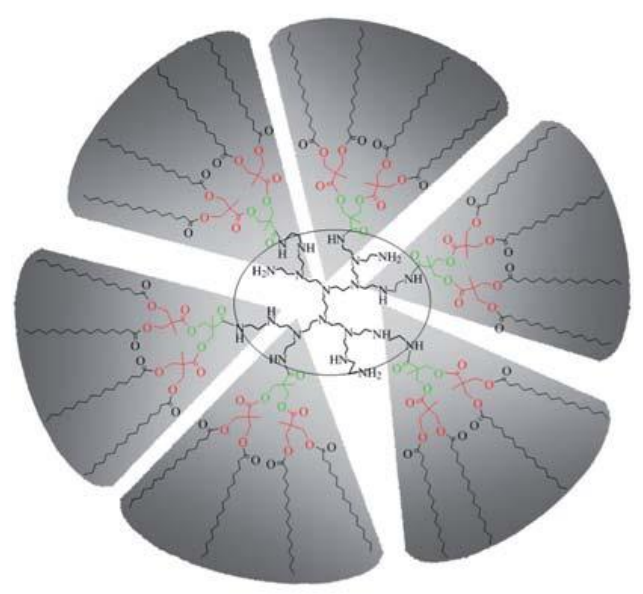

PEI-D2-C16

(a)

Figure 7. (a) Amphiphilic hyperbranched PEI copolymers with different shell morphologies bearing 1, 2 or 4 palmitamides per external amino group of the parent dendritic core: Au NP templates and stabilizers Reproduced with permission from [87].; (b) Chemical structures of G1, G3, G5 triazine-based dendrimers and front and back sides of dendrimers G1-NBoc, G3-NBoc, and G5NBoc with Boc groups (green), peripheral triazines (blue), outer generation (purple), inner generation (raspberry), and core (salmon) indicated by color Reproduced with permission from [93].

It was also discovered that dendritic composites containing PEI moieties not only stabilize AuNPs but they may also act as reducing agents. The first such example was the outcome of the synthesis of a tripartite dendritic copolymer containing commercial aliphatic hyperbranched polyesters (Boltorn Hx) as cores and alternating linear poly (ethylene glycol) PEG chains and hyperbranched PEI at the periphery (Figure 8) [94]. By starting from 2,2-bis(methylol)propionic acid polyester (H104) core and attaching polyethylene glycol monomethyl ether chains and a variety 
oligo(ethylenimines) a resembling hybrid amphiphile is produced and induces the formation of $\mathrm{Au}$ NPs with diameters 2-4 nm (Figure 9). In this case the branched triaminoethyl amine and the longest linear tetraethylenepentamine present the best catalytic activity and the most efficient protection. The beneficial stabilizing effect of the multiple amino groups profoundly overcomes the steric effects [95]. A third dendronized copolymer containing three moieties as well (PEG-PEI-PCL) was produced for stabilizing Pt NPs by attaching hyperbranched PEI to one linear poly (ethylene glycol) chain and then grafting poly( $\boldsymbol{\varepsilon}$-caprolactone) chains to the terminal amino groups. Self-assembly in aqueous solutions afforded organized micelles producing upon reduction of $\mathrm{PtCl}_{6}{ }^{2-}$ large nanoparticles $(8 \mathrm{~nm})$ suitable for catalytic hydrogenation of 4-Nitrophenol [96] All the homogenous catalysis systems researched and discussed herein for the specific nitrophenol reaction are summarized in Table 1.

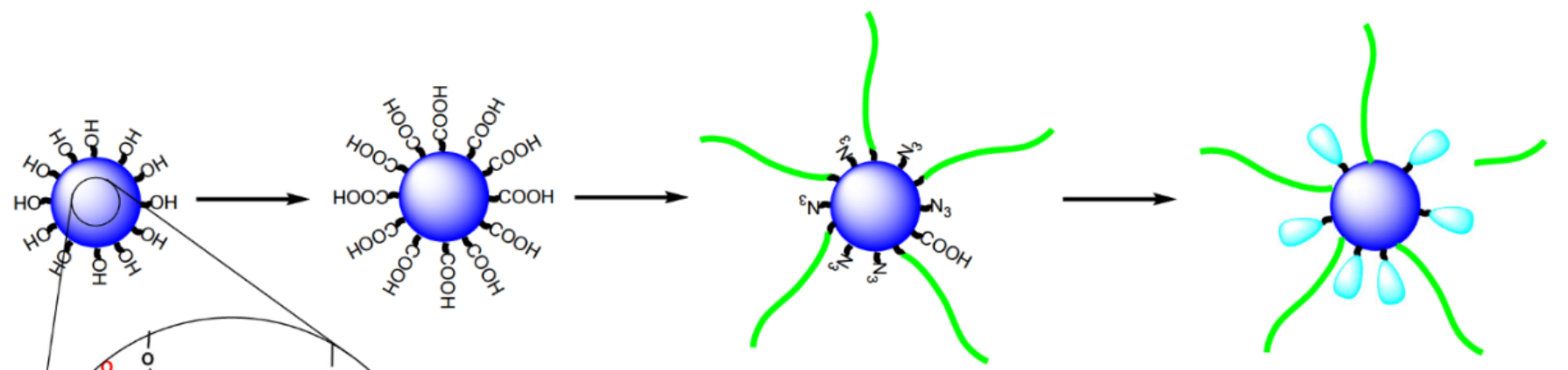

HX-PEI-PEG

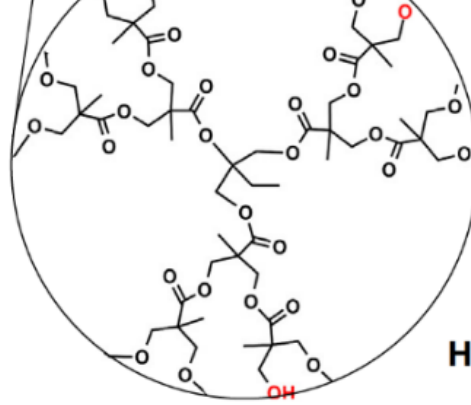

Hyperbranched polyester $(\mathbf{H x})$<smiles>NCCNCCNCCN(CCNCCN)CCN(CCN(CCN)CCN)CCN(CCN)CCNCCN</smiles>
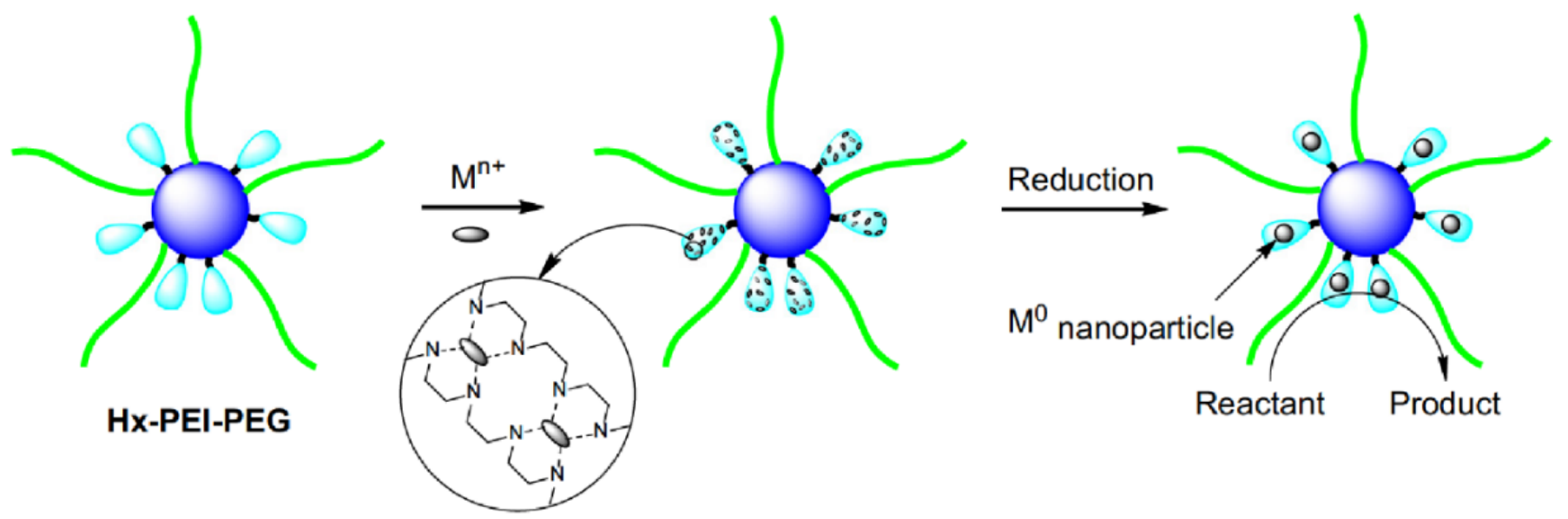

Hx-PEI-PEG

Figure 8. Schematic representation of the synthetic route for the assembly of the composite polymers Hx-PEI-PEG and the subsequent reduction of $\mathrm{Au}$ ions into PEI cavities Reproduced with permission from [94]. 


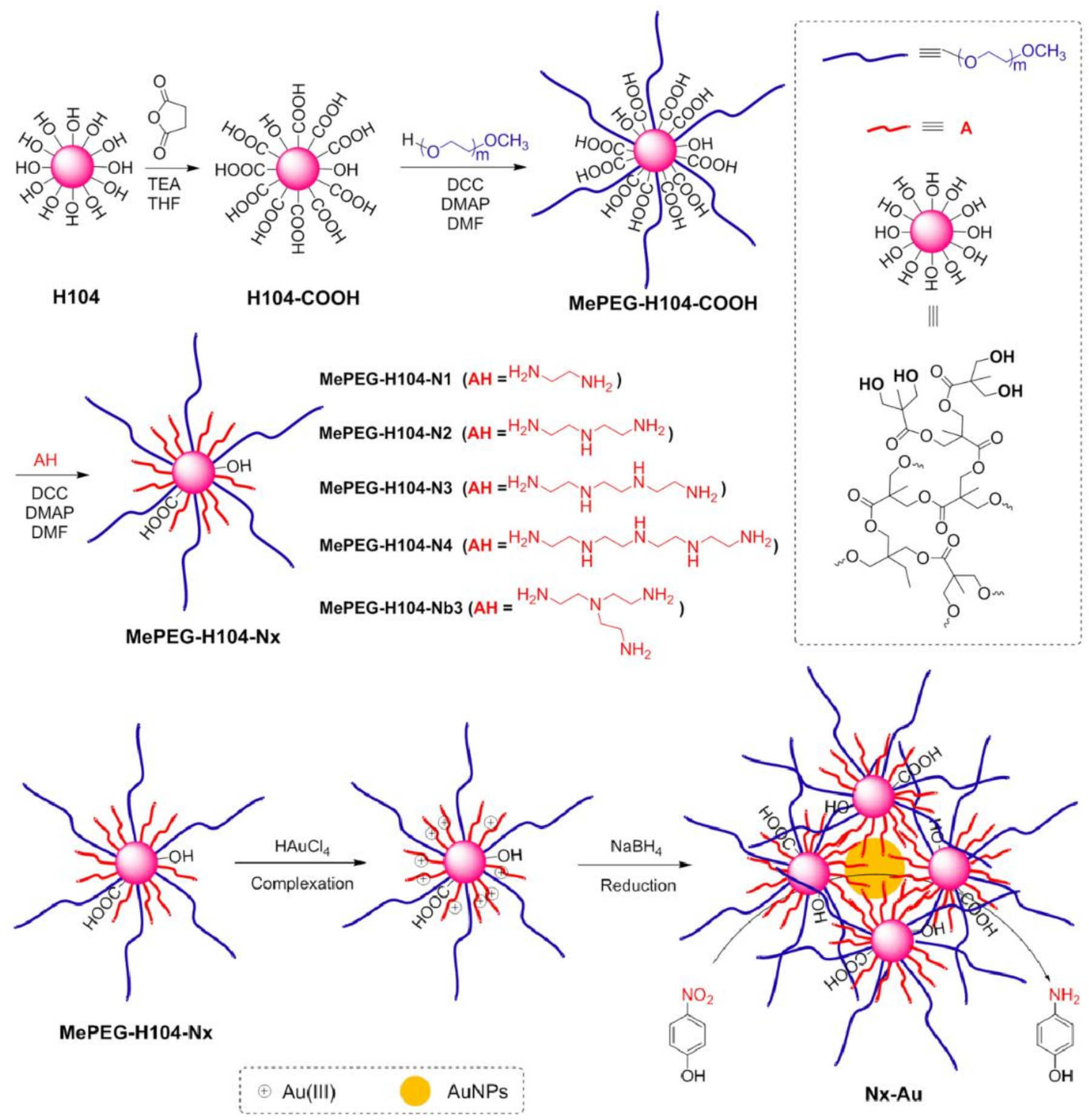

Figure 9. Synthesis of the amine modified copolymers H104-PEG-Nx and the subsequent reduction and stabilization of Au ions Reproduced with permission from [95]. 


\begin{tabular}{|c|c|c|}
\hline Dendritic Polymer & Metal Nanoparticles & Reference \\
\hline PAMAM G3, G5 PPI G3, G4 & $\mathrm{Au}$ & {$[60]$} \\
\hline PAMAM G3, G4, G5, PPI G2, G3, G4 & $\mathrm{Ag}, \mathrm{Pt}, \mathrm{Pd}$ & [61] \\
\hline PAMAM G3, G3.5, G5, G5.5 & $\mathrm{Ag}, \mathrm{Au} \mathrm{Ag} / \mathrm{Au}$ alloy & [70] \\
\hline PAMAM-OH G6 PAMAM G4 & $\mathrm{Au}, \mathrm{Cu}, \mathrm{Pd}, \mathrm{Pt}, \mathrm{Au} / \mathrm{Cu}, \mathrm{Pd} / \mathrm{Cu}, \mathrm{Pt} / \mathrm{Cu}$ & [71] \\
\hline PAMAM G4 & $\mathrm{Cu}$ & [63] \\
\hline PAMAM-OH G4 & $\mathrm{Ru}, \mathrm{Ni}, \mathrm{Ru} / \mathrm{Ni}$ & [73] \\
\hline [PEG-G1-(3,5-DHB-OH)16] & $\mathrm{Ag}$ & [84] \\
\hline PEI core 2,2-Bis(hydroxymethyl)propionic acid dendrons & $\mathrm{Au}$ & [87] \\
\hline Hyperbranched Polystyrene & $\mathrm{Au}$ & [88] \\
\hline PAMAM-OH G4, G5, G6 & $\mathrm{Ru}$ & [72] \\
\hline PAMAM-OH, PAMAM-NH2 G4, G6 & $\mathrm{Cu}, \mathrm{Ag}, \mathrm{Au}$ & [65] \\
\hline PAMAM G4 PAMAM-OH G4, G6 & $\mathrm{Pd}$ & [64] \\
\hline Glycodendrimers & $\mathrm{Pd}$ & [75] \\
\hline Glycodendrimers & $\mathrm{Au}$ & [74] \\
\hline PAMAM-OH G4, G5, G6 & $\mathrm{Pd}$ & [66] \\
\hline PAMAM-OH G4, G5 & $\mathrm{Pd}$ & [62] \\
\hline Amphiphilic PPI-G2 & $\mathrm{Ru}$ & [86] \\
\hline PAMAM G4 & $\mathrm{Ag}, \mathrm{Au}$ & [67] \\
\hline Nona-PEG-branched Triazole Dendrimers & $\mathrm{Au}$ & [76] \\
\hline Glycodendrimers G1-G4 & $\mathrm{Au}$ & [79] \\
\hline PAMAM-OH G4, G5, G6 & $\mathrm{Pd}, \mathrm{Pt}$ & [69] \\
\hline PEI core amide shells & $\mathrm{Au}$ & [89] \\
\hline Hyperbranched Polyester Boltron-PEI-PEG & $\mathrm{Au}$ & [94] \\
\hline Linear PEG-Hyperbranched PEI poly( $\boldsymbol{\varepsilon}$-caprolactone) & $\mathrm{Pt}$ & [96] \\
\hline Bistriazole-based dendritic amphiphile micelles & $\mathrm{Ag}, \mathrm{Cu}$ & [80] \\
\hline PAMAM G5 - maleic anhydride - cysteamine & $\mathrm{Au}$ & [91] \\
\hline Triethylene glycol-Arene-Triazole click Dendrimers & $\mathrm{Fe}, \mathrm{Co}, \mathrm{Ni}, \mathrm{Cu}, \mathrm{Ru}, \mathrm{Rh}, \mathrm{Pd}, \mathrm{Ag}$. Ir, Pt, $\mathrm{Au}$ & [77] \\
\hline Amine-modified hyperbranched polyester PEG copolymer & $\mathrm{Au}$ & [95] \\
\hline PAMAM-OH G4, G5, G6 & $\mathrm{Cu}$ & [68] \\
\hline Jeffamine core PAMAM G4 & $\mathrm{Ag}$ & [85] \\
\hline 1,2,3-Triazolyl Dendronized Polymers & $\mathrm{Au}$ & [81] \\
\hline Ferrocenyl/Triethylele glycol Dendronized Polymers & $\mathrm{Au}$ & [82] \\
\hline Ferrocenyl/Triethylele glycol Dendronized Diblock Polymers & $\mathrm{Au}, \mathrm{Ag}$ & [83] \\
\hline 4-carbo-methoxypyrrolidone PAMAM G3-G5 & $\mathrm{Ag}$ & [92] \\
\hline Triazine-based dendrimers & Ir, $\mathrm{Pt}$ & [90] \\
\hline
\end{tabular}

\subsubsection{Aromatic Nitro-derivates in general}

As expected, inspiration from the first successful experimentations with 4-nitrophenol drove for further investigations with close related nitroaromatic pollutants. The first such expansion was carried out by Yang et al. in 2006. Polyaryl ether trisacetic acid ammonium chloride dendrons were used for the reduction of platinum ion and subsequent organization around the resulting Pt NPs (Figure 10a). The mean diameters of the latter ranged from 2.0 to $5.5 \mathrm{~nm}$, depending on the metal to dendron molar ratio. The catalysts were able to accomplish hydrogenation of p-nitrophenol, o-nitroanisol, o-,m-, p-nitrotoluene to $\mathrm{p}$-nitroaniline, o-anisidine and $\mathrm{o}-\mathrm{m}-\mathrm{m}, \mathrm{p}$-aminotoluene respectively under an atmosphere pressure of $\mathrm{H}_{2}$. Activity dropped by increasing dendron generation [97]. The exact same structures were used for the assembly of Au/Pt bimetallic core/shell NPs with 6-nm Au cores and average overall sizes of $9.0 \pm 2.4 \mathrm{~nm}, 10.4 \pm 2.8 \mathrm{~nm}$, and $13.0 \pm 3.2 \mathrm{~nm}$ as a function of $\mathrm{Pt} / \mathrm{Au}$ molar ratio and improved performance over monometallic platinum. Apart from the already discussed variety of nitrobenzenes the catalyst was successfully tested for the catalytic hydrogenation of 3-phenoxybenzaldehyde which comes of environmental transformation of the pesticide beta-cypermethrin. [98]. Au NPs reduced and stabilized by amphiphilic PPI were effective for nitrobenzene conversion to aniline as well [99]. 
Besides the amino groups of PPI dendrimer and hyperbranched PEI hydroxyl functionalities of dendritic PEG may also act as reducing agents for metal cations. The first such example is reported lately by Asharani. Polyethylene glycol (PEG) core dendrimer reduced encapsulated silver ions to Ag NPs and effectively catalyzed a wide range of substituted nitroaromatics under the following reduction rate order 4-nitrobenzaldehyde $>$ nitrobenzene $>$ 4-nitrocatechol $>$ 4-nitroaniline $>$ 5-hydroxy-2-nitrobenzaldehyde $>$ 4-nitroanisole $>$ 2-hydroxy-5-nitrobenzylbromide [100]. Functionalization of PAMAM G3 terminal amino groups with long linear PEG chains also permitted the assembly of $\mathrm{Cu}$ [101] (Figure 10b) and Au NPs [102] (Figure 10c). Reduction of 4-(4-nitrophenyl) morpholine and two pharmaceutically important derivatives (4-(2-fluoro-4-nitrophenyl) morpholine) and 4-(4-nitrophenyl) morpholin-3-one was attained. The best performance was observed at 0.4 PAMAM/Metal ratio. Hydrogenation of nitroaromatics was even reproduced by $\mathrm{Cu}$ NPs incubated into simple PAMAM G2 dendrimers by hydrazine hydrate instead of $\mathrm{NaBH}_{4}$. Nine modified aromatic nitro benzenes were tested (4-nitrophenol, 2-nitrophenol, 4-nitrobenzaldehyde, 2,4 dinitrophenol, 2-nitroaniline, 4-nitroaniline, 3-nitrotoluene, 4-nitrotoluene, 4-nitrochlorobenzene). Chemo selective reduction of nitro groups in the presence of other reducible groups such as aldehydes was detected as previously and even regioselective reduction of 2-nitro group close to the hydroxyl in the case 2,4 dinitrophenol was recorded [103]. The catalytic composites presented herein for nitro-derivative reduction are summarized in Table 2.

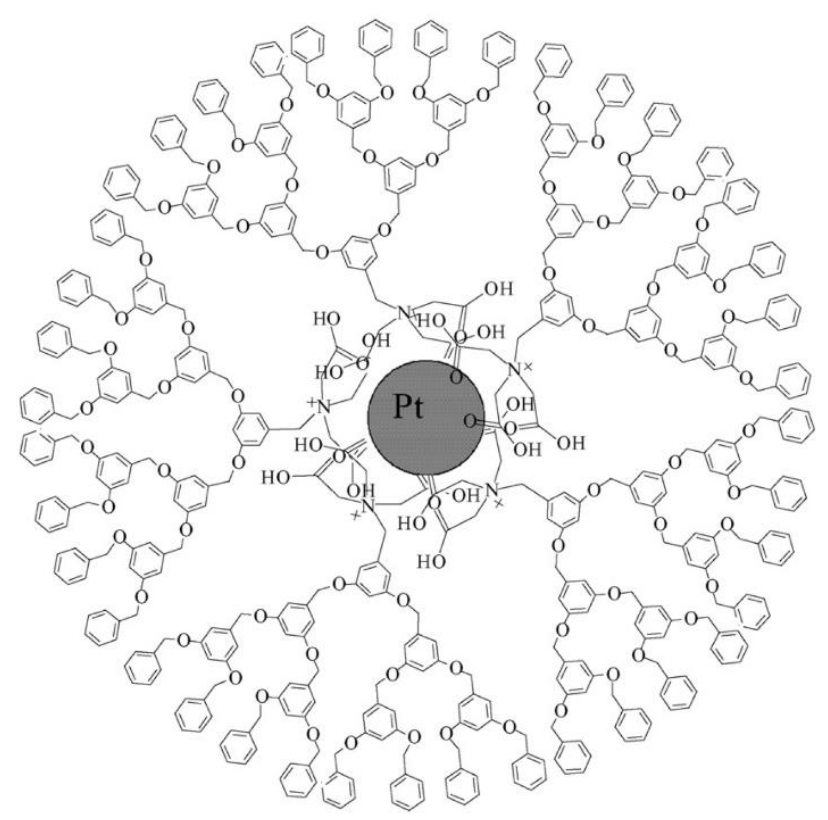

(a)

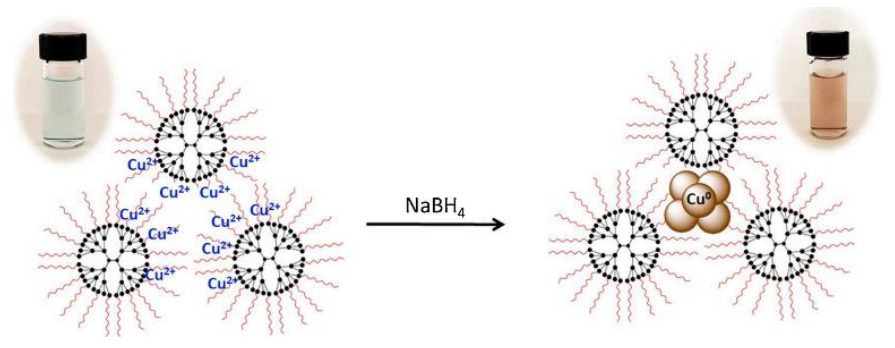

(b)

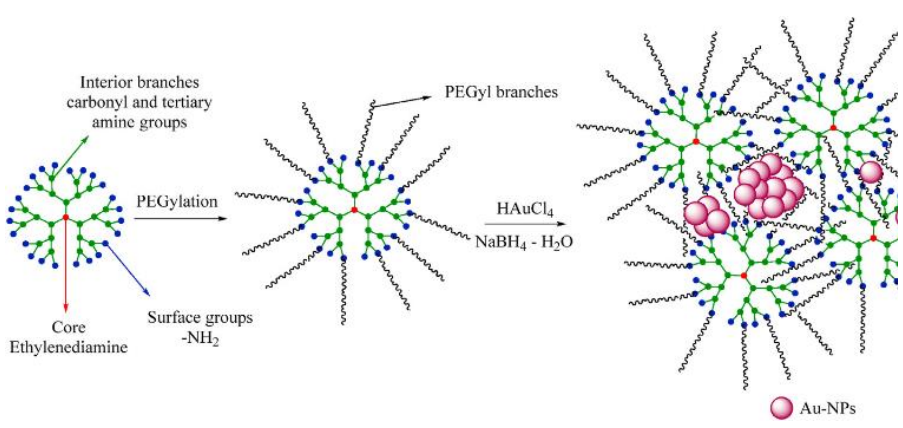

(c)

Figure 10. (a) Organization of Polyaryl ether trisacetic acid ammonium chloride dendrons around Pt NPs Reproduced with permission from [97]; (b) Incorporation of Cu NPs into the dendrimer layer of PEG-PAMAM G3. Reproduced with permission from [101]; (c) Synthesis of PEG-PAMAM G3 Au NPs Reproduced with permission from [102]

Table 2. Dendritic polymer - Nanoparticle combinations designed for nitroaromatic derivatives reduction 


\begin{tabular}{|c|c|c|c|c|}
\hline Dendritic Polymer & Metal NPs & Pollutant & Degradation Products & Ref. \\
\hline $\begin{array}{l}\text { Polyaryl ether trisacetic acid } \\
\text { ammonium chloride dendrons }\end{array}$ & $\mathrm{Pt}$ & $\begin{array}{l}\text { p-nitrophenol, o-nitroanisol, o-,m-, p-nitro- } \\
\text { toluene }\end{array}$ & $\begin{array}{r}\text { - p-nitroaniline, o-anisidine and o-, } \mathrm{m}-\mathrm{p} \text { - } \\
\text { aminotoluene }\end{array}$ & [97] \\
\hline $\begin{array}{l}\text { Polyaryl ether trisacetic acid } \\
\text { ammonium chloride dendrons }\end{array}$ & $\mathrm{Au} / \mathrm{Pt}$ & $\begin{array}{c}\text { p-nitrophenol, o-nitroanisol, o-,m-,p-nitro- } \\
\text { toluene, } \\
\text { 3-phenoxybenzaldehyde }\end{array}$ & $\begin{array}{r}\text { - p-nitroaniline, o-anisidine and o-, } \mathrm{m}-, \mathrm{p}- \\
\text { aminotoluene, } \\
\text { 3-phenoxyphenyl methanol }\end{array}$ & [98] \\
\hline Amphiphilic PPI-G2 & $\mathrm{Au}$ & Nitrobenzene & Aniline & [99] \\
\hline PEG-PAMAM G3 & $\mathrm{Cu}$ & $\begin{array}{l}\text { 4-(4-nitrophenyl) morpholine, 4-(2-fluoro-4 } \\
\text { nitrophenyl) morpholine), 4-(4-nitrophenyl } \\
\text { morpholin-3-one }\end{array}$ & $\begin{array}{l}\text { 4-(4-aminophenyl) morpholine, 4-(2- } \\
\text { 1) fluoro-4-aminophenyl) morpholine), } 4 \text { - } \\
\text { (4-aminophenyl) morpholin-3-one }\end{array}$ & [101] \\
\hline PAMAM G2 & $\mathrm{Cu}$ & $\begin{array}{l}\text { 4-nitrophenol, 2-nitrophenol, } \\
\text { 4-nitrobenzaldehyde, } \\
\text { 2,4 dinitrophenol, 2-nitroaniline, } \\
\text { 4-nitroaniline, 3-nitrotoluene, 4-nitrotolu- } \\
\text { ene, 4-nitrochlorobenzene }\end{array}$ & $\begin{array}{l}\text { 4-aminophenol, 2-aminophenol, 4- } \\
\text { aminobenzaldehyde, 2-nitro-4-amino- } \\
\text { phenol, 2-phenyldiamine, 4-phenyldia- } \\
\text { mine, 3-aminotoluene, 4-aminotolu- } \\
\text { ene, 4-aminochlorobenzene }\end{array}$ & [103] \\
\hline
\end{tabular}

\subsection{Treatment of pigments}

The next step in research for catalytic handling of water pollution originates from problems caused mainly by textile industry and other sources of pigment and dye effluents. Considering the early successes of the preliminary efforts with metal nanoparticles enclosed into dendritic polymers the evolution on this field is rather delayed. An initial example of such investigation is the employment of quaternary octyl ammonium salts of PPI dendrimer for the induction of Ag, Pd, Pt NPs. Amphiphile catalysts with 5 and 10 alkyl chains were used for the reduction of methyl orange to 4-aminobenzenesulfonic acid and 4-dimethylamino aniline. Palladium proved more suitable over silver and platinum and as expected from the stereochemical point of view the longer alkyl chains slowed the diffusion of the bulky pollutant [104]. The formation of bimetallic Pd/Au nanoparticles into PAMAM-OH G6 produced an additional successful suggestion for methyl orange degradation that established the excellent potential of Pd NPs [105].

Conventional PAMAM G5 with Au, or Ag NPs [106], PAMAM G6 Au hybrids [107] and hydroxy terminated PAMAM-OH G6 dendrimers combined with monometallic Pd and Pt NPs [108] or bimetallic Pd/Au alloys [109] were employed for the oxidative degradation of morin by hydrogen peroxide to morin oxide. In addition, Pd NPs stabilized into the previously described biocompatible system i.e., G5 PAMAM functionalized with maleic anhydride and cysteamine, were also checked for their ability to perform this particular reaction in bacteria contaminated solutions [110,111]. Diffusion of the reactants through the dendritic periphery and subsequent adsorption on the metal NPs surface was again the critical step defining the reaction constants. The presence of palladium proved particularly beneficial for this oxidative path as well, leading to lower activation energies and faster reaction rates.

In another instance methylene blue underwent catalytic oxidative decomposition by the mediation of PAMAM G5 and Au or Ag NPs [112]. The same dye is treated by an alternative reductive path by sodium borohydride. Interestingly among others (PAMAMOH G4, G5 with Pd NPs, PAMAM G4 with Au) the exact same catalytic composite used for oxidation PAMAM G5/Au may also accomplish the reduction. Once more Pd NPs were the most efficient catalyst [113]. Examples of catalytic degradation paths for Methyl 
Orange, Morin and Methylene Blue by metal NPs incorporated into PAMAM are depicted in Figure 11. A summary of all the formulations employed for homogenous dye discoloration is presented in Table 3.

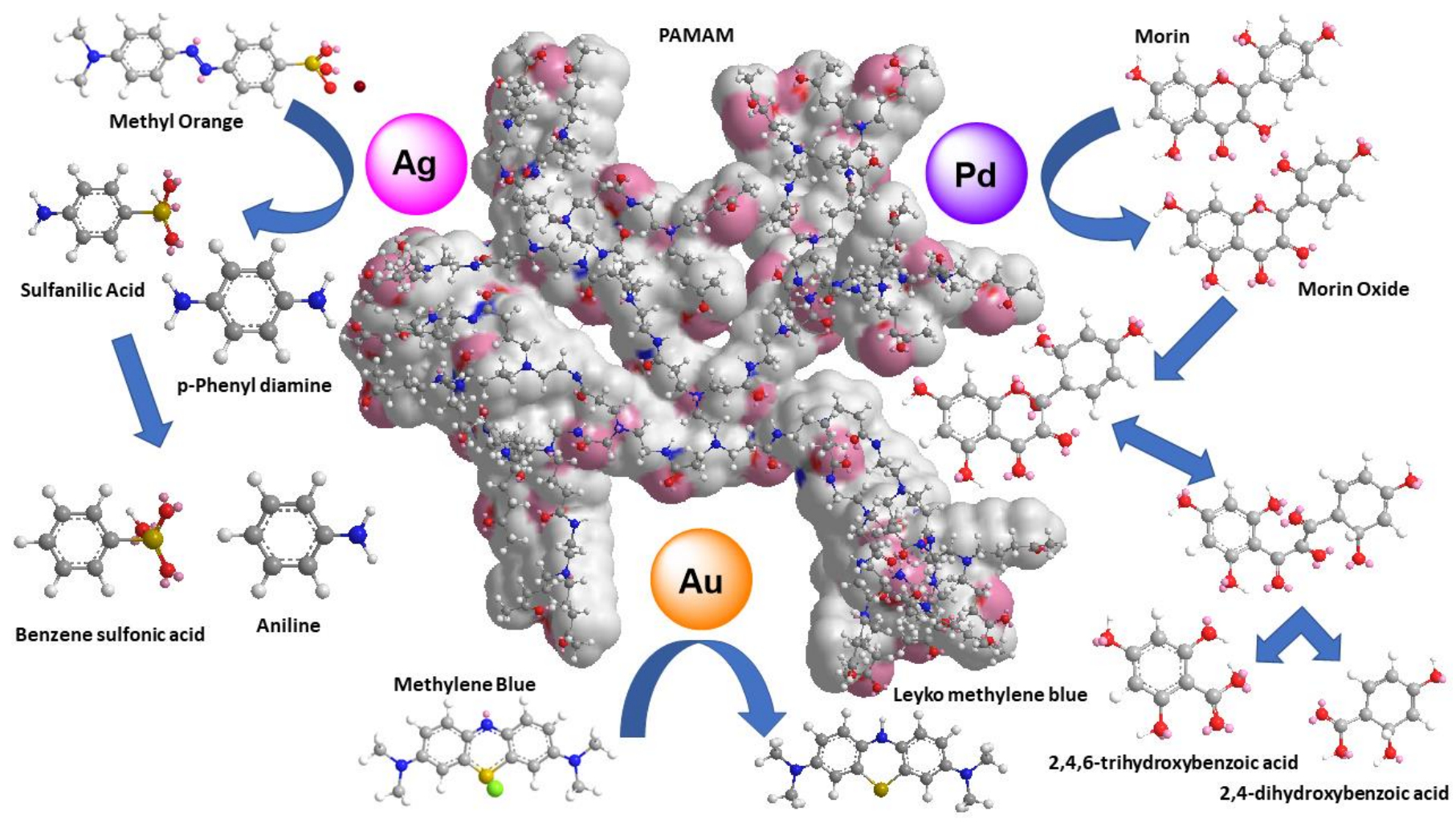

Figure 11. Schematic representation of catalytic decomposition paths of Morin, Methyl Orange, Methylene Blue dyes mediated by metal NPS.

Table 3. Dendritic polymer - Nanoparticle combinations designed for treatment of dyes 


\begin{tabular}{|c|c|c|c|c|}
\hline Dendritic Polymer & Metal NPs & Dye & Degradation Products & Reference \\
\hline Octyl PPI-G2 & $\mathrm{Ag}, \mathrm{Pd}, \mathrm{Pt}$ & Methyl Orange & $\begin{array}{l}\text { a) Sulfanilic acid } \\
\text { N,N-dimethyl, p-phenyldiamine } \\
\text { b) Benzene sulfonic acid, aniline }\end{array}$ & {$[104]$} \\
\hline PAMAM-OH G6 & $\mathrm{Pd}, \mathrm{Pt}$ & Morin & $\begin{array}{r}\text { a) Substituted benzofuranone } \\
\text { (morin oxide) }\end{array}$ & [108] \\
\hline G6-PAMAM-NH 2 & $\mathrm{Au}$ & Morin & $\begin{array}{r}\text { b) Substituted benzofuranone } \\
\text { (morin oxide) } \\
\text { 2,4-dihydroxybenzoic acid, 2,4,6- } \\
\text { trihydroxybenzoic acid }\end{array}$ & [107] \\
\hline PAMAM PAMAM-OH G4, G5 & $\mathrm{Pd}, \mathrm{Au}$ & Methylene Blue & Leuko-Methylene Blue & [113] \\
\hline PAMAM G5 & $\mathrm{Au}, \mathrm{Ag}$ & Methylene blue & $\begin{array}{l}\text { a) Methylene blue Oxide, } \\
\text { b) Phenol, Benzene Sulfonic Acid }\end{array}$ & [112] \\
\hline PAMAM G5 & $\mathrm{Au}, \mathrm{Ag}$ & Morin & 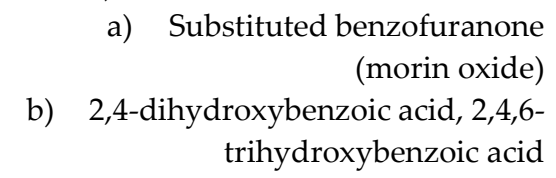 & [106] \\
\hline PAMAM G6 & $\mathrm{Pd} / \mathrm{Au}$ & Morin & 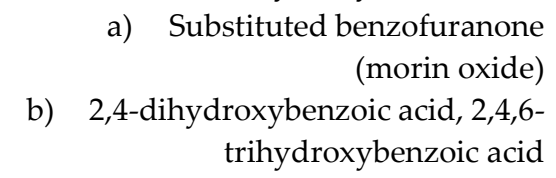 & [109] \\
\hline PAMAM-OH G6 & $\mathrm{Pd} / \mathrm{Au}$ & Methyl Orange & $\begin{array}{l}\text { a) Sulfanilic acid } \\
\text { N,N-dimethyl, p-phenyldiamine } \\
\text { b) Benzene sulfonic acid, aniline }\end{array}$ & [105] \\
\hline $\begin{array}{l}\text { PAMAM G5 functionalized by } \\
\text { maleic anhydride and cysteamine }\end{array}$ & $\mathrm{Pd}$ & Morin & $\begin{array}{r}\text { a) Substituted benzofuranone } \\
\text { (morin oxide) } \\
\text { b) 2,4-dihydroxybenzoic acid, } \\
\text { 2,4,6-trihydroxybenzoic acid }\end{array}$ & [111] \\
\hline $\begin{array}{l}\text { PAMAM G5 functionalized by } \\
\text { maleic anhydride and cysteamine }\end{array}$ & $\mathrm{Pd}$ & Morin & $\begin{array}{r}\text { a) Substituted benzofuranone } \\
\text { (morin oxide) } \\
\text { b) 2,4-dihydroxybenzoic acid, } \\
\text { 2,4,6-trihydroxybenzoic acid }\end{array}$ & [110] \\
\hline
\end{tabular}

\section{Formulations and Solid Supports for Heterogenous Catalysis}

\subsection{Early evolution efforts by following the p-Nitrophenol standart}

Grafting the dendritic polymer on the surface of an organic or an inorganic support was the obvious choice in order to secure the easy recovery of the catalyst. The first such substrate was crosslinked poly(4-vinylpyridine) beads for PPI G2 dendrimer bearing Au NPs. The catalyst was removed by simple filtration and could be reused for at least 10 times Due to its spherical shape it can be applied as filling material in continuous column reactors [114]. Polystyrene microspheres bearing carboxy reactive groups present one more spherical organic base suitable for divergent PAMAM G5 dendron expansion. After typical incorporation of silver NPs, a hierarchical structure is formed by coating with silica shell via an improved Stöber method in order to construct a different packing medium for stainless steel column reactors [115]. A further very popular organic substrate cellulose in the form of nanocrystals can be oxidized via (2,2,6,6-tetramethylpiperidin-1-yl)oxidanyl, TEMPO regent in order to form surface carboxy groups. Attaching PAMAM G6 through carbodiimidemediated amidation reaction allowed two different Au NPs nucleation mechanisms (Figure 12a). Encapsulation of NPs having diameters of approximately 2 to $4 \mathrm{~nm}$ at neutral $\mathrm{pH}$ with 
$\mathrm{NaBH}_{4}$ and stabilization of NPs with sizes 10 to $50 \mathrm{~nm}$ at pH 3.3 with no additional reducing agent. As usual the smaller NPs are the more effective [116].

Polymer fibers present also an interesting substrate as they may form dendronized polymers by grafting with dendritic polymers. One such example is the grafting of hyperbranched PEI to polyacrylamide through hydrolysis and amidation. The copolymer produced small Au NPs around $3 \mathrm{~nm}$. Particle size increased stereotypically by decreasing dendritic polymer generation. This configuration presented an extremely high turnover value of 50000 [117]. Another two strategies practiced in a related substrate consisted from electrospun polyacrylic acid (PAA)/polyvinylalcohol (PVA) nanofibrous mats was to bind low generation PAMAM G2 either through supramolecular electrostatic interactions or through the covalent 1-ethyl-3-(3-dimethyl- aminopropyl) carbodiimide hydrochloride (EDC) reaction. Surprisingly after doping with $5 \mathrm{~nm}$ Au NPs the physically coupled polymer exhibited the best performance without undesired side effects such as polymer leaching [118].

As expected, the hybrid inorganic-organic-metal nanoparticle composite catalysts were initially based on ceramic silica and specifically ordered mesoporous SBA-15 SiOz. Reaction of the ceramic with aminopropyl triethoxysilane (APTES) functionalized its surface with reactive amino groups. Conventional divergent PAMAM G4 dendron propagation by alternating Michael additions of methyl acrylate and amidations with ethylene diamine and reduction of $\mathrm{Pt}^{4+}$ afforded 1.2 to $2.6 \mathrm{~nm} \mathrm{Pt}$ NPs (Figure 12b). Apart from 4-nitrophenol the catalyst was able to convert ferricyanide to ferrocyanide by thiosulfates [119]. Silica in the form of glass microreactors reacts with APTES as well. Subsequent interaction by p-phenylene diisothiocyanate covalently attached PAMAM G4 to their inner walls. Co-complexation of $\mathrm{AgNO}_{3}$ and $\mathrm{HAuCl}_{4}$ in the dendritic template resulted to bimetallic NPs. Catalytic performance was heavily dependent to $\mathrm{Ag} / \mathrm{Au}$ stoichiometry with the best results obtained at $1: 1$ ratio [120]. 

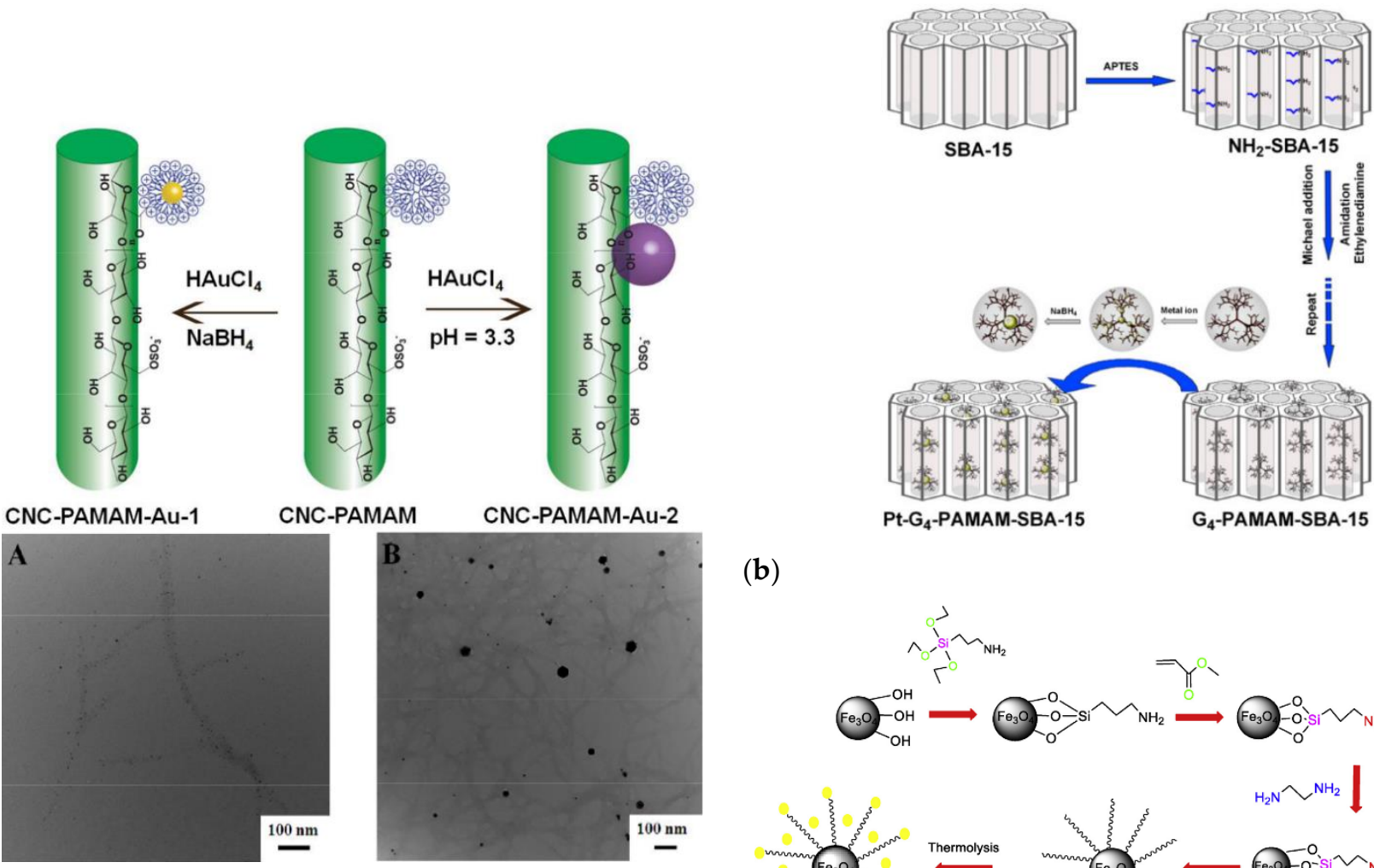

(b)

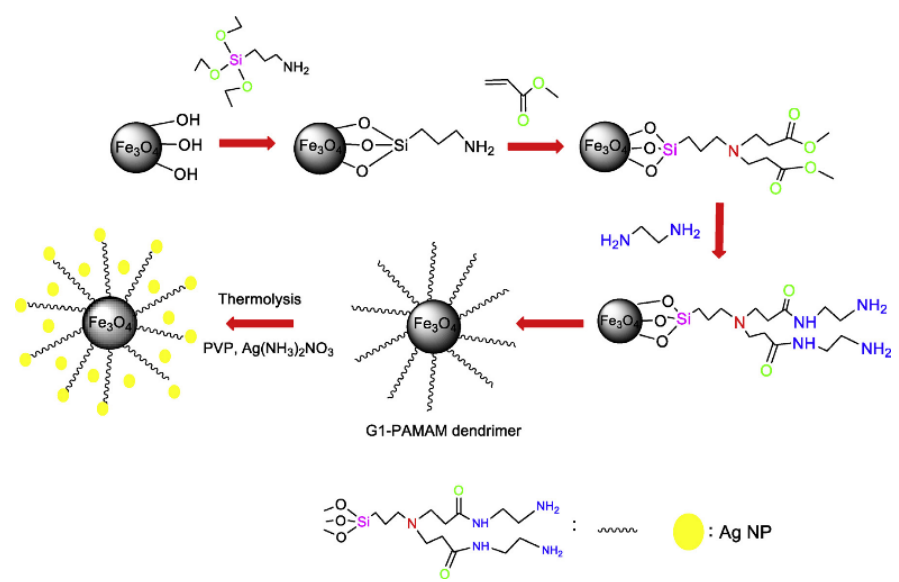

(c)

Figure 12. (a) Schematic illustration of the synthetic process and TEM images for Au NPs formed by two distinctive nucleation mechanisms. Reproduced with permission from [116]; (b) Procedure for the synthesis of SBA15-PAMAM G4-Pt Reproduced with permission from [119]; (c) Schematic illustration of the formation of Fe3O4@APTES@PAMAM G1-Ag Magnetically Recyclable Catalyst Reproduced with permission from [122].

Magnetic supports originating predominantly from a $\mathrm{Fe}_{3} \mathrm{O}_{4}$ core, offer even more easy separation by simple application of a magnet. In an early implementation after coating the magnetic nucleus with a preparatory polystyrene layer PAMAM G7 dendrons emanated and incubated formation of Ag NPs [121]. From the same magnetite core reaction with APTES introduced a silica interlayer that permitted posterior covering with PAMAM G1 via the typical divergent reaction to the reactive amino groups (Figure 12c) and encapsulation of narrowly dispersed Ag NPs to give another variant of magnetically recyclable catalyst [122]. More sophisticated conformations were equally developed. Successive coatings first with 3-methacryloxypropyltrimethoxysilane $\mathrm{KH}-570$ silane coupling agent, then with glycidyl methacrylate and divinylbenzene by distillation precipitation copolymerization and finally with hexamethylenediamine in order to pin primary amine groups pending from the microspheres through a six-carbon spacer provided an ideal substrate for PAMAM propagation without stereochemical limitations (Figure 13a). Coupling with Au Nps led to composition capable of achieving up to $78.7 \%$ 4-nitrophenol degradation after ten cycles [123] A closing reference to inorganic magnetic substrates will be made to an exceptional idea completely "out of the box" that concerns dendritic architecture based exclusively on silica. After an initial sol-gel coating of the magnetic core with tetraethoxy silane (TEOS), a dendritic $\mathrm{SiO}_{2}$ shell is formed by oil-water biphase stratification method. Decoration of these branches with 
external amino groups by treatment with APTES and doping with silver NPs generated a catalyst suitable for 4-nitrophenol and 2-nitroaniline [124].

Carbon allotropic forms constitute further promising surfaces for dendritic polymer grafting. In a first combination hyperbranched PAMAM dendrons emanate from graphite surface activated by $\mathrm{KMnO}_{4}$ oxidation, (Figure 13b). Leaving aside the ordinary p-nitrophenol, embodied Ag NPs enabled the reductive transformation of a wide variety of nitroaromatics (nitrobenzene, o-nitrophenol, o- and p-nitroaniline, $\mathrm{p}$-nitrotoluene, (p-nitrophenyl) methanol, 4-chloro-1,2-dinitrobenzene, o-chloronitrobenzene, p-bromo nitrobenzene, $\mathrm{p}$ iodo nitrobenzene, (1E,1'E)-N, N'-(cyclohexane-1,2-diyl) bis(1-(4-nitrophenyl) methanimine)). No side dehalogenations or hydrogenations of the imine groups occurred indicating high level of chemo-selectivity [125]. In a synergistic scheme magnetic graphene oxide is obtained through doping with $\mathrm{MnFe}_{2} \mathrm{O}_{4} \mathrm{NPs}$ by solvothermal technique. Following typical induction of amino groups by APTES and PAMAM G3 dendron evolution; the immobilization of Pd NPs (Figure 14) led to a catalyst with reducing potential towards an extensive range of nitropollutants: 2-nitroaniline, 2-chloro-6-nitrophenol, 1-chloro-4-nitrobenzene, 1,2-dinitrobenzene and 2,5-dinitrophenylhydrazine [126]. Multi-Walled Carbon Nanotubes (MWCNT) may be activated by similar induction of carboxyl groups onto their surface by oxidative procedures such as $\mathrm{KMnO}_{4}$ phase transfer catalysis. Chemical attachment of PPI G2, G3, dodecyl quaternary ammonium groups and immobilization of Pd and Ag NPs produced a recyclable, five-fold more efficient catalytic agent in comparison to the simple metal dendritic polymer hybrid [127]. Moreover, this composition proved a very efficient antibacterial agent for the gram-negative representative pathogen Pseudomonas aeruginosa and the respective gram-positive Staphylococcus aureus. [128].
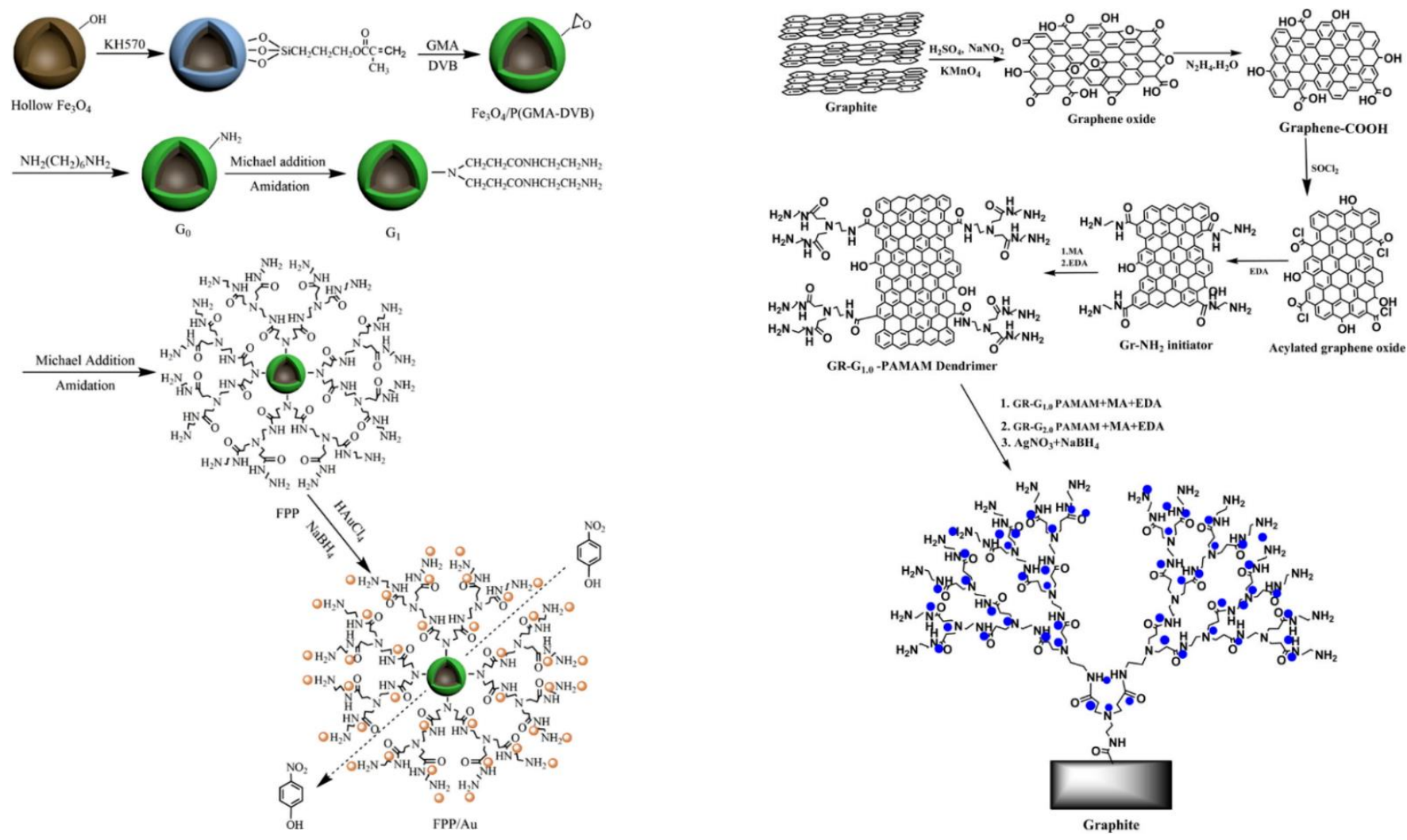

(a)

(b)

Figure 13. (a) Schematic representation of the process for the synthesis of magnetic $\mathrm{Fe}_{3} \mathrm{O}_{4} / \mathrm{P}(\mathrm{GMA}-\mathrm{DVB}) / \mathrm{PAMAM} / \mathrm{Au} \mathrm{mi}-$ crospheres Reproduced with permission from [123]; (b) Procedure for the synthesis of Graphite-PAMAM G3-Ag dendrimer. Reproduced with permission from [125]. 


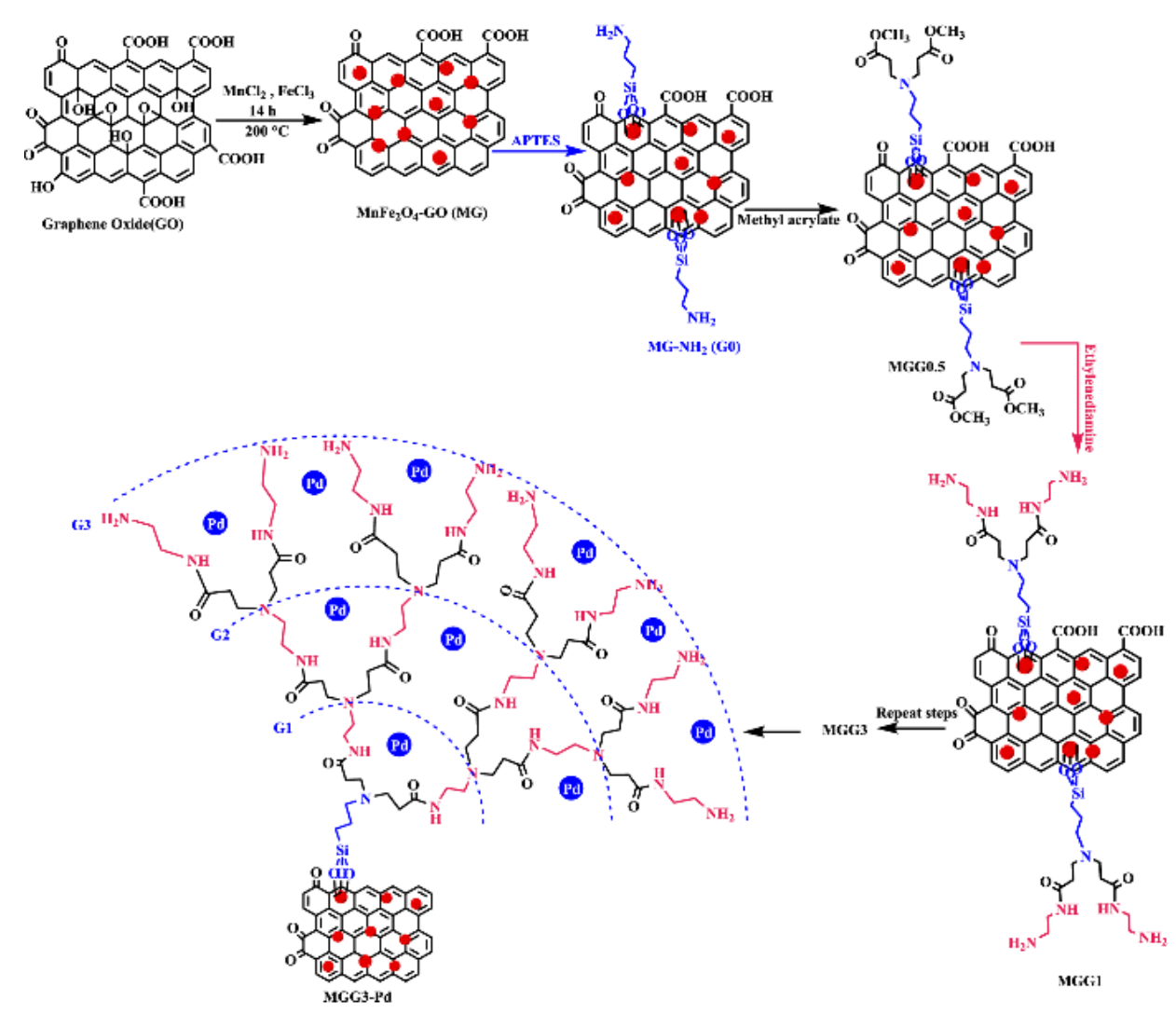

Figure 14. Synthetic procedure of the Graphene oxide- $\mathrm{MnFe}_{2} \mathrm{O}_{4}-\mathrm{PAMAM}$ G3-Pd nanocomposites. Reproduced with permission from [126].

A very simple concept defining the limits of homogenous catalysis and where the realm of heterogenous mechanisms begins concerns the use of a dialysis membrane in order to enclose a PAMAM G4 Au NPs solution prepared as usual. Immersion of this container to a solution containing $\mathrm{p}-\mathrm{Nitrophenol}$ and $\mathrm{NaBH}_{4}$ initiates the common catalytic reaction. After the reaction termination the catalytic solution is easily isolated and may be reused after recycling in a new catalytic cycle [129]. In a second fundamental idea amphiphilic dendritic polymers consisting of a PEI core bearing hydrophobic shells of saturated palmitamides, octadecanamides, or unsaturated oleamides enhanced the stability of spherical Au NPs and their solubility in organic solvents such as petroleum ether, n-butyl acetate and toluene enabling them to be employed in heterogenous biphasic catalytic reduction systems with turnover number values up to 5040 [130].

PEI core combined with a poly (styrene-co-2-ethylhexyl acrylate shell was combined with Pt nanoclusters (Figure 15a) [131,132] whereas a slightly different shell containing polystyrene and dodecyl aliphatic chains was paired with Au NPS (Figure 15b) [133]. Reaction of the intermediate composite in a biphasic water-toluene system caused organization into high internal phase emulsion. Radical emulsion polymerization initiated by azodiisobutyronitrile produced an open-cellular, elastic monoliths (Figures 15c, 15d) that proved highly recyclable catalysts with excellent properties. The heterogenous systems designed and tested for nitro-derivatives elimination are listed in Table 4. 


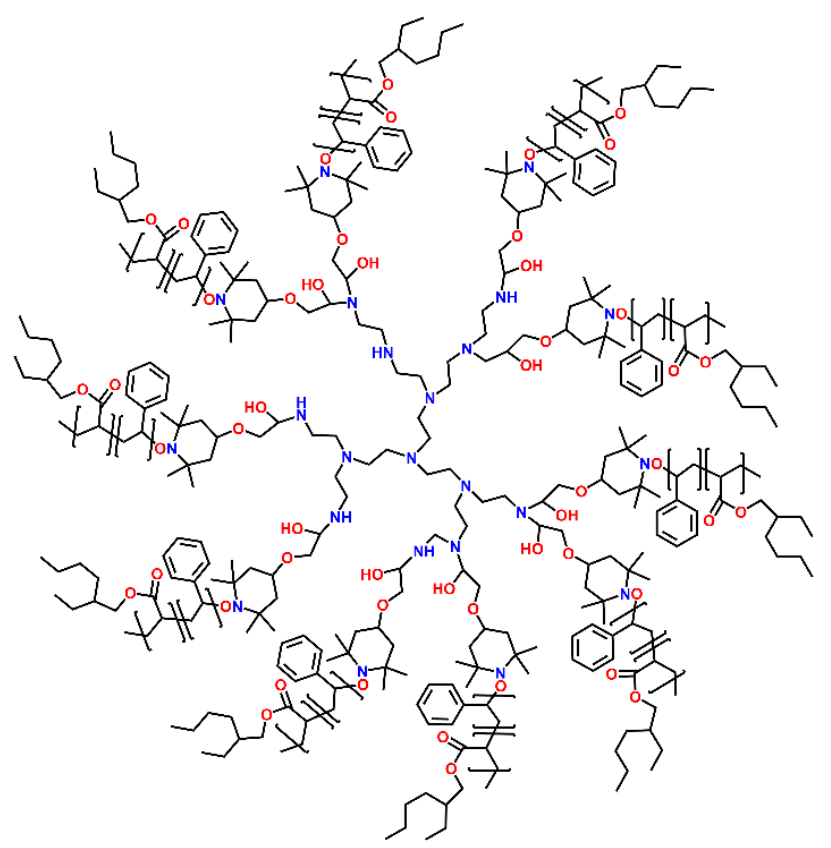

(a)

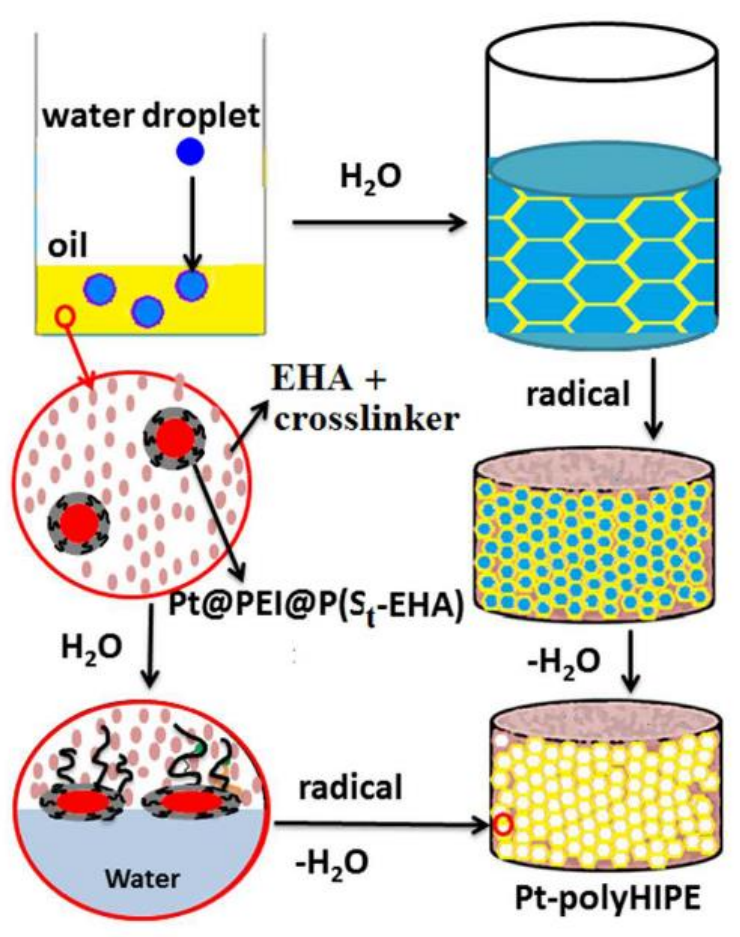

(c)

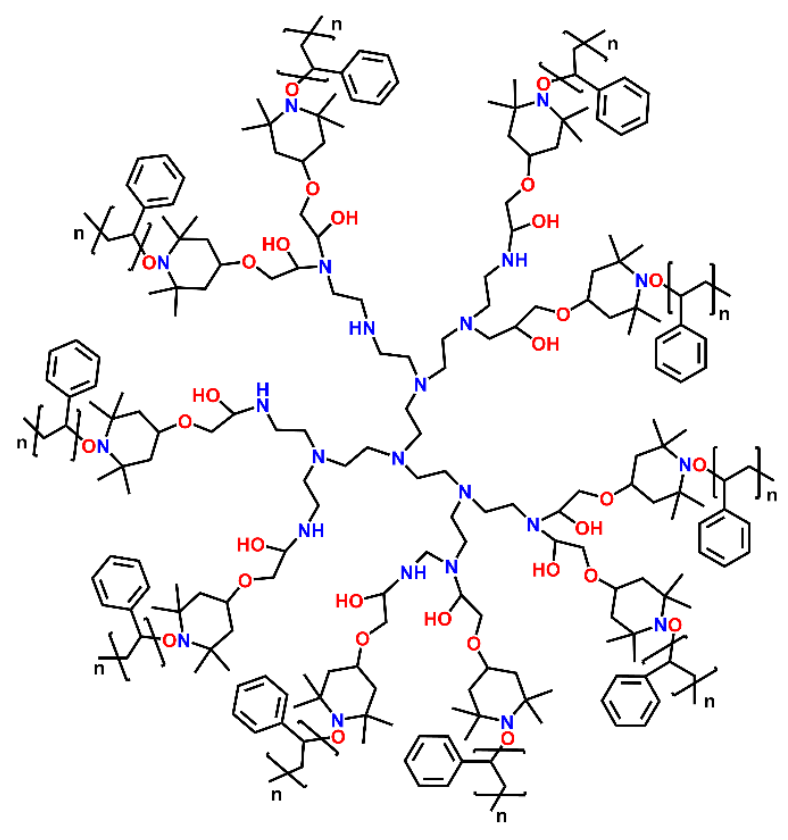

(b)

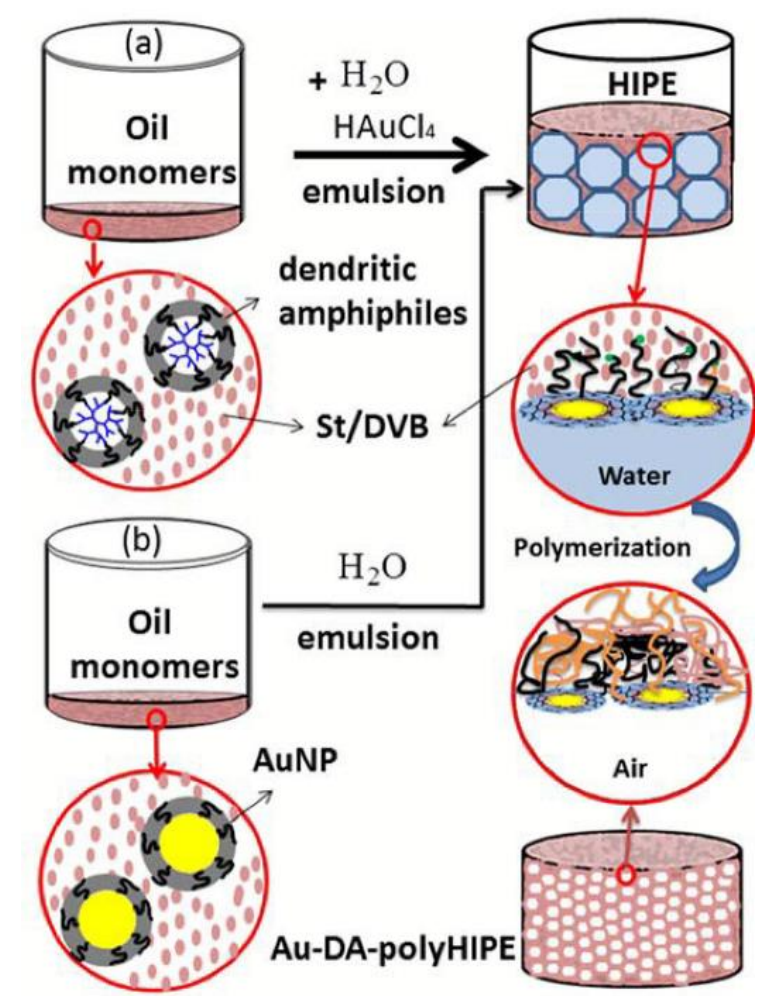

(d)

Figure 15. (a) PEI Core Poly (styrene-co-2-ethylhexyl acrylate shell dendritic amphiphile. Synthetic procedure of the Graphene oxide-MnFe2O4-PAMAM G3-Pd nanocomposites. Adapted from [131]; (b) PEI Core Polystyrene do-decyl shell dendritic amphiphile. Adapted from [133]; (c) Preparation of Pt-polyHIPE open-cellular and elastic monolith Reproduced with permission from [131]; (d) Schematic presentation of the synthesis of Au-DA-polyHIPE open-cellular and elastic monolith. Reproduced with permission from [133]. 
Table 4. Dendritic Polymer - Metal NPs formulations for heterogenous catalysis of nitroaromatics

\begin{tabular}{|c|c|c|c|}
\hline Dendritic Polymer & Metal NPs & Substrate-Formulation & Reference \\
\hline PPI-G2 & $\mathrm{Au}$ & Poly(4-vinylpyridine) beads & {$[114]$} \\
\hline PAMAM G4 Dendrons & $\mathrm{Pt}$ & SBA-15 $\mathrm{SiO}_{2}$ & [119] \\
\hline PAMAM G5 Dendrons & $\mathrm{Ag}$ & Polystyrene Microspheres Cores $\mathrm{SiO}_{2}$ Shells & [115] \\
\hline PAMAM G7 Dendrons & $\mathrm{Ag}$ & $\mathrm{Fe}_{3} \mathrm{O}_{4}$ coated by polystyrene & [121] \\
\hline PAMAM G3 Dendrons & $\mathrm{Ag}$ & Graphite & [125] \\
\hline PEI & $\mathrm{Au}$ & polyacrylonitrile fiber & [117] \\
\hline Amphiphilic PPI G2, G3 & $\mathrm{Ag}, \mathrm{Pd}$ & MWCNT & [127] \\
\hline PAMAM G1 & $\mathrm{Ag}$ & $\mathrm{Fe}_{3} \mathrm{O}_{4}$ & [122] \\
\hline PAMAM G2 & $\mathrm{Au}$ & Polyacrylic acid/polyvinyl alcohol nanofibers & [118] \\
\hline $\begin{array}{l}\text { PEI Core Polystyrene dodecyl } \\
\text { shell }\end{array}$ & $\mathrm{Au}$ & Polymer open-cellular elastic monolith & \\
\hline $\begin{array}{l}\text { PEI Core Poly(styrene-co-2- } \\
\text { ethylhexyl acrylate shell. }\end{array}$ & $\mathrm{Pt}$ & $\begin{array}{l}\text { Copolymer with 2-ethylhexyl acrylate-poly(ethylene } \\
\text { glycol) dimethacrylate open-cellular elastic monolith }\end{array}$ & [131] \\
\hline Amphiphilic PEI & $\mathrm{Au}$ & Chloroform, Toluene, or Petroleum ether & [130] \\
\hline PEI Core & $\mathrm{Au}$ & Polystyrene dodecyl shell & [133] \\
\hline PAMAM G6 & $\mathrm{Au}$ & Cellulose Nanocrystals & [116] \\
\hline PAMAM-G4 & $\mathrm{Au} / \mathrm{Ag}$ & Glass Microreactors & [120] \\
\hline PPI G2 & $\mathrm{Ag}$ & MWCNT & [128] \\
\hline $\begin{array}{l}\text { PEI Core poly(styrene-co-2- } \\
\text { ethylhexyl acrylate) Shell }\end{array}$ & $\mathrm{Pt}$ & $\begin{array}{l}\text { Copolymerization with 2-ethylhexyl acrylate- } \\
\text { poly(ethylene glycol) dimethacrylate }\end{array}$ & [132] \\
\hline PAMAM G4 & $\mathrm{Au}$ & Dialysis membrane & [129] \\
\hline $\mathrm{SiO}_{2}$ Dendrons & $\mathrm{Ag}$ & $\mathrm{Fe}_{3} \mathrm{O}_{4} @ \mathrm{SiO}_{2} @$ Dendritic-SiO $2-\mathrm{NH}_{2}-\mathrm{Ag}$ & [124] \\
\hline PAMAM G2 Dendrons & $\mathrm{Au}$ & $\begin{array}{l}\mathrm{Fe}_{3} \mathrm{O}_{4}, \mathrm{KH}-570 \text { Glycidyl methacrylate divinylbenzene } \\
\text { copolymer, }\end{array}$ & [123] \\
\hline PAMAM G3 dendrons & $\mathrm{Pd}$ & Graphene Oxide, $\mathrm{MnFe}_{2} \mathrm{O}_{4} \mathrm{NPs}$ & [126] \\
\hline
\end{tabular}

\subsection{Heterogenous catalytic degradation of dyes}

In a second implementation step, aligned with homogenous catalysis, the experience gained from the interactions of heterogenous dendritic polymer-NP hybrids with nitrophenol and the overall family of nitroaromatic compounds was put into action for dye decomposition. Research on this particular subsector is quite fresh covering only the last seven years. Covalent grafting of PAMAM on graphene oxide as previously described provided a scaffold for the formation of bimetallic Ag/Au NPs. The products were able to eliminate commercial colorants used in the dyeing industry such as methyl orange and Congo red [134]. An impressively interesting proposition introduces dendrigrafts to water purification technologies and moreover integrates benefits from two different classes of dendritic polymers with distinct functionalities. Notably 6-armed PEG-NH 2 covalently interacts with the epoxide, hydroxyl, and carboxyl oxygenated functions of nanographene oxide (PEGylation) and then thiol-functionalization occurs without (Figure 16a) or with intermediate amidation reaction with PAMAM (Figure 16b). Au NPs evolved from the thiol sites, effectively reduced 4-nitrophenol, 4-nitroaniline and Congo red [135]. 

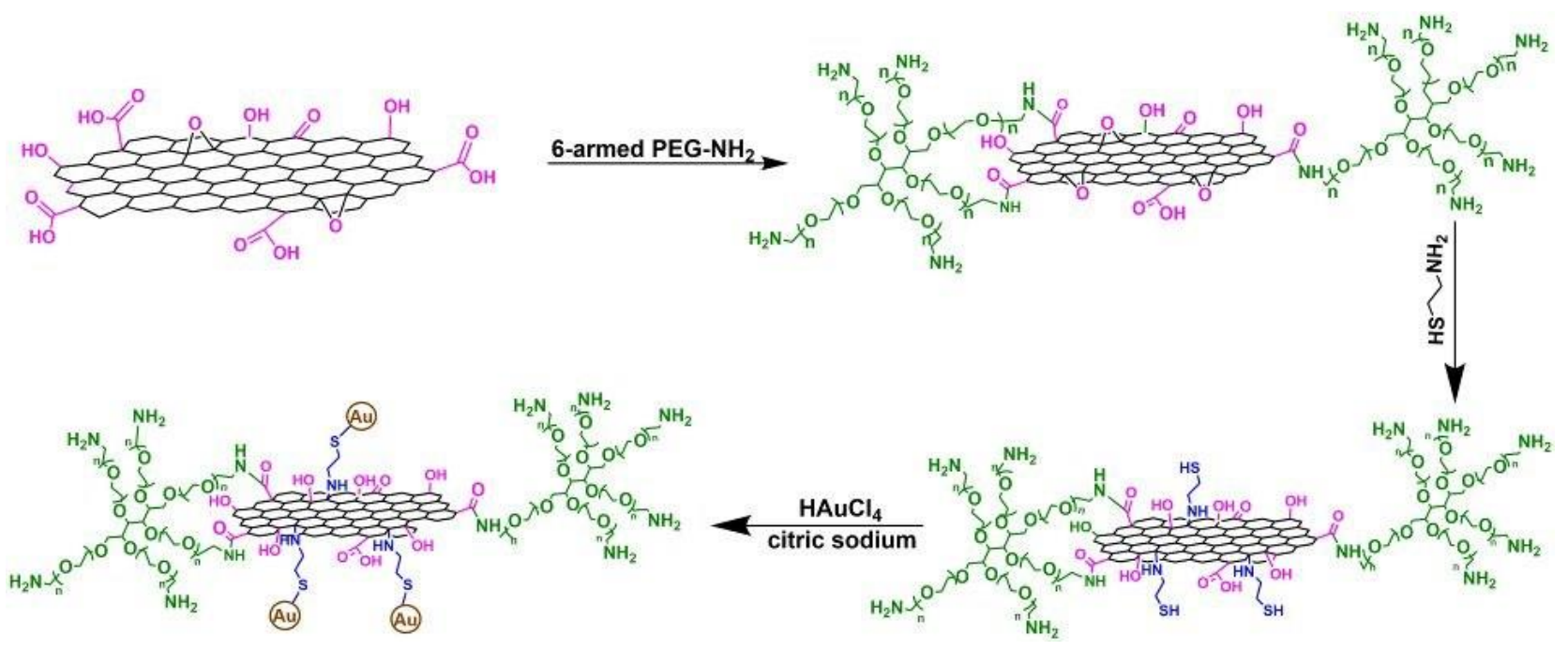

(a)
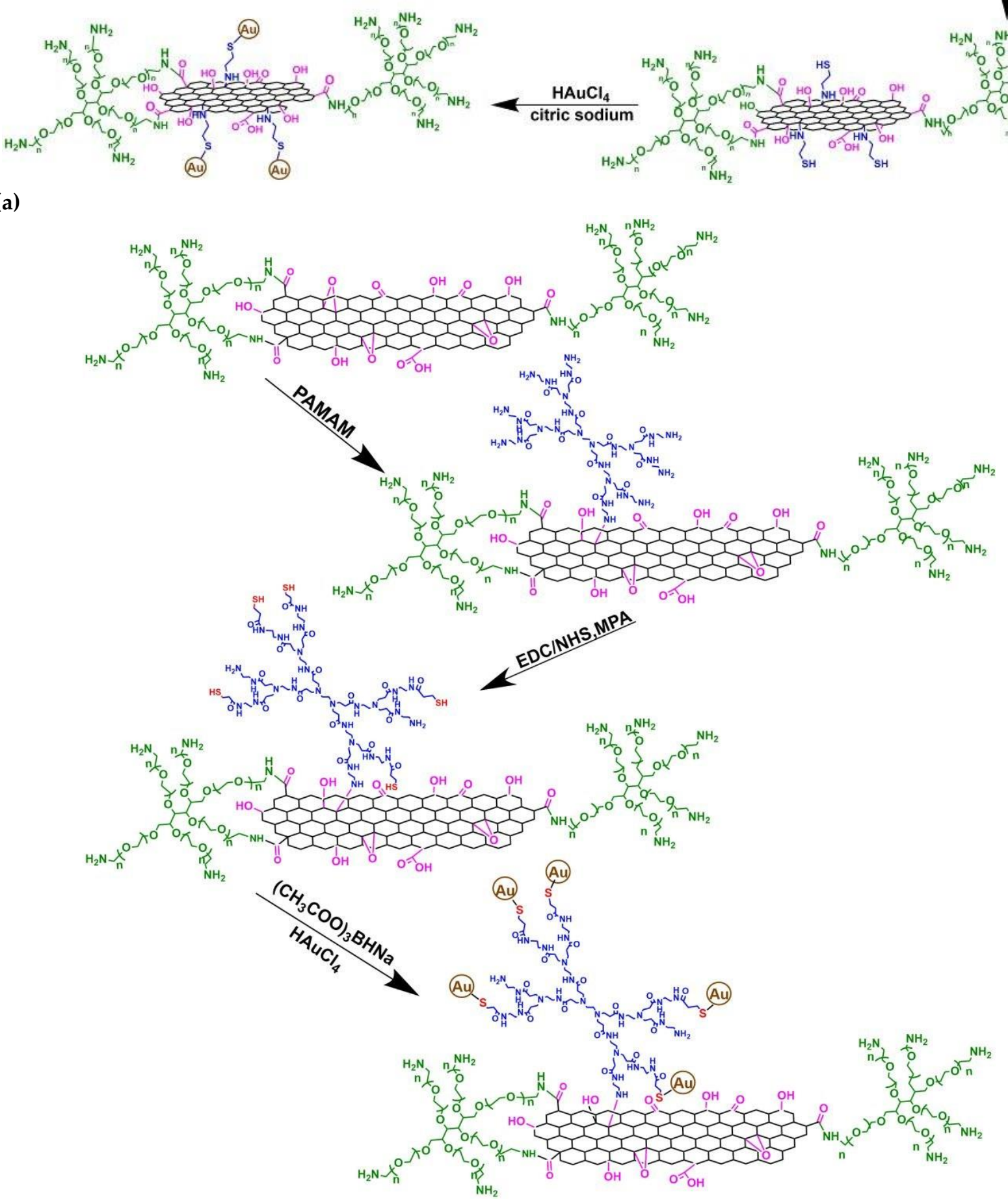

(b)

Figure 16. (a) Au NPs loading on PEG and thiol dual-functionalized nanographene oxide (b) Au NPs loading on PEG and thiol-PAMAM dual functionalized nanographene oxide Both reproduced with permission from [135]. 
A second inorganic point of view consists in the physical immobilization of PAMAM$\mathrm{OH}$ G5 dendrimer encapsulating random alloy Pd-Au NPs $(2.66 \pm 0.51 \mathrm{~nm})$ on reducible mesoporous transition metal oxides $\left(\mathrm{CeO}_{2}, \mathrm{NiO}, \mathrm{Co}_{3} \mathrm{O}_{4}, \mathrm{Fe}_{2} \mathrm{O}_{3}, \mathrm{MnO}_{2}\right.$, and $\left.\mathrm{SiO}_{2}\right)$ by sonication. Synergistic catalytic activity of the ceramic host with the metal guest was established. The best results in morin oxidation were demonstrated by $\mathrm{Pd} / \mathrm{Au}-\mathrm{Co}_{3} \mathrm{O}_{4}$ and $\mathrm{Pd} / \mathrm{Au}-\mathrm{CeO}_{2}$ [136]. This synergy was verified when platinum NPs of different sizes $\left(\mathrm{Pt}_{\mathrm{n}}, \mathrm{n}=55,140,225\right)$ nucleated into PAMAM G6-OH were adsorbed via wet impregnation procedure into mesoporous $\mathrm{C}_{3} \mathrm{O}_{4}$ synthesized by inverse micelle method. Oxidation of methylene blue proceeded faster by the mediation of these composites in comparison to PAMAM G6-OH-Pt adsorbed in simple silica and kept up for at least 8 cycles with minimum metal leaching [137].

Organic substrates play a protagonistic role in dendritic polymer grafting for composite catalyst manufacturing. As was the case with GO, experiments with organic polymer fibers and 4-nitrophenol promoted the development of dispersions for dye effluents treatment. In a first approach 2,2,6,6-tetramethylpiperidine-1-oxyl radical-oxidized nanofibrillated cellulose. Association with PAMAM G4 and $\mathrm{AgNO}_{3}$ produced an effective multifunctional material for reductive discoloration of Rhodamine $\mathrm{B}$ and antibacterial action against both Gram-positive and Gram-negative bacteria [138]. Polyester (PET) fibers functionalized by PAMAM or APTES and decorated by $\mathrm{Cu}$ and Ag NPs were tested at first for their reducing potential towards 4-nitrophenol, methylene blue, malachite green and Remazol red. In a second stage, multifunctional filters based on a three-layered sandwich structure PET1PAMAMIPET2-APTES-Ag/CuIPET1-PAMAM of nonwoven fabrics were manufactured from these fibers. They accomplished simultaneous dissolved solids filtration, bacteria disinfection (Escherichia Coli, Staphylococcus Epidermis) and catalytic p-nitrophenol and dye discoloration in continuous flow [139]. Air atmospheric plasma treatment to hydrophobic PET fibers of a nonwoven membrane introduces hydrophilic carboxy and hydroxy groups that facilitate the optional step of hyperbranched poly-(ethylene glycol)-pseudo generation 5 chemical binding. Ferric ions adsorbed to these functionalized substrates are transformed to zero valent iron (ZVI) via $\mathrm{NaBH}_{4}$ by two different mechanisms either one step (in-situ simultaneous adsorption and reduction) or two steps ex-situ (Figure 17a). Formation of an external iron oxide layer that reduces the risk of further oxidation has been observed in both occasions (Figure 17b). The extra dendritic lamellae ameliorated immobilization and stabilization of the ZVI particles that supported malachite green mineralization for at least 8 consecutive cycles (Figure 17c) [140]. Alternative activation procedure of the PET fibers, alkaline hydrolysis, and optional PAMAM binder layer permitted uniform reduced GO coating and high $\mathrm{Fe}^{0}$ loading after dip coating in $\mathrm{Fe}^{3+}$ and $\mathrm{GO}$ solutions and in-situ reduction-immobilization (Figure 17d). The produced non-woven fabrics were used for the removal of crystal violet (Figure 17e) [141]. In contrast PAMAM G1 proved rather incompatible host for Fe NPs since its attachment to polyester fabrics yielded inferior 4-nitrophenol and methylene blue degradation rates in comparison to APTES or thioglycerol [142]. 


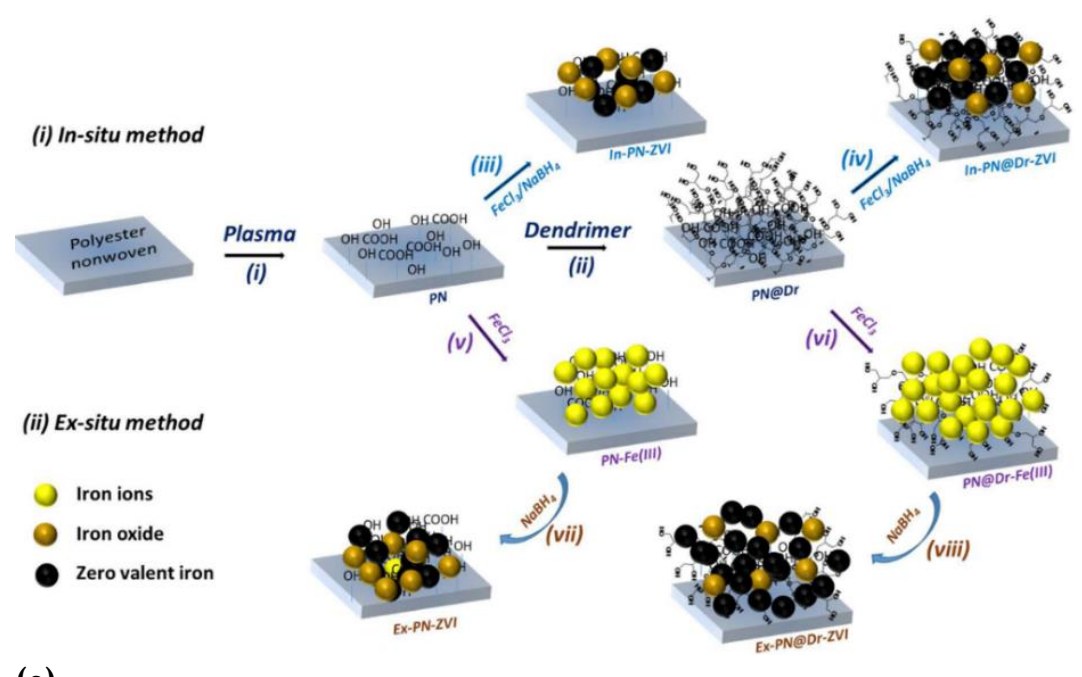

(a)
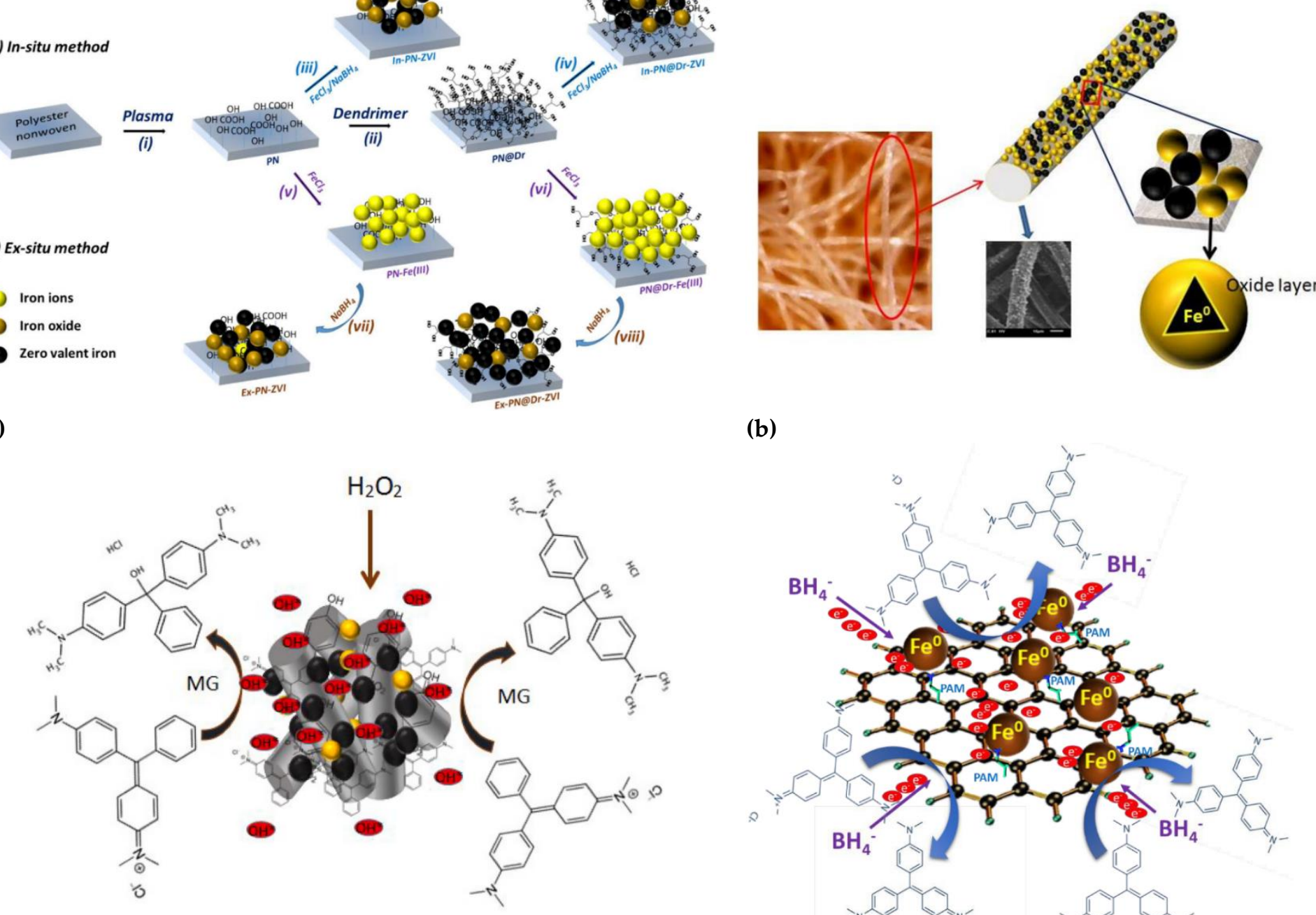

(b)

(c)

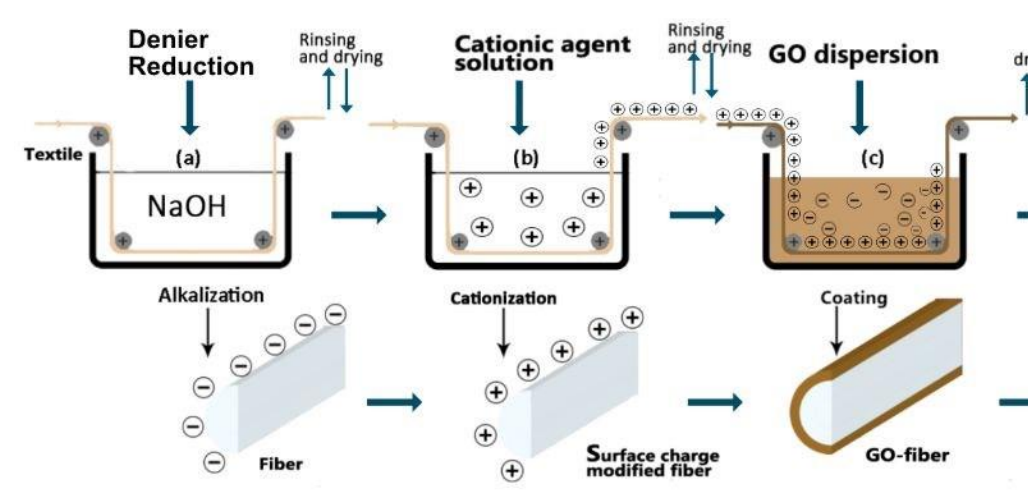

(e)
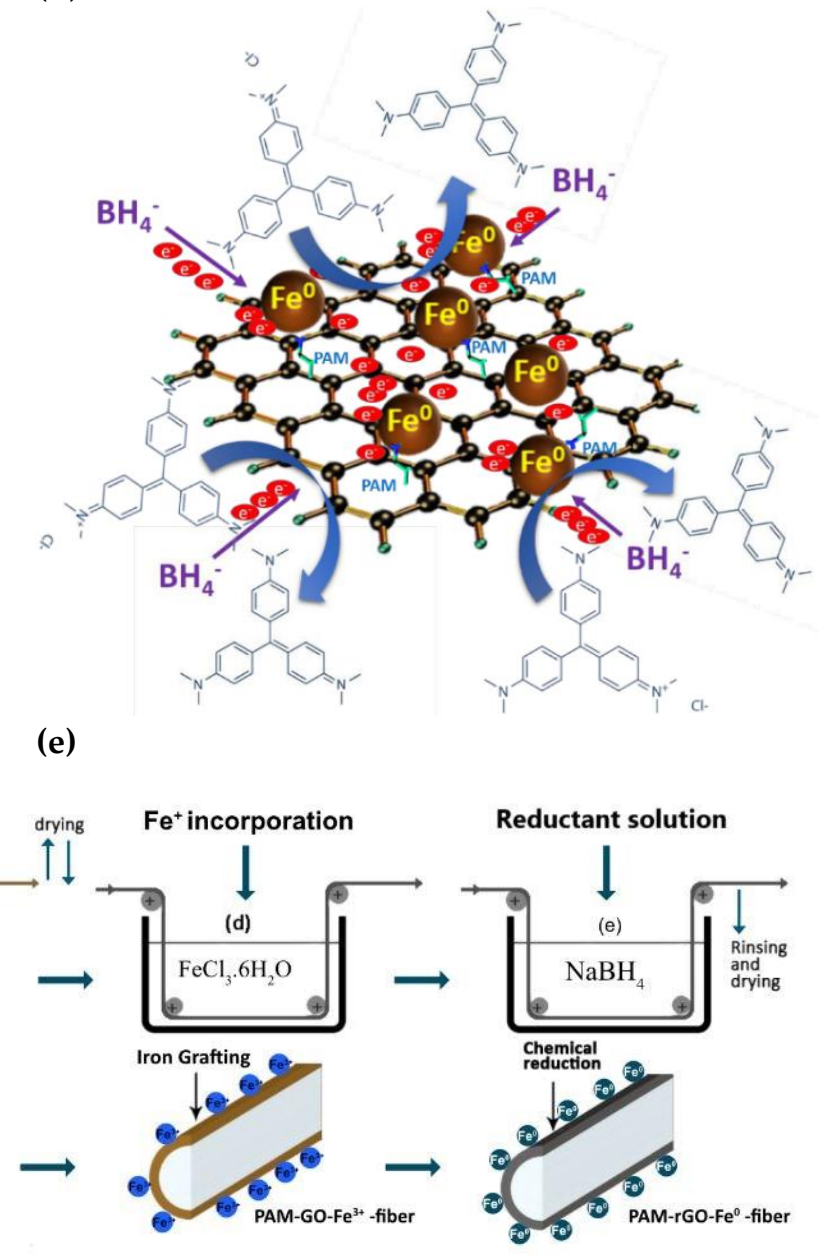

(d)

Figure 17. (a) Pathways used to immobilize Fe on nonwoven PET, (i) plasma treatment (ii) dendrimer grafting (iii, iv) in-situ and (v/vii, vi/viii) ex-situ reduction method. [Yellow spheres represent iron (III) ions, orange spheres represent ZVI with iron oxides shell, and black spheres represent ZVI]; (b) Schematic illustration of Fe ${ }^{0}$ immobilization on PET fibers. (c) Mechanism of the catalytic degradation of Malachite Green by ZVI immobilized PET nonwoven. All three reproduced with permission from [140] (d) Schematic illustration of (a) alkalization of polyester fibers; (b) PAMAMgrafting; (c) incorporation of GO; (d) incorporation of $\mathrm{Fe}^{3+}$ (e) in-situ immobilization of rGO and Fe0; (e) Mechanism for catalytic decomposition of crystal violet dyes using $\mathrm{Fe}^{0}$ incorporated polyester nonwoven fabric. Both reproduced with permission from [141]. 
The majority of the heterogenous catalysis systems though are in the form of microspheres or beads. The superiority of dendritic polymers-metal NPs over linear analogues was established by a direct comparison of poly(styrene)-co-poly(vinyl benzene chloride) cores surrounded by three different types of polymer-shells (i) triethanolamine, (ii) glycidyl trimethyl ammonium chloride and hyper-branched polyglycerol. Regardless of the metal NPs (Ag or Au) Congo Red was processed at least twice faster in the suspension of the catalyst with the hyperbranched polymer exterior in comparison to the linear nitrogen containing analogues [143]. Au NPs stabilized with PPI G2, G3 based on Poly(styrene)-copoly(4-vinyl pyridine) divinylbenzene beads exhibited best performance over $\mathrm{Ag}$, and Pd for reduction of trypan blue [144]. PPI G2, G3 were also grafted on poly(vinylimidazole) microbeads prepared by suspension co-polymerization of styrene, $\mathrm{N}$-vinylimidazole and divinylbenzene. When bimetallic Au/Pd NPs were immobilized into the dendrimers they exhibited 3-fold superiority in comparison to monometallic Au against Malachite Green and unaltered performance over 5 catalytic circles after recovery with simple filtration [145].

Apart from metal NPs matrices, dendritic polymers may also act as templates for the supporting nanospheres. PAMAM G4 dendrimers bearing Au and Ag NPs molded within their cavities acted as dual templating agent by further constructing external mesoporous silica nanosphere shells. After removing the organic content by calcination at $500^{\circ} \mathrm{C}$ and preliminary survey with p-nitrophenol oxidative degradation of methylene blue was observed with very little leaching. Preparative oxidation of benzyl alcohol was also attained [146]. A similar configuration with Ag NPs and hyperbranched PEI in the place of PAMAM established the capability of further water disinfection from Staphylococcus Aureus, Pseudomonas Aeruginosa Escherichia Coli bacterial load as well [147]. Onisuru presented a second way to take advantage of this dual templating mechanism. At first PAMAM G4 enfolded Cu NPs then mesoporous $\mathrm{SiO}_{2}$ integument was created. The organic scaffold was pyrolyzed by calcination at $500^{\circ} \mathrm{C}$. Displacement of $\mathrm{Cu}$ by galvanic exchange with $\mathrm{Au}$ led to nanospheres able for 4-nitrophenol reduction, and oxidation of rhodamine B and styrene (Figure 18) [148].
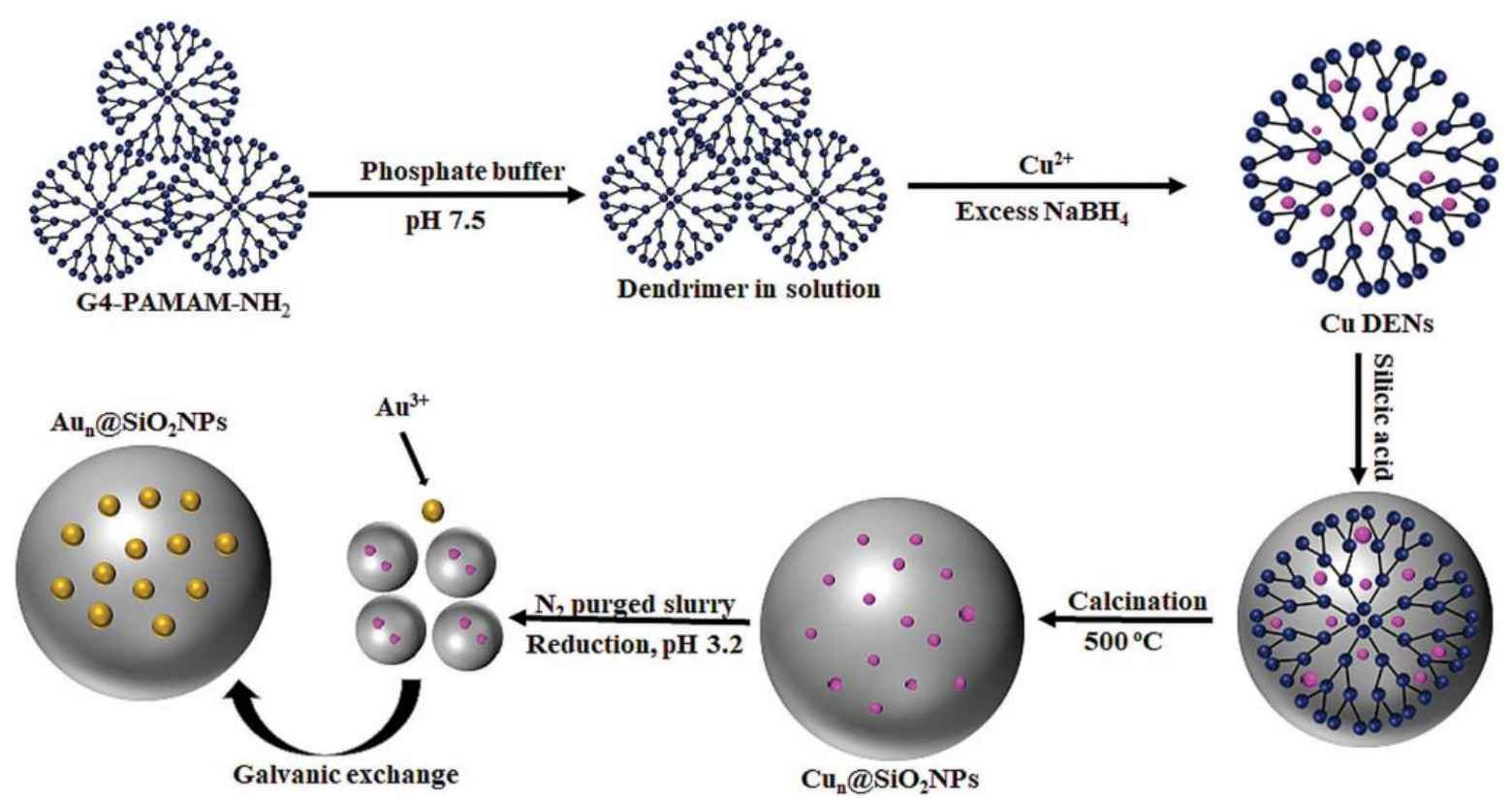

Figure 18. Schematic illustration of Cu NPs immobilization on silica and subsequent in situ replacement by Au NPs. Reproduced with permission from [148]. 
The field of dye elimination and subsequent recovery of magnetic beads took also advantage from the initial evolution based on experiments on nitro-derivatives. The productive merging of divinylbenzene and glycidyl methacrylate coating was upgraded with the inclusion of 4-methylstyrene. Suspension polymerization led to a copolymer, coating for 8nm magnetite cores. Grafting PAMAM dendrons G2 doped with Au NPs proved 6 times more effective for Rhodamine B discoloration than employing G0 analogies for five consecutive cycles. [149]. The heterogenous catalysts suitable for pigment discoloration are listed in Table 5.

Table 5. Dendritic Polymer - Metal NPs formulations for heterogenous catalysis of pigments

\begin{tabular}{|c|c|c|c|c|}
\hline Dendritic Polymer & Metal NPs & Substrate-Formulation & Dyes & Reference \\
\hline PAMAM Dendrons & $\mathrm{Ag} / \mathrm{Au}$ & $\mathrm{GO}$ & Methyl orange, Congo red & {$[134]$} \\
\hline PAMAM G4 & $\mathrm{Ag}$ & Cellulose Nanofibril Films & Rhodamine B & [138] \\
\hline PAMAM Dendrons G0, G1, G2 & $\mathrm{Au}$ & $\begin{array}{l}\mathrm{Fe}_{3} \mathrm{O}_{4} \text { core } 4 \text {-methylstyrene divinylben- } \\
\text { zene glycidylmethacrylate shell beads }\end{array}$ & Rhodamine B & [149] \\
\hline Hyperbranched PG & $\mathrm{Ag}, \mathrm{Au}$ & $\begin{array}{l}\text { Poly(styrene)-co-poly(vinyl benzene chlo- } \\
\text { ride) beads }\end{array}$ & Congo Red & [143] \\
\hline PAMAM G4 & $\mathrm{Ag}, \mathrm{Au}$ & $\mathrm{SiO}_{2}$ nanospheres & Methylene blue & [146] \\
\hline PAMAM-OH G5 & $\mathrm{Pd} / \mathrm{Au}$ & $\mathrm{CeO}_{2}, \mathrm{NiO}, \mathrm{Fe}_{2} \mathrm{O}_{3}, \mathrm{MnO}_{2}, \mathrm{SiO}_{2}, \mathrm{Co}_{3} \mathrm{O}_{4}$ & Morin & [136] \\
\hline PPI G2, G3 & $\mathrm{Au}, \mathrm{Au} / \mathrm{Pd}$ & Poly(vinyl imidazole) microbeads & Malachite Green & [145] \\
\hline PPI(G2) and PPI(G3) & $\mathrm{Ag}, \mathrm{Au}, \mathrm{Pd}$ & 4-Vinyl pyridine) beads & Trypan Blue & [144] \\
\hline PAMAM & $\mathrm{Cu}, \mathrm{Ag}$ & polyester nonwoven fabrics & $\begin{array}{l}\text { 4-Nitrophenol, Methylene blue, } \\
\text { Malachite green, Remazol Red }\end{array}$ & [139] \\
\hline PAMAM-OH G6 & $\mathrm{Pt}$ & Mesoporous $\mathrm{Co}_{3} \mathrm{O}_{4}$ & Methylene blue & [137] \\
\hline PAMAM G1 & $\mathrm{Fe}$ & Polyester fabrics & 4-Nitrophenol, Methylene Blue & [142] \\
\hline PEG & $\mathrm{Fe}$ & Fibrous Polyester Membrane & Malachite Green & [140] \\
\hline PAMAM & $\mathrm{Fe}$ & GO, Polyester Textile & Crystal Violet & [141] \\
\hline PAMAM, PEG dendrigraft & $\mathrm{Au}$ & Nanographene Oxide & $\begin{array}{r}\text { 4-nitrophenol, 4-nitroaniline } \\
\text { Congo red }\end{array}$ & [135] \\
\hline PAMAM G4 & $\mathrm{Au}$ & $\mathrm{SiO}_{2}$ nanospheres & 4-nitrophenol, Rhodamine B & [148] \\
\hline
\end{tabular}

\subsection{Applications of Heterogenous Catalysis in the Treatment of other Water Contaminants}

Recently, efforts to address water contamination issues caused by toxic compounds that do not come under the dyes and nitro aromatic derivatives categories have begun. All these efforts concern equipping filtration membranes with the ability to decompose the absorbed pollutants and interestingly all involve bimetallic NPs. A PPI $\beta$-cyclodextrin derivative was synthesized by typical conjugation reaction from b-cyclodextrin carbonyl imidazole. Interfacial polymerization by dip coating of commercial polysulfone microporous membranes into an aqueous solution of this dendrimer and subsequent crosslinking with trimesoyl chloride afforded reactive films. These membranes adsorbed $\mathrm{Fe}^{2+}$ and $\mathrm{Ni}^{2+}$ that amalgamated into bimetallic $\mathrm{Fe} / \mathrm{Ni} \mathrm{NPs}$ by the aid of $\mathrm{NaBH}_{4}$. The final membranes managed dichlorination of adsorbed 2,4,6-trichlorophenol to 2,4-dichlorophenol ,4-chlorophenol and phenol [150]. Polyether sulfone support membrane modified by simple PPI G2, G3 hosted Fe/Ni NPs induced by the same process. When standard solutions of three absorbed arginine containing microcystin congeners (MCY - LR, MCY - YR and MCY - RR) were filtered by the combined membrane, degradation greater than $80 \%$ was observed. [151] Replacement of PPI with its non-symmetric PEI analogue on polysulfone and selecting a different bimetallic pair Fe/Pd of $4 / 1$ ratio (Figure 19a) carried out the dechlorination of adsorbed polychlorinated biphenyl-153 (Figure 19b). The minimal metal leaching was observed after a period of four days was attributed to the solid incorporation of the NPs into the internal hyperbranched cavities [152]. 


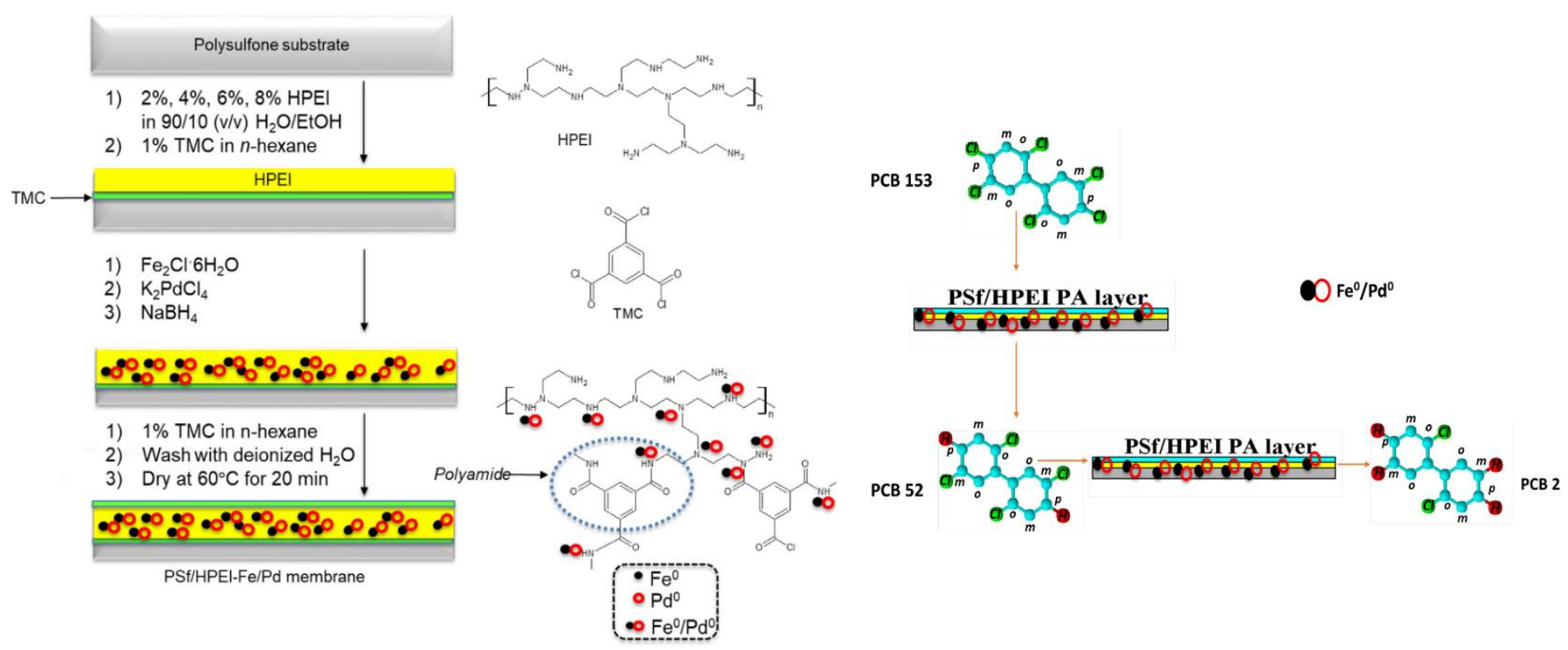

(a)

(b)

Figure 19. (a) Synthesis route for the preparation of Fe/Pd bimetallic nanoparticles embedded in HPEI/PSf membranes. (b) Proposed dechlorination reaction scheme. Both reproduced with permission from [152].

\section{Unconventional Catalysis Involving Dendritic Polymers}

Although the vast majority of both conventional homogenous and heterogenous catalytic pollutant degradation concerning dendritic polymers is accomplished with the inclusion or the stabilization of metal NPs the are some fascinating exceptions. The minimal deviation from the norm is the omission of the cation reduction step. In a first example common polyacrylonitrile fibers were molded with polyamines (ethylenediamine, tetraethylenepentamine and hyperbranched PEI) susceptible to complex formation with $\mathrm{Fe}^{3+}$ and were applied for synthetic reactive dye wastewater (including Reactive Red 195) discoloration [153]. Chitosan is contemplated as a second intriguing option since it is a biocompatible renewable organic carrier with very advantageous molecular architecture. In the form of dendronized microbeads covalently bonded with hexa and nona-functionalized aromatic or aliphatic polyamido-dendrons (Figure 20a) it can retain $\mathrm{Cu}^{2+}$ ions and form a multipurpose catalyst capable of promoting decomposition of $\mathrm{H}_{2} \mathrm{O}_{2}$ for water and soil organic pollutant oxidative degradation [154].

Besides metal NPs and ions PAMAM G3 cavities may envelop other inorganic materials such as montmorillonite or rice-straw-ash NPs (RSA) and magnetite NPs (Figure 20b). Increasing the percentage of the latter from 0.4 to $1.2 \mathrm{wt} . \%$ causes clustering of the organic scaffolds to "dendrimer colonies". As secondary side effect coalescence of $\mathrm{SiO}_{2} \mathrm{NPs}$ of RSA from 53 to $180-650 \mathrm{~nm}$ and exfoliation of clay layers is observed. These two hybrids although designed for optimal adsorption properties $\left(\mathrm{NH}_{4}{ }^{+}, \mathrm{NO}_{3}{ }^{-}\right.$for Magnetite @PAMAM/Montmorillonite), ( $\mathrm{Hg}^{2-}, \mathrm{Br}$ - for Magnetite @PAMAM/Rice Straw Ash) they also displayed oxidative degradation potential to xylenol-orange ( 85\%) and malachite-green ( $99 \%)$ respectively. Mineralization in the first instance was justified by the interactions of the dye with the chemical linkage of Magnetite NPs to amidic groups of PAMAM whereas in the second case by the anchorage of Magnetite NPs to the terminal amine groups [155]. 

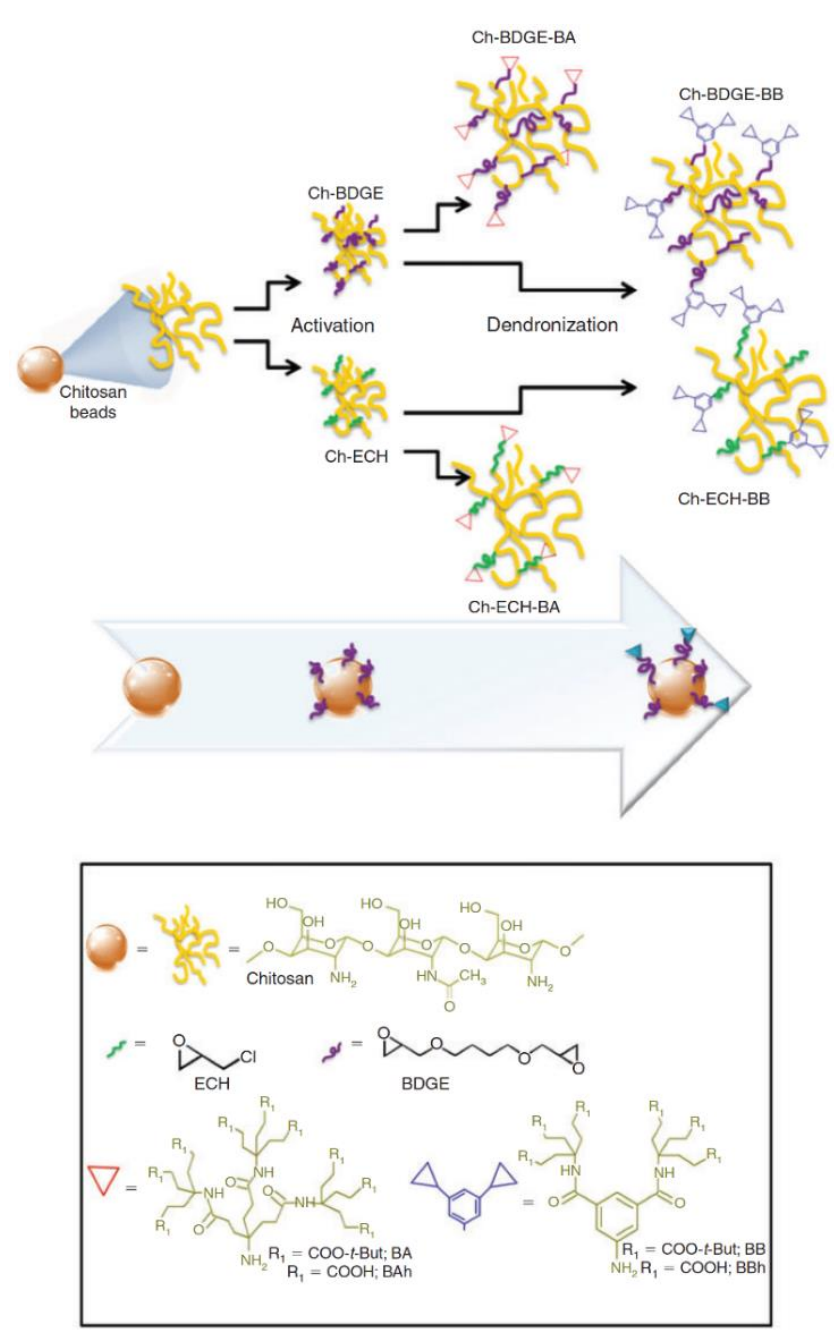

(a)

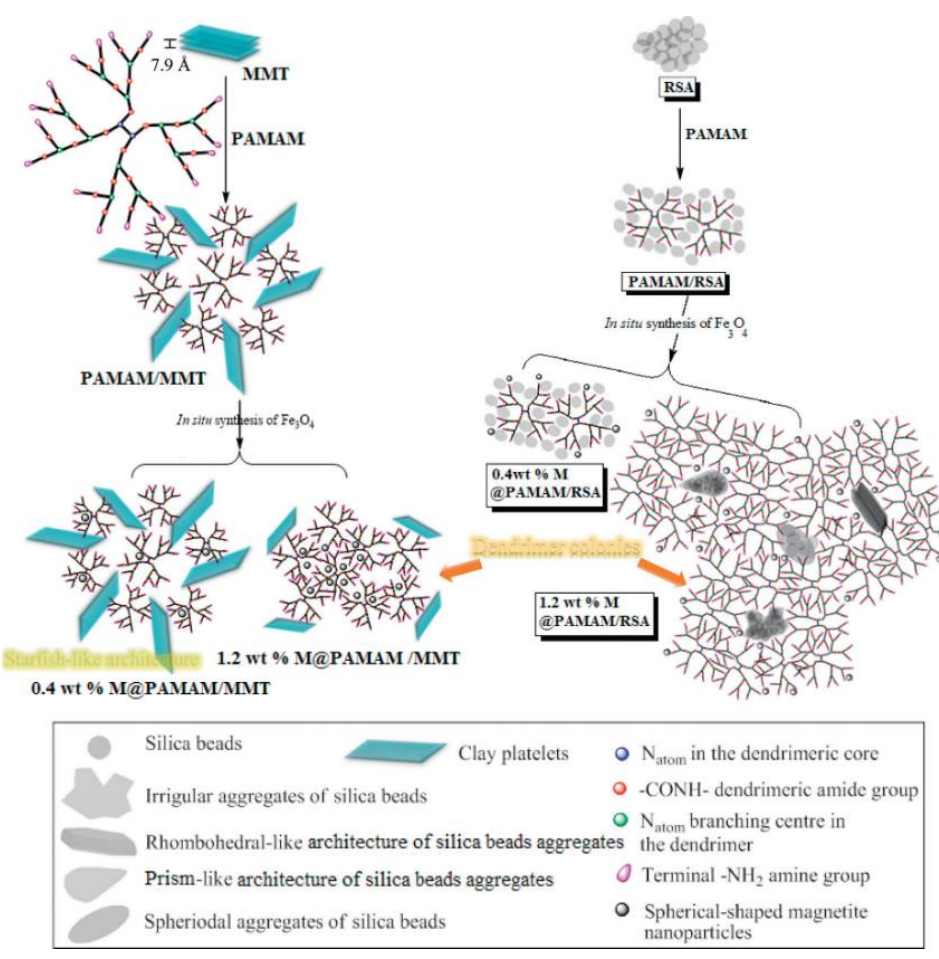

(b)

Figure 20. (a) Schematic representation of the synthetic routes used for the preparation of the dendronized chitosan microbeads reproduced with permission from [154]. (b) Synthetic path for the formation of Magnetite @PAMAM/Montmorillonite nanocomposites (left) and right Magnetite @PAMAM/Rice Straw Ash nanocomposites. Reproduced with permission from [155].

Templating properties of dendritic polymers for inorganic ceramic formations were exploited for the manufacturing of $\mathrm{SiO}_{2} @ \mathrm{TiO}_{2}$ core-shell nanospheres. Conventional hydrolysis-condensation of tetra ethoxy silane created the spherical core. Following calcination at $500^{\circ} \mathrm{C}$, hydrolysis of titanium isopropoxide created a homogenous titania coating. Apart from the photooxidation of NO the nanospheres carried out 4-nitrophenol reduction [156]. Replacing the external $\mathrm{TiO}_{2}$ overlay by a shell of $\mathrm{CeO}_{2}$ cubic nanocrystals with sizes ranging between 2 and $6 \mathrm{~nm}$ produced similar result [157]. A further occasion where templating by a dendritic polymer plays a substantial role to catalytic properties is the synthesis of $\mathrm{CuFe}_{2} \mathrm{O}_{4}$ nanoscale-confined precursor via coprecipitation of $\mathrm{Fe}^{+3}$ and $\mathrm{Mn}^{3+}$ nitrates with a hyperbranched polyamide. Restriction into the constrained dendritic cavities generates much smaller particles with higher specific surface area in comparison to the ordinary $\mathrm{CuFe}_{2} \mathrm{O}_{4}$. This effect is reflected to the of Fenton oxidation output of several dyes (Reactive Red 2, Reactive Yellow 3, Basic Red 46, and Basic Yellow 24) and is so profound that this technique proved superior to the calcination treatment [158]. Hyperbranched phenylene diamine methyl methacrylate HBPDMMA G2 exerts equivalent templating function to the coprecipitation of ferrous and manganese cations in $\mathrm{pH}=9$ directing the formation of layered double hydroxides (G2 /FeMn-LDH) (Figure 21a). Subsequent calcination yields ferromanganese oxide $\left(\mathrm{FeMnO}_{3}\right)$ suitable activator to peroxymonosulfate for methylene blue, tetracycline, and rhodamine b decomposition [159]. 
Closing this chapter, it is worth mentioning two commendable efforts for formation of complexes between dendritic polymers and enzymes for water purification purposes. The first concerns enveloping laccase enzyme from Trametes Versicolor with an amphiphilic dendritic linear dendritic ABA dendronized copolymer consisted from linear polyethylene glycol and poly (benzyl ether) dendrons. This treatment enhanced the biodegradation capabilities of the enzyme towards Bisphenol. The effect was more pronounced with G2, G3 dendron generations while stereochemical restrictions were observed with G4 [160]. Hyper-branched PAMAM was further combined with hyaluronidase (Figure 21b). The attachment was performed by adsorption in phosphate buffer solution. The resulting nanobiocatalyst proved ideal for the enzymatic degradation of hyaluronic acid exceeding the performance of the bare enzyme [161]. All these unorthodox examples are summarized in Table 6.

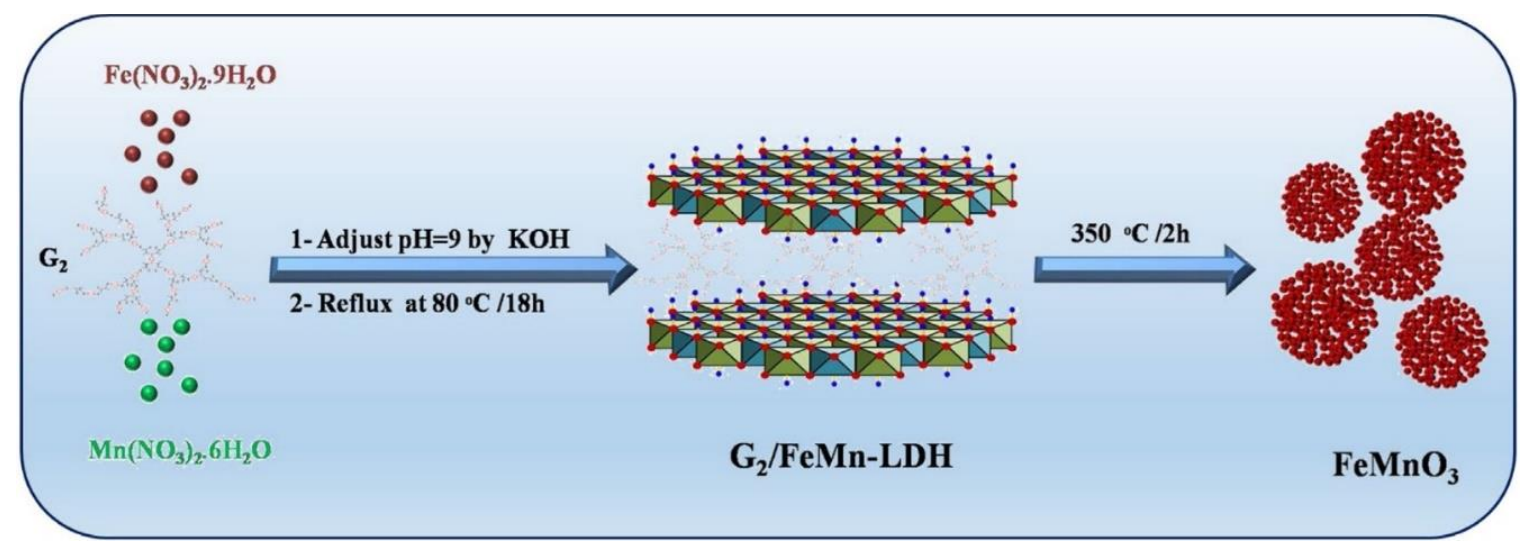

(a)

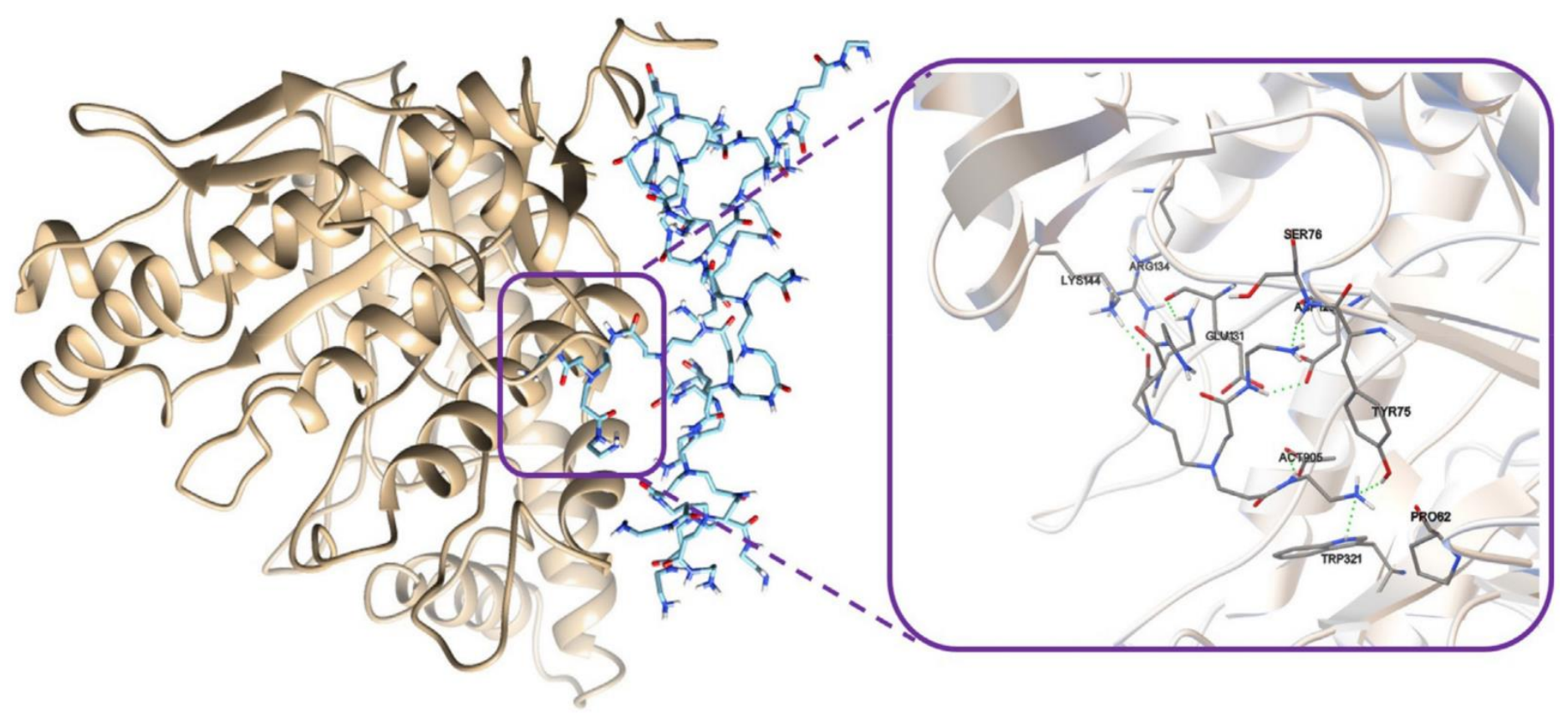

(b)

Figure 21. (a) Synthesis of $\mathrm{FeMnO}_{3}$ through calcination of its precursor G2 /FeMn-LDH. Reproduced with permission from [158]. (b) The 3D position of the minimum docking energy pose of PAMAM with Hyaluronidase enzyme, and representation of interactions (hydrogen bonds and electrostatic binding) of PAMAM (blue color, stick) in enzyme. Reproduced with permission from [161].

Table 6. Unconventional Dendritic Polymer formulations 


\begin{tabular}{|c|c|c|c|c|}
\hline $\begin{array}{l}\text { Hexa and nona-functionalized } \\
\text { amido dendrons }\end{array}$ & $\mathrm{Cu}^{2+}$ & Chitosan microbeads & Organic water and soil pollutants & [154] \\
\hline PEI & $\mathrm{Fe}^{3+}$ & Polyacrylonitrile fiber & Reactive Red 195 & [153] \\
\hline $\begin{array}{l}\text { Dendritic linear dendritic copoly- } \\
\text { mer Polybenzyl ether G2,G3,G4- } \\
\text { PEG5000-G2 }\end{array}$ & Laccase & - & Bisphenol A & [160] \\
\hline PAMAM G3 & $\mathrm{Fe}_{3} \mathrm{O}_{4}$ & $\begin{array}{l}\text { montmorillonite or rice- } \\
\text { straw-ash }\end{array}$ & malachite green, xylenol orange & [155] \\
\hline PEI & $\begin{array}{l}\text { SiO2@TiO2 core-shell nano- } \\
\text { spheres }\end{array}$ & - & 4-nitrophenol & [156] \\
\hline PEI & $\begin{array}{l}\mathrm{CeO} 2 @ \mathrm{SiO} 2 \text { core-shell nano- } \\
\text { spheres }\end{array}$ & - & 4-nitrophenol & [157] \\
\hline Hyperbranched polyamide & $\mathrm{CuFe}_{2} \mathrm{O}_{4}$ & - & $\begin{array}{l}\text { Reactive Red 2, Reactive Yellow } \\
\text { 3, Basic Red 46, Basic Yellow } 24\end{array}$ & [158] \\
\hline $\begin{array}{l}\text { Hyperbranched Phenylene Dia- } \\
\text { mine Methyl Methacrylate }\end{array}$ & $\mathrm{FeMnO}_{3}$ & - & $\begin{array}{r}\text { Methylene, Blue, Tetracycline, } \\
\text { Rhodamine b }\end{array}$ & [159] \\
\hline PAMAM G4 & Hyaluronidase & - & Hyaluronic acid & [161] \\
\hline
\end{tabular}

\section{Photocatalytic Decomposition}

\subsection{Photocatalysis on the Prominent $\mathrm{TiO}_{2}$ substrate}

Since the discovery that water splits photo-catalytically in contact with $\mathrm{TiO}_{2}$ electrodes by Fujishima and Honda in 1972 [162] titania is recognized as one of the most auspicious photocatalysts. As expected, research on the dendritic polymers' potential involvement to aqueous pollutants photocatalytic degradation was initially based on $\mathrm{TiO}_{2}$ and was conducted almost in parallel with conventional catalysis. NPs. PAMAM G4, PAMAM-OH G4, PAMAM-COONa G4,5 acted as templated agents for the development of $\mathrm{TiO}_{2}$ NPs confined into the dendrimer cavities. This was achieved by hydrolysis of $\mathrm{TiCl}_{4}$. Smaller sizes were observed $(4.4-6.7 \mathrm{~nm})$ in comparison to the method without dendrimer mediation $(7.5 \mathrm{~nm})$ and this was reflected to their better efficiency on the photodegradation of 2,4-dichlorophenoxyacetic acid [163]. Even smaller (1-5 nm) $\mathrm{TiO}_{2} \mathrm{NPs}$ were synthesized at $\sim 0 \circ \mathrm{C}$ by hydrolyzing $\left[\left(\mathrm{CH}_{3}\right)_{2} \mathrm{CHO}\right]_{4} \mathrm{Ti}$ in 1-propanol. PAMAM dendrons with a triethoxy silyl focal point and hexyl chains at their periphery (Figure 22a) successfully inhibited aggregation and reinforced photocatalytic decomposition of 2,4-dichlorophenoxyacetic as well. As confirmed by X-ray photoelectron spectroscopy this was realized by the formation of Si-O-Ti covalent bonds [164]. Aromatic polyamide dendrimer pairing with $\mathrm{TiO}_{2}$ NPs also yield an improved hybrid photocatalyst for phenol under visible light irradiation in comparison to bare titania. Functionalization by spiro lactam molecular switch further tendered $\mathrm{pH}$ responsive capability. At $\mathrm{pHs}$ below 3 spiro lactam transforms to the ring-opened amide (Figure 22b) form which absorbs more intensely and exhibits even better activity [165]. $\mathrm{TiO}_{2}$ nanowires (NWs) were shaped too by an hyperbranched polyester with hydroxyl terminal groups. The reaction took place in alkaline medium by hydrothermal treatment of $\mathrm{TiO}_{2}$. NPs Photocatalytic mineralization of wastewater proceeded much faster with these very active hybrids than the respective simple NWs [166].

As is the case with conventional catalysts magnetic photocatalysts may equally derive from dendritic polymers with $\mathrm{Fe}_{3} \mathrm{O}_{4}$ core. Instead of a templated core nano-sized titania terminals were linked to the periphery of PAMAM dendrons propagated by the divergent method. Alongside to the advantage of convenient magnetic separation, discoloration of methyl orange proceeded more promptly in comparison to bare nano $\mathrm{TiO}_{2}$ or Fe/Ti mixture. Dendrons cavities act as adsorbents that are "regenerated" by the catalytic decomposition of the pigment on the $\mathrm{TiO}_{2} \mathrm{NPs}$ [167]. Methyl orange mineralization effectiveness grows with increasing generation number due to the larger number of external nano- $\mathrm{TiO}_{2} \mathrm{NPs}$ and their smaller size. On the other hand, in multiple reaction cycles PAMAM G3 composites were losing their activity more rapidly [168]. Combination of $\mathrm{TiO}_{2}$ 
with CdS NPs (Figure 22c) produced an even better a photocatalyst than $\mathrm{TiO}_{2} \mathrm{NPs}_{\text {alone }}$ as established by calculated apparent quantum yields ( $3.6 \times 10^{-5}$ molecules photon $\left.^{-1}\right)$ and figures of merit (100) [169].

Besides the role of matrices there are simpler prospects for fruitful interaction between dendritic polymers and $\mathrm{TiO}_{2}$. Polycrystalline calcinated $\mathrm{TiO}_{2}$ was impregnated with a dendrimer with zinc phthalocyanine core bearing poly (aryl benzyl ether) branches. This process improved photolytic capacity for Rhodamine B to 97\% (compared to both titania about $65 \%$ after $5 \mathrm{~h}$ and zinc (II) phthalocyanine complex about $90 \%$ after $5 \mathrm{~h}$ [170]. In a second example PAMAM G4 was used to exfoliate nanoclay modified by an amphiphilic quaternary ammonium salt; nano $\mathrm{TiO}_{2}$ was added in order to introduce photocatalysis properties to the absorbent. Polyester fabrics were immersed to this dispersion and impregnated by the pad-dry-cure method (Figure 22d). The composite textiles successfully discolored Reactive Red 4 solutions without getting colored themselves [171]. A very simple, yet extremely interesting idea is doping titania by Pt and $\mathrm{N}$ atoms by a modified solgel method using PAMAM G0, G1 and PEI for platinum nucleation and as sources of nitrogen. After calcination the resultant ceramic photocatalyst was able to eliminate Brilliant Black (99.83\%) in 3 hours by irradiation with visible light. Higher activity enhancement and more profound reduction of the band gap was observed with PAMAM G1 matrix [172].
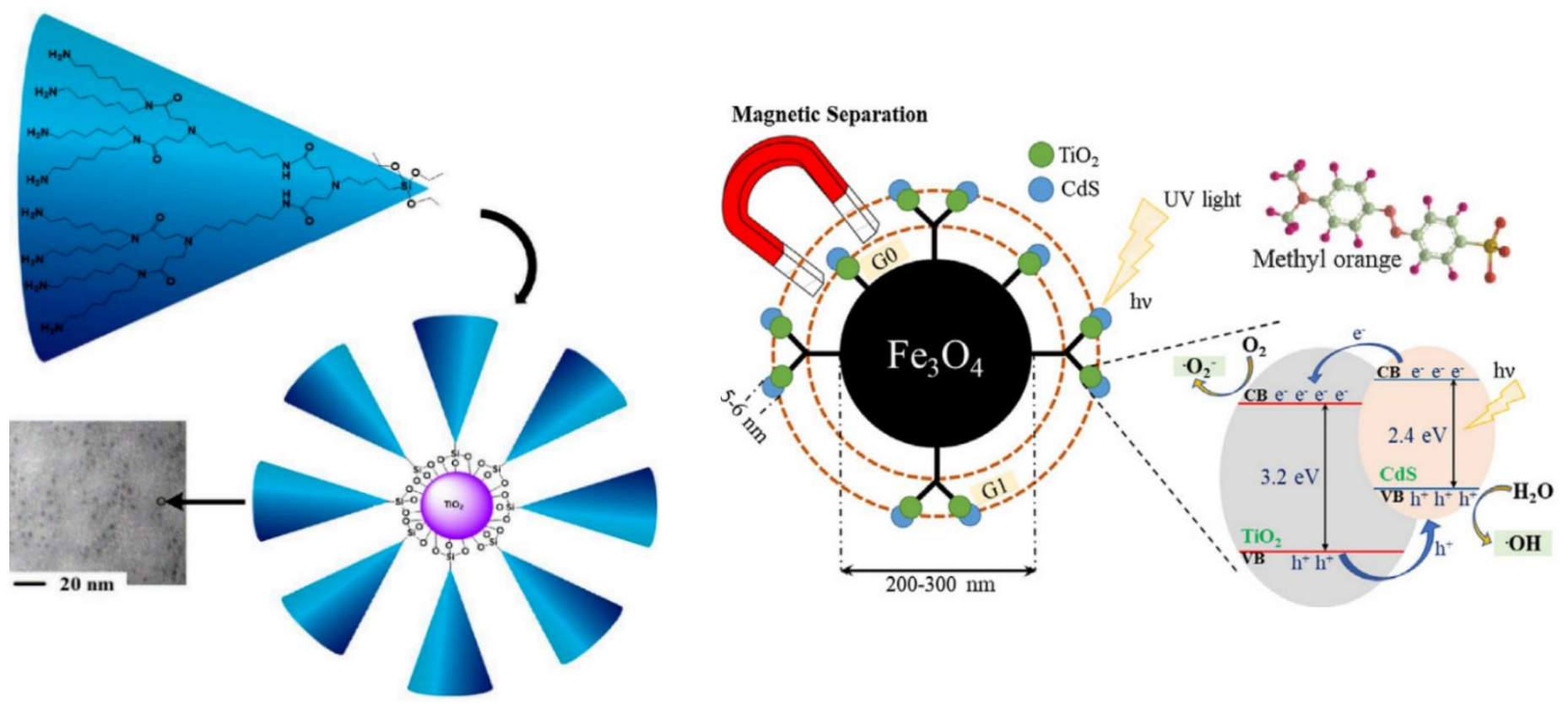

(a) 


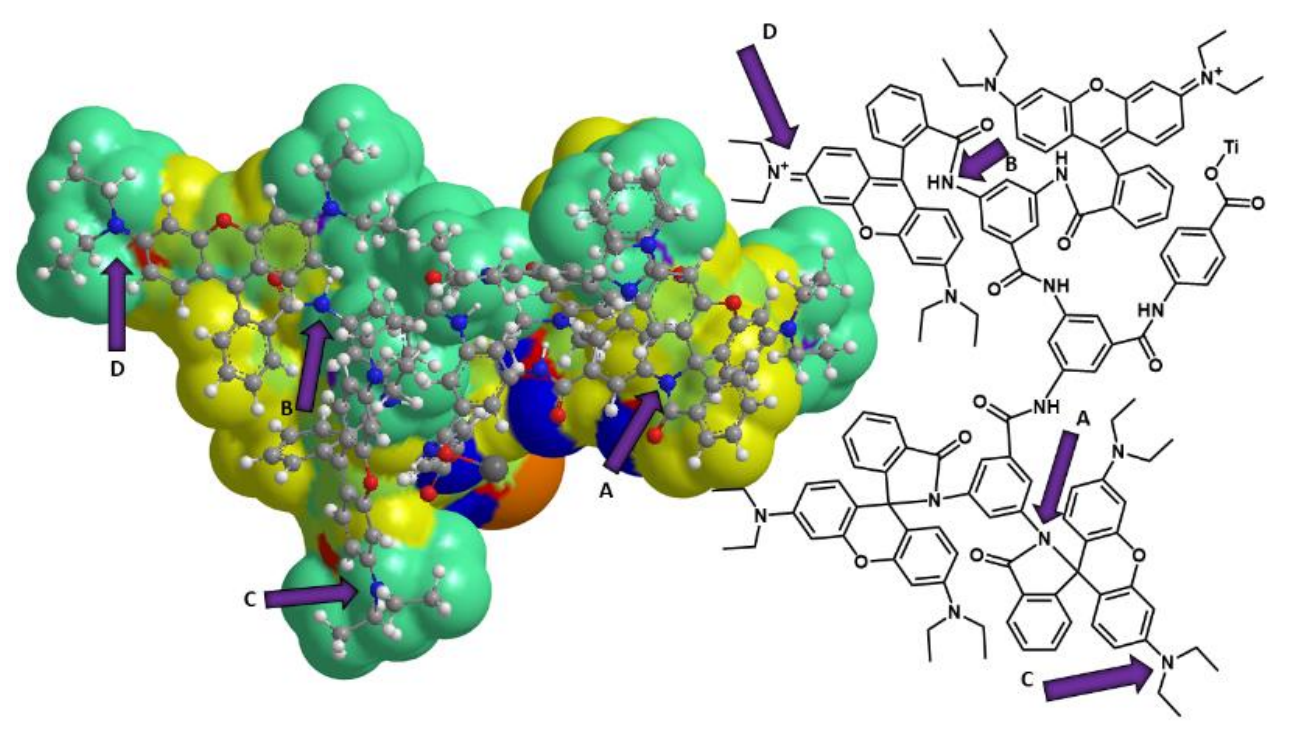

(b)

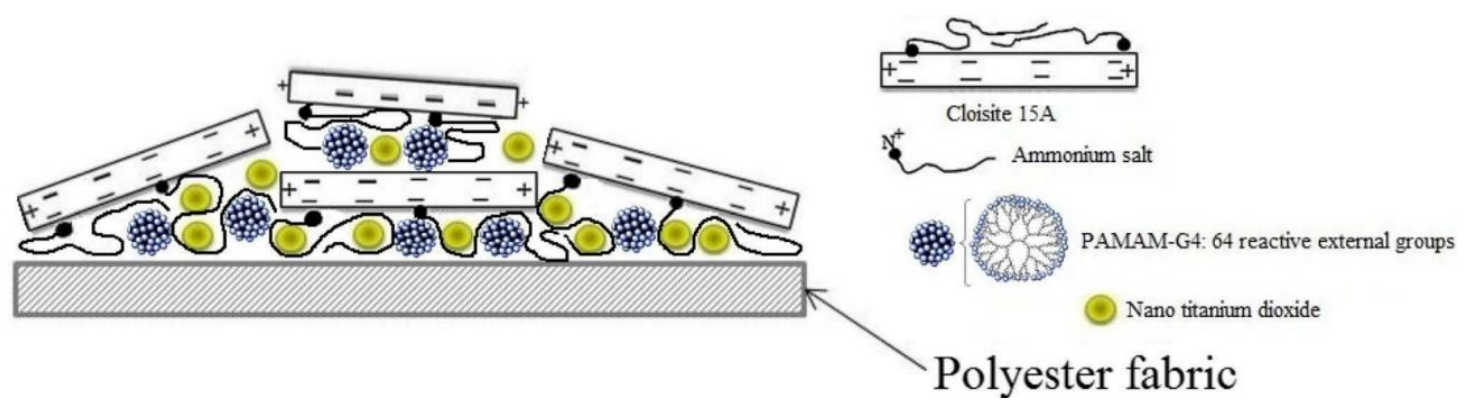

(d)

Figure 22. (a) Pathway for the clipping of the PAMAM dendron protective layer to titania photocatalytic nanoparticles and SEM micrograph of the complexes. Adapted with permission from [164]. (b) Chemical formula and partial charge molecular model (yellow to red positive, cyan to blue negative) of two dendritic branches depicting the two modes of the molecular switch: Spirolactam, ring-closed (A) amine external groups (C) (switch off) Amide, ring-opened (B) aminium external groups (D) (switch on) Adapted with permission from [165]. (c) Schematic representation of TiO2/CdS nanocomposite stabilized on a $\mathrm{Fe}_{3} \mathrm{O}_{4}$ core by PAMAM G0, G1 dendrons and the photolytic mechanism for Methyl Orange. Reproduced with permission from [169] (d) Schematic of polyester fabric coated with three components of nano clay, nano TiO2 and PAMAM dendrimers. Reproduced with permission from [171].

\subsection{Photocatalysis with Other Photoactive NPs}

MWCNT technology initially developed for 4-nitrophenol treatment was adapted for photocatalysis too. Nanosized $(3-5 \mathrm{~nm})$ spherical semiconductor CdS particles were fastened onto aryl modified MWCNTs by PAMAM-COOH dendrons (Figure23a). Under visible light irradiation MWCNTs accumulate photo induced electrons, transferred from CdS. Ensuing reaction with oxygen, generates $\mathrm{O}^{2 \cdot-}$ superoxide radicals that are transformed to very reactive $\mathrm{HO}^{-}$and $\mathrm{HOO}^{-}$. In synergy with the holes created in CdS they substantially exceed the performance of simple reference CdS NPs towards of Rhodamine $B$ degradation [173]. In the allotropic layered reduced grapheme oxide (RGO) hyperbranched polyamide-amine fulfilled the binary role of binder to dialdehyde cellulose fibers and of templating nanoreactor for the nucleation of semiconductor copper sulfide NPs (Figure 23b). The outcome was a composite paper able for efficient photolytic elimination of rhodamine B about 2.7 times faster than simple dialdehyde cellulose with CuS. This was associated with improved charge separation efficiency since RGO effectively suppresses the recombination of photogenerated carriers. The solid attachment of RGO and the uniformity of CuS were also credited for this higher activity that was retained up to $90 \%$ after 10 cycles [174]. The reverse concept is also feasible and practical. Electrospun nanofiber mats obtained from pullulan/poly (vinyl alcohol)/poly (acrylic acid) were impregnated into ceria suspensions. PAMAM G3 was attached to the immobilized $\mathrm{CeO}_{2} \mathrm{NPs}$ by the aid 
of glycidyl triethoxysilane (Figure 23c). This addition shifted the band gap of the semiconductor towards visible light for the photolysis of phenol, 4-Hydroxy-1-naphthalenesulfonic acid sodium salt and azorubine dye [175].

Self-Assembly of anionic polyoxometalate (POM) $\mathrm{K}_{4}\left[\mathrm{SiW}_{12} \mathrm{O}_{40}\right]$-PAMAM G4 agglomerates by electrostatic interactions in $100 \mathrm{~nm}$ coil-like structures (Figure 23d) produced a promising photocatalyst exhibiting electrostatic selectivity. Best results were obtained by cationic dyes Methyl Red and Methylene Blue in comparison to neutral Alizarin Yellow $\mathrm{R}$ and in contrast to anionic Xylenol Orange which is in fact protected from POM photolysis by the dendrimer [176]. Simple templating of $\mathrm{MoS}_{2}$ by reduction of sodium molybdate by thiourea in the presence of PAMAM G2 yielded monodispersed and well-distributed NPs that reduced more than 95\% the percentage of two commonly used pesticides, chlorpyrifos and glyphosate in water [177]. Hydrothermal preparation of bismuth vanadate into the cavities of hyperbranched PEI on top of affecting NPs size also changes the monoclinic lattice organization of $\mathrm{BiVO}_{4}$ to $72 \%$ tetragonal, $28 \%$ monoclinic, reduces the electron-hole recombination rate and the band gap. Preparation of modified polyethersulphone membranes incorporating these $\mathrm{PEI}-\mathrm{BiVO}_{4}$ complexes via the phase inversion method improved water flux and hydrophilicity and allowed the degradation of triclosan up to $86 \%$. [178].

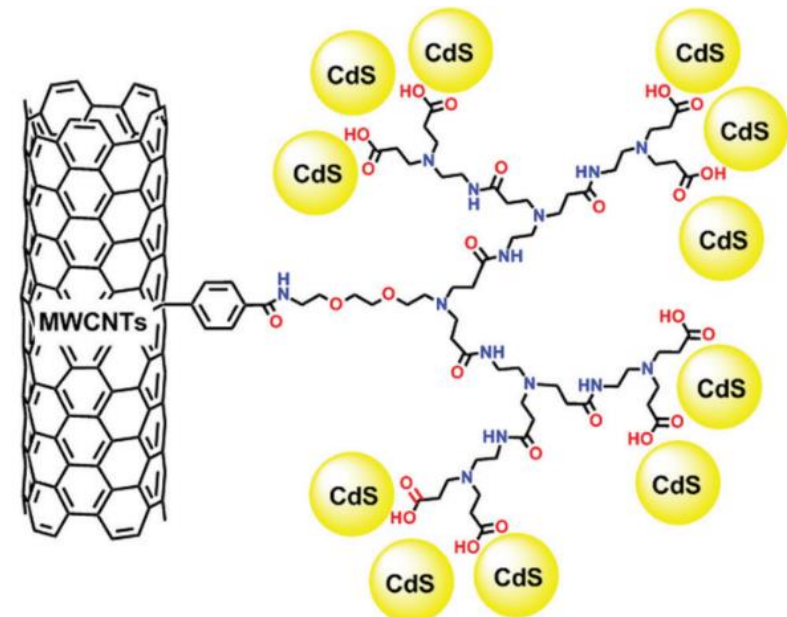

(a)

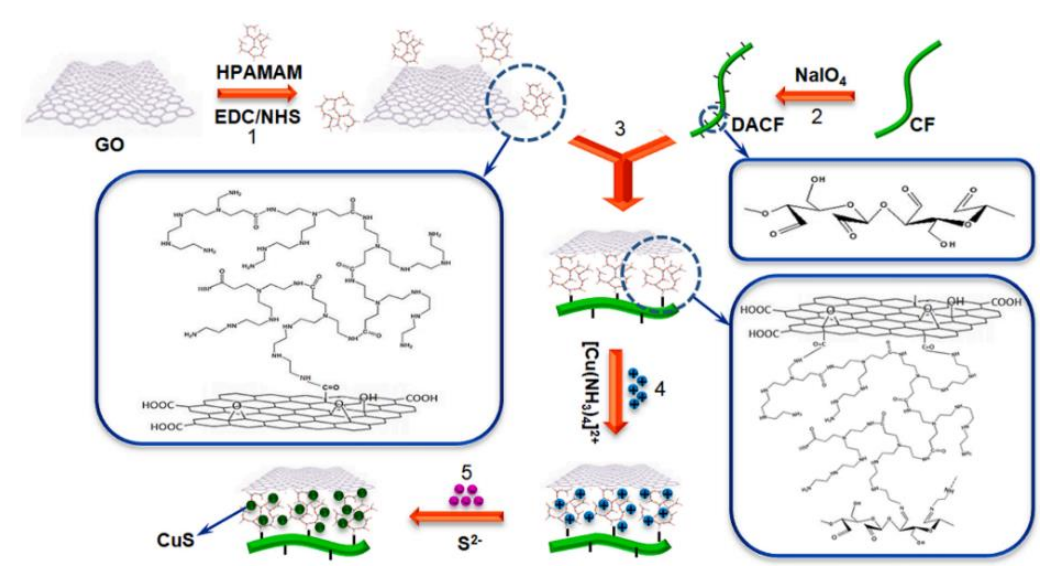

(b) 

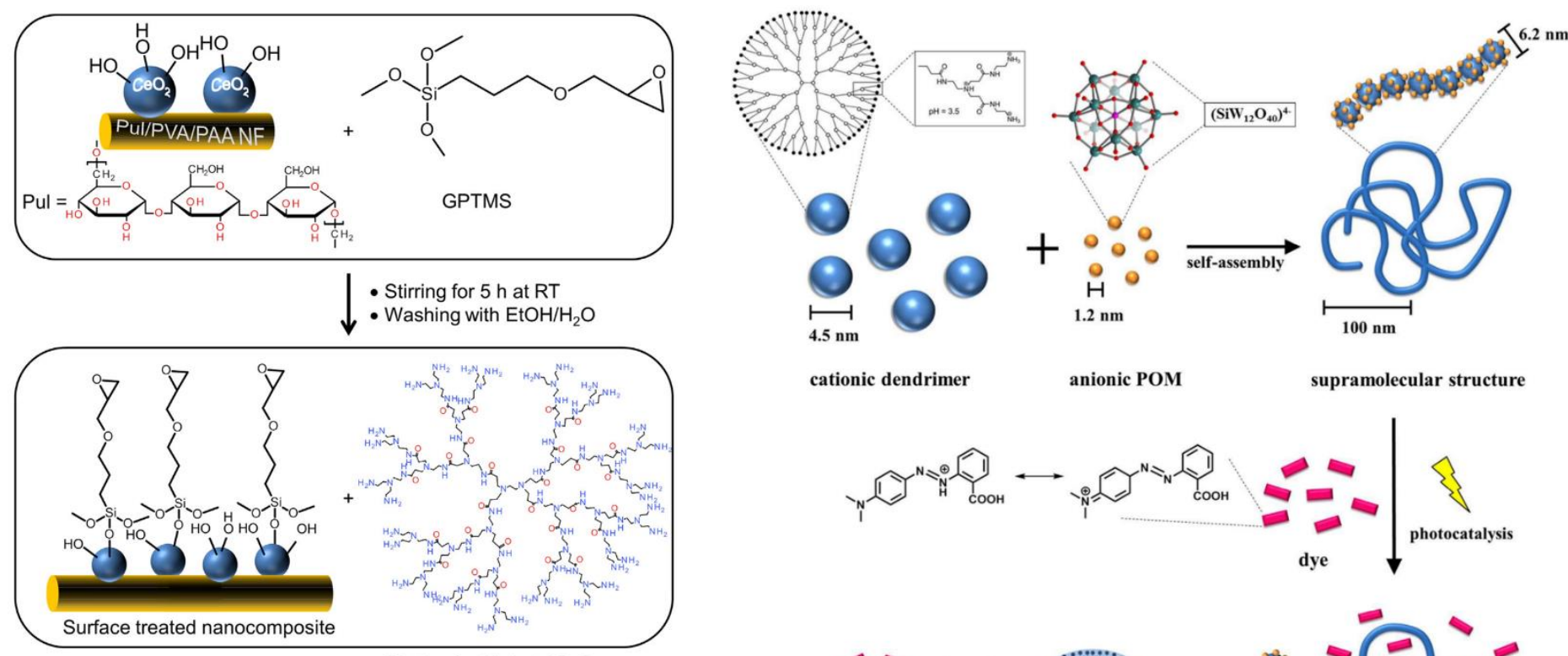

cationic dendrimer

anionic POM

supramolecular structure

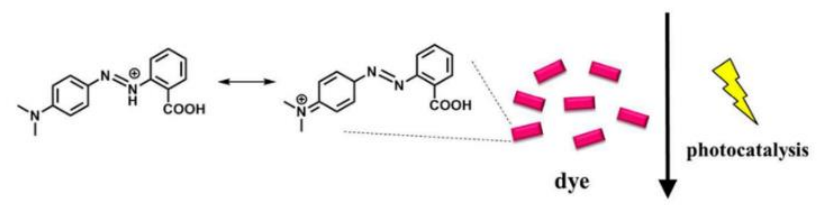

- Stirring for $24 \mathrm{~h}$ at $45^{\circ} \mathrm{C}$

- Washing with $\mathrm{EtOH} / \mathrm{H}_{2} \mathrm{O}$ and drying

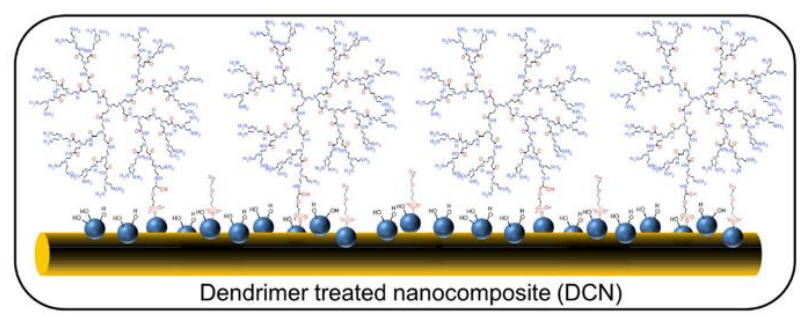

(c)

(d)

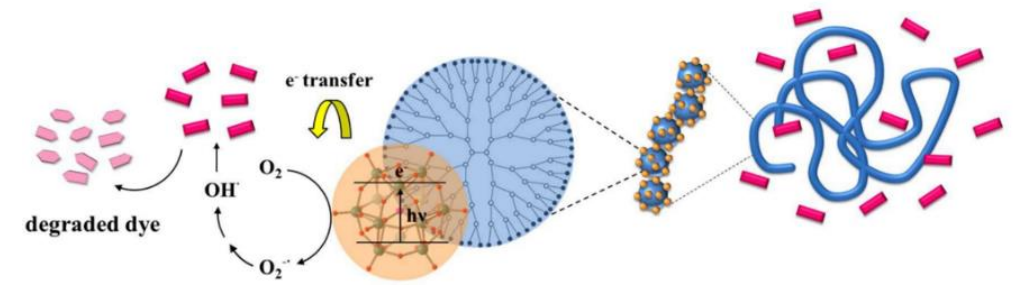

Figure 23. (a) Nanosized CdS immobilized onto PAMAM-aryl modified MWCNTs. Reproduced with permission from [173]. (b) Synthesis of dialdehyde cellulose fiber/hyperbranched polyamide-amine/reduced graphene oxide/copper sulfide (DACF/HPAMAM/rGO/CuS) hybrid. Reproduced with permission from [174]. (c) Surface modification of ceria impregnated nanofiber mats with PAMAM using GPTMS. Reproduced with permission from [175]. (d) Schematic representation of POM-dendrimer self-assembly and photocatalysis of methyl red. Reproduced with permission from [176].

Adsorption of PAMAM-COOH G2.5 by ZnO/CuS low-dimensional heterostructured functional materials afforded a hybrid displaying potent photo response properties that were further enhanced by doping with GO and verified by processing rhodamine B and methylene blue [179]. The same ex-situ mixing technique was adopted for the surface modification of $\mathrm{ZnO}$ nanorods by hyperbranched polyester and was accompanied by a second in-situ method where the polycondensation reaction for the synthesis of the polymer took place in the presence of $\mathrm{ZnO}$. Both methods increased photocatalytic degradation of phenolic organic pollutants (N-(1-naphthyl)-ethylene diamine dichloride, catechol, and sulfanilamide) and antibacterial activity against gram-positive Bacillus cereus, and gram-negative Escherichia coli. The conventional adsorption method, exhibited the best results [180].

On the other hand, chemical binding of dendritic polymers to $\mathrm{ZnO}$ is accomplished in the same way as $\mathrm{SiO}_{2}$ and $\mathrm{Fe}_{3} \mathrm{O}_{4}$ oxides. Glycidoxy propyl trimethoxy silane conjoined PAMAM G4 to Wurtzite nanorods and rendered them more efficient to azo dye naphthol blue black disintegration under UV light than bare $\mathrm{ZnO}$ nano rods [181]. In another rather more sophisticated way starch modified hyperbranched polyol was copolymerized by an in-situ polymerization process with a prepolymer composed from polycaprolactone diol, 2,4/2,6-toluene diisocyanate and 1,4 butandiol to give the respective polyurethane (Figure 24a). This resulting dendrigraft was further crosslinked by varying amounts of zinc oxide merged with reduced carbon dots (RCD). The optical band gap of the final composites $(2.12 \mathrm{eV})$ was significantly lower to $\mathrm{RCD}(3.18 \mathrm{eV})$ and $\mathrm{ZnO}(3.3 \mathrm{eV})$ and this decrease was 
mirrored to their photocatalytic potential towards aqueous surfactant contaminants, dodecyl benzenesulfonate $(96.7 \%$ in $110 \mathrm{~min})$ and commercial detergent $(94.8 \%$ in $150 \mathrm{~min})$ [182]. The selection for the presentation of the last example of this review is in our opinion the most impressive one. It is about a dendritic polymer hyperbranched polyimide with inherent photocatalytic properties that are magnified by the oxidative introduction of $\mathrm{N}$ $\mathrm{O}$ bonds to the triazine core (Figure 24b). The transformation to polyimide N-oxide changes dramatically the electronic structure of the conjugated polymer. The localization of the highest occupied molecular orbital is shifted from the melamine groups to the N-O bonds (Figure 24c) which are also the main adsorption sites. This synergistic adsorptionphotocatalytic decomposition mechanism proved very drastic towards the elimination of Methyl Orange [183]. All photocatalysts comprising dendritic polymers that were employed for aqueous pollutant elimination are summarized in Table 7.

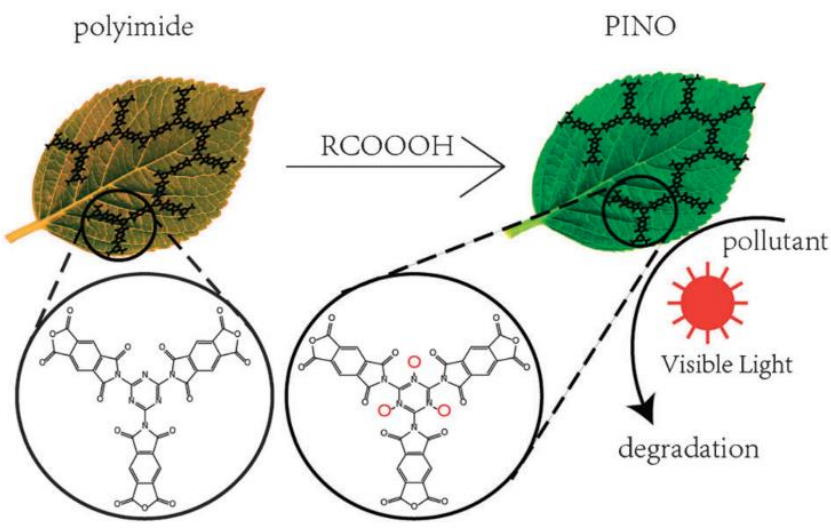

(b) 
Polycaprolactone diol
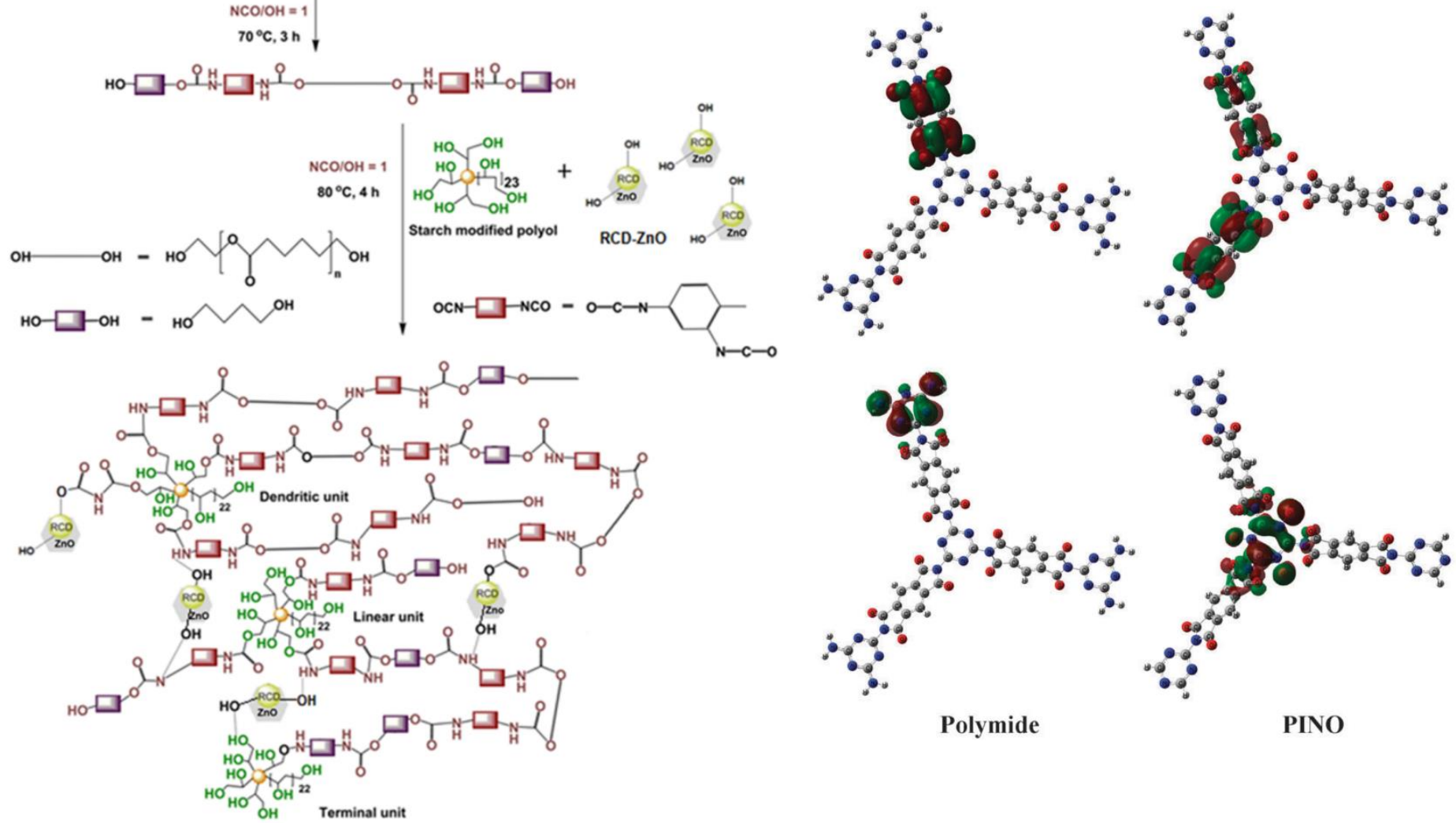

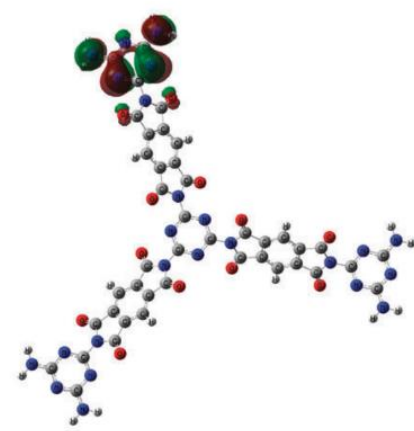

Polymide

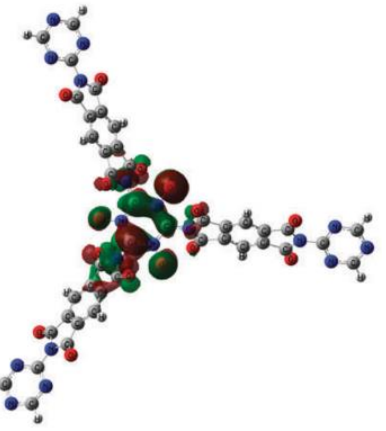

PINO

(a)

(c)

Figure 24. (a) Synthetic route for the polyurethane/polyol/reduced carbon dot/ZnO crosslinked dendrigraft composite. Reproduced with permission from [182]. (b) N-site oxidation reaction of the hyperbranched polyimide (c) LUMO (above) and HOMO (below) of polyimide and polyimide N-oxide. Both reproduced with permission from [183].

Table 7. Dendritic polymer photocatalyst formulations for aqueous pollutant disintegration.

\begin{tabular}{|c|c|c|c|}
\hline Dendritic Polymer & Photocatalyst/Substrate & Pollutants & Reference \\
\hline $\begin{array}{l}\text { PAMAM-NH } 2 \text { G4 PAMAM-OH G4 PA- } \\
\text { MAM-COONa G4 }\end{array}$ & $\mathrm{TiO}_{2}$ & 2,4-dichlorophenoxyacetic acid & [163] \\
\hline Alkylated PAMAM G1, G2, G3 Dendrons & $\mathrm{TiO}_{2} @ \mathrm{SiO}_{2}$ core-shell & 2,4-dichlorophenoxyacetic acid & [164] \\
\hline Hyperbranched polyimide N-oxide (PINO) & - & Methyl Orange & [183] \\
\hline $\begin{array}{l}\text { Aromatic Polyamide Dendrimer Functional- } \\
\text { ized with Spirolactam }\end{array}$ & $\mathrm{TiO}_{2}$ & Phenol & [165] \\
\hline
\end{tabular}




\begin{tabular}{|c|c|c|c|}
\hline Hyperbranched polyester HPES-OH & $\mathrm{T}_{1} \mathrm{O}_{2}$ nanowires & Wastewater & [166] \\
\hline PAMAM dendrons & $\mathrm{Fe}_{3} \mathrm{O}_{4}, \mathrm{TiO}_{2}$ & Methyl Orange & [167] \\
\hline $\begin{array}{l}\text { Poly (aryl benzyl ether) Zn phthalocyanine } \\
\text { Dendrimer }\end{array}$ & Polycrystalline $\mathrm{TiO}_{2}$ & Rhodamine B & [170] \\
\hline PAMAM Dendron & $\mathrm{CdS}$ & Rhodamine B & [173] \\
\hline PAMAM G4 & $\mathrm{ZnO}$ & naphthol blue black & [181] \\
\hline PAMAM G4 & $\begin{array}{c}\mathrm{TiO}_{2} / \text { Nanoclay Polyester } \\
\text { Fabric }\end{array}$ & Reactive Red 4 & [171] \\
\hline PAMAM dendrons & $\mathrm{Fe}_{3} \mathrm{O}_{4}, \mathrm{TiO}_{2}$ & Methyl Orange & [168] \\
\hline PAMAM G2.5 & $\begin{array}{l}\mathrm{ZnO} / \mathrm{CuS} \text { low-dimensional } \\
\text { heterostructured composites }\end{array}$ & Rhodamine B, Methylene blue & [179] \\
\hline PAMAM G4 & K4 [SiW12O40] (POM) & $\begin{array}{r}\text { Methyl Red, Methylene Blue, } \\
\text { Alizarin Yellow R, Xylenol Or- } \\
\text { ange }\end{array}$ & [176] \\
\hline PAMAM G0, G1, PEI & $\mathrm{Pt} \mathrm{TiO}_{2}$ & Brilliant black & [172] \\
\hline PAMAM G0, G1 Dendrons & $\mathrm{TiO}_{2}, \mathrm{CdS}, \mathrm{Fe}_{3} \mathrm{O}_{4}$ & Methyl Orange & [169] \\
\hline Hyperbranched Polyester & $\mathrm{ZnO}$ & $\begin{array}{l}\text { (N-(1-naphthyl)-ethylene dia- } \\
\text { mine dichloride, catechol, sul- } \\
\text { fanilamide }\end{array}$ & [180] \\
\hline Hyperbranched polyurethane & Reduced Carbon Dot-ZnO2 & $\begin{array}{r}\text { Dodecyl-benzenesulfonate, } \\
\text { Commercial Detergent }\end{array}$ & [182] \\
\hline PAMAM G3 & $\begin{array}{c}\mathrm{CeO}_{2} \text { pullulan/poly(vinyl al- } \\
\text { cohol)/poly(acrylic acid) nan- } \\
\text { ofibers }\end{array}$ & $\begin{array}{r}\text { Phenol, 4-Hydroxy-1-naphtha- } \\
\text { lenesulfonic acid sodium salt } \\
\text { and azorubine dye }\end{array}$ & [175] \\
\hline PEI & $\mathrm{BiVO} 4$ & $\begin{array}{l}\text { Triclosan (5-chloro-2-(2,4-di- } \\
\text { chlorophenoxy) phenol) }\end{array}$ & [178] \\
\hline Hyperbranched PAMAM & $\begin{array}{l}\text { CuS Reduced GO, Dialde- } \\
\text { hyde cellulose fiber }\end{array}$ & Rhodamine B & [174] \\
\hline PAMAM & $\mathrm{MoS}_{2}$ & Chlorpyrifos, Glyphosate & [177] \\
\hline
\end{tabular}

\section{Conclusions}

It is evident than in spite of the multitude of efforts and examples presented herein, the research field of pollutant disintegration by involvement of dendritic polymers is still in its early adolescence compared to the maturity of the adsorption alternatives since the majority of the systems proposed have only been tested to simple catalytic reactions. In addition, continuous mode treatment through columns is implemented in just one case; scaling up and application of the purification layouts in actual wastewater management in static batch reactors or fixed beds so far has not been tried so far. Yet pairing dendritic molecules with catalytic and photocatalytic ingredients proved very beneficial as it enhanced their activity, stability and overall properties. They offer a substantial advantage since smaller quantities can address far heavier water pollution incidents due to easier regeneration in contrast to the adsorbents. They may also act synergistically with adsorbents inhibit their poisoning and prolong their use. Collation with other NPs templating agents reveals both their metal nucleation and pollutant decomposition potential. As general rules of thumb, the size of the NPs can be manipulated by specific functional groups in the internal dendritic cavities and the host-guest stoichiometry. Particle size and specific surface area play more important roles than crystallinity. Smaller is better leading to increased activity and faster reaction rates. Bulky dendritic layers repeatedly caused reactant diffusion delays.

Future perspectives in the field of basic research could be based on the following axes a) Thorough research of the formation mechanisms and catalytic properties of metal NPs. Some metals such as Ni, Rh, Co, Ir, with established catalytic potential have not received deserved interest. b) Expansion of the investigation of more semiconductors that 
are capable of photolyzing water contaminants c) Application of bimetallic or polymetallic nanoparticles and dual dendritic polymer functionalities d) Implementation of multifunctional composites capable of simultaneous adsorption, catalytic degradation and disinfection. e) Expansion of the test to other classes of pollutants. Pesticides, surfactants and antibiotics for instance have not attracted enough research.

Author Contributions: For research articles with several authors, a short paragraph specifying their individual contributions must be provided. The following statements should be used "Conceptualization, M.A.; methodology, M.A.; investigation, A.F., E.N., R.P. and T.K.; resources, A.F., E.N., R.P. and T.K.; writing-original draft preparation, M.A. M.D; writing - review and editing, I.A., M.A., M.D., D.G, I.P., M.V.; visualization, M.A.; supervision, I.A., M.A., D.G, I.P., M.V.; project administration, M.V.; All authors have read and agreed to the published version of the manuscript."

Funding: This research received no external funding

Conflicts of Interest: The authors declare no conflict of interest.

\section{References}

1. Y. Fan, W. Sun, and X. Shi, "Design and Biomedical Applications of Poly(amidoamine)-Dendrimer-Based Hybrid Nanoarchitectures," Small Methods, vol. 1, no. 12, p. 1700224, 2017.

2. A. A. Yetisgin, S. Cetinel, M. Zuvin, A. Kosar, and O. Kutlu, "Therapeutic Nanoparticles and Their Targeted Delivery Applications," Molecules, vol. 25, no. 9, p. 2193, May 2020.

3. Petrakli, F., Arkas, M., \& Tsetsekou, A. (2018). $\alpha$-Alumina nanospheres from nano-dispersed boehmite synthesized by a wet chemical route. Journal of the American Ceramic Society, 101(8), 3508-3519. https://doi.org/10.1111/jace.15487.

4. N. T. T. Le, T. N. Q. Nguyen, V. Du Cao, D. T. Hoang, V. C. Ngo, and T. T. H. Thi, "Recent progress and advances of multistimuli-responsive dendrimers in drug delivery for cancer treatment," Pharmaceutics, vol. 11, no. 11, 2019.

5. M. Rani, N. K. Sharma, and V. Sajal, “Localized surface plasmon resonance based fiber optic sensor with nanoparticles," Opt. Commun., vol. 292, pp. 92-100, 2013.

6. A. K. Ilunga and R. Meijboom, "A Review of Dendrimer-Encapsulated Metal Nanocatalysts Applied in the Fine Chemical Transformations," Catal. Letters, vol. 149, no. 1, pp. 84-99, 2019.

7. M. Zubair, M. Daud, G. McKay, F. Shehzad, and M. A. Al-Harthi, "Recent progress in layered double hydroxides (LDH)-containing hybrids as adsorbents for water remediation," Appl. Clay Sci., vol. 143, no. April, pp. 279-292, 2017.

8. M. P. Shah, "Bioremediation-Waste Water Treatment," J. Bioremediation Biodegrad., vol. 09, no. 01, pp. 1-10, 2018.

9. K. Golka, S. Kopps, and Z. W. Myslak, "Carcinogenicity of azo colorants: Influence of solubility and bioavailability," Toxicol. Lett., vol. 151, no. 1, pp. 203-210, 2004.

10. F. Akarslan and H. Demiralay, "Effects of textile materials harmful to human health," Acta Phys. Pol. A, vol. 128, no. 2, pp. 407408, 2015.

11. B. J. Brüschweiler and C. Merlot, "Azo dyes in clothing textiles can be cleaved into a series of mutagenic aromatic amines which are not regulated yet," Regul. Toxicol. Pharmacol., vol. 88, pp. 214-226, 2017.

12. S. Said, S. Mikhail, and M. Riad, "Recent progress in preparations and applications of meso-porous alumina," Mater. Sci. Energy Technol., vol. 2, no. 2, pp. 288-297, 2019.

13. S. Vadivel, A. N. Naveen, J. Theerthagiri, J. Madhavan, T. Santhoshini Priya, and N. Balasubramanian, "Solvothermal synthesis of BiPO4 nanorods/MWCNT (1D-1D) composite for photocatalyst and supercapacitor applications," Ceram. Int., vol. 42, no. 12, pp. 14196-14205, 2016.

14. M. Arkas, K. Panagiotaki, I. Kitsou, and F. Petrakli, Dendritic Polymer-Enhanced Ultrafiltration. Elsevier Inc., 2018.

15. A. F. Strickland and W. S. Perkins, "Decolorization of continuous dyeing wastewater by ozonation," Text. Chem. Color., vol. 27, no. 5, pp. 11-15, 1995.

16. M. Kornaros and G. Lyberatos, "Biological treatment of wastewaters from a dye manufacturing company using a trickling filter," J. Hazard. Mater., vol. 136, no. 1 SPEC. ISS., pp. 95-102, 2006.

17. J. L. Gong et al., "Removal of cationic dyes from aqueous solution using magnetic multi-wall carbon nanotube nanocomposite as adsorbent," J. Hazard. Mater., vol. 164, no. 2-3, pp. 1517-1522, 2009.

18. S. Khan, Q. Cao, Y. M. Zheng, Y. Z. Huang, and Y. G. Zhu, “Health risks of heavy metals in contaminated soils and food crops irrigated with wastewater in Beijing, China," Environ. Pollut., vol. 152, no. 3, pp. 686-692, 2008.

19. D. C. Tully and J. M. J. Fréchet, "Dendrimers at surfaces and interfaces: chemistry and applications," Chem. Commun., no. 14, pp. 1229-1239, 2001.

20. M. Jikei and M. Kakimoto, “Hyperbranched polymers: a promising new class of materials," Prog. Polym. Sci., vol. 26, no. 8, pp. 1233-1285, Oct. 2001.

21. Y. H. Kim, "Hyperbranched polymers 10 years after," J. Polym. Sci. Part A Polym. Chem., vol. 36, no. 11, pp. 1685-1698, Aug. 1998. 
22. A. Sunder, J. Heinemann, and H. Frey, "Controlling the Growth of Polymer Trees: Concepts and Perspectives For Hyperbranched Polymers," Chem. - A Eur. J., vol. 6, no. 14, pp. 2499-2506, Jul. 2000.

23. D. A. Tomalia and J. M. J. Fréchet, “Discovery of dendrimers and dendritic polymers: A brief historical perspective," J. Polym. Sci. Part A Polym. Chem., vol. 40, no. 16, pp. 2719-2728, 2002.

24. D. A. T. Jean M. J. Fréchet, Dendrimers and Other Dendritic Polymers. Chichester, UK: John Wiley \& Sons, Ltd, 2001.

25. S. M. Grayson and J. M. J. Fréchet, “Convergent Dendrons and Dendrimers: from Synthesis to Applications," Chem. Rev., vol. 101, no. 12, pp. 3819-3868, Dec. 2001.

26. D. Astruc, E. Boisselier, and C. Ornelas, “Dendrimers Designed for Functions: From Physical, Photophysical, and Supramolecular Properties to Applications in Sensing, Catalysis, Molecular Electronics, Photonics, and Nanomedicine," Chem. Rev., vol. 110, no. 4, pp. 1857-1959, Apr. 2010.

27. A. D. Schlüter and J. P. Rabe, "Dendronized Polymers: Synthesis, Characterization, Assembly at Interfaces, and Manipulation," Angew. Chemie Int. Ed., vol. 39, no. 5, pp. 864-883, Mar. 2000.

28. C. R. Yates and W. Hayes, "Synthesis and applications of hyperbranched polymers," Eur. Polym. J., vol. 40, no. 7, pp. 12571281, Jul. 2004.

29. M. Arkas, D. Tsiourvas, and C. M. Paleos, “Functional dendrimeric 'Nanosponges' for the removal of polycyclic aromatic hydrocarbons from water," Chem. Mater., vol. 15, no. 14, pp. 2844-2847, 2003.

30. S. Aliannejadi, A. H. Hassani, H. A. Panahi, and S. M. Borghei, "Preparation and characterization of a recyclable highbranched/generation dendrimer nano-polymer based on the enhanced magnetic core for naphthalene sorption from aqueous solutions," Desalin. Water Treat., vol. 202, pp. 364-380, 2020.

31. G. R. Newkome and C. D. Shreiner, "Poly(amidoamine), polypropylenimine, and related dendrimers and dendrons possessing different $1 \rightarrow 2$ branching motifs: An overview of the divergent procedures," Polymer (Guildf)., vol. 49, no. 1, pp. 1-173, Jan. 2008.

32. G. R. Newkome, C. N. Moorefield, G. R. Baker, A. L. Johnson, and R. K. Behera, “Alkane Cascade Polymers Possessing Micellar Topology: Micellanoic Acid Derivatives,” Angew. Chemie Int. Ed. English, vol. 30, no. 9, pp. 1176-1178, Sep. 1991.

33. Y. H. Kim, O. W. Webster, T. D. Getman, and C. B. Knobler, “Water-Soluble Hyperbranched Polyphenylene: 'A Unimolecular Micelle'?," no. d, pp. 4592-4593, 1990.

34. G. R. Newkome, C. N. Moorefield, G. R. Baker, M. J. Saunders, and S. H. Grossman, "Unimolecular Micelles," Angew. Chemie Int. Ed. English, vol. 30, no. 9, pp. 1178-1180, Sep. 1991.

35. C. J. Hawker, K. L. Wooley, and J. M. J. Fréchet, “Unimolecular micelles and globular amphiphiles: dendritic macromolecules as novel recyclable solubilization agents," J. Chem. Soc., Perkin Trans. 1, no. 12, pp. 1287-1297, 1993.

36. Arkas, M., Kitsou, I., Gkouma, A., \& Papageorgiou, M. (2019). The role of hydrogen bonds in the mesomorphic behaviour of supramolecular assemblies organized in dendritic architectures. Liquid Crystals Reviews, 7(1), 60-105. 9;

37. Sowinska, M., \& Urbanczyk-Lipkowska, Z. (2014). Advances in the chemistry of dendrimers. New Journal of Chemistry, 38(6), 2168-2203. DOI: 10.1039/C3NJ01239E.

38. R. M. Crooks, M. Zhao, L. Sun, V. Chechik, and L. K. Yeung, “Dendrimer-encapsulated metal nanoparticles: Synthesis, characterization, and applications to catalysis," Acc. Chem. Res., vol. 34, no. 3, pp. 181-190, 2001.

39. S. Svenson and D. A. Tomalia, "Dendrimers in biomedical applications - reflections on the field," Adv. Drug Deliv. Rev., vol. 64, pp. 102-115, Dec. 2012.

40. B. D.-N. Olivier Turrin, Regis Laurent, Armelle Ouali, “Dendrimers: Towards Catalytic, Material and Biomedical Uses," John Wiley \& Sons, Ltd, 2011, p. 456.

41. X. Xu et al., "Multifunctional drug carriers comprised of mesoporous silica nanoparticles and polyamidoamine dendrimers based on layer-by-layer assembly," Mater. Des., vol. 88, pp. 1127-1133, 2015.

42. Y.-X. Ma, D. Xing, W.-J. Shao, X.-Y. Du, and P.-Q. La, “Preparation of polyamidoamine dendrimers functionalized magnetic graphene oxide for the adsorption of $\mathrm{Hg}(\mathrm{II})$ in aqueous solution," J. Colloid Interface Sci., vol. 505, pp. 352-363, Nov. 2017.

43. M. Jaymand, M. Lotfi, and R. Lotfi, "Functional dendritic compounds: potential prospective candidates for dental restorative materials and in situ re-mineralization of human tooth enamel," RSC Adv., vol. 6, no. 49, pp. 43127-43146, 2016.

44. D. Tsiourvas, A. Tsetsekou, M. I. Kammenou, and N. Boukos, "Controlling the formation of hydroxyapatite nanorods with dendrimers," J. Am. Ceram. Soc., vol. 94, no. 7, pp. 2023-2029, 2011.

45. M. Sheikhpour, L. Barani, and A. Kasaeian, "Biomimetics in drug delivery systems: A critical review," J. Control. Release, vol. 253, pp. 97-109, 2017.

46. V. Leiro et al., Design and preparation of biomimetic and bioinspired materials. Elsevier Ltd., 2017.

47. E. J. Acosta, S. O. Gonzalez, and E. E. Simanek, "Synthesis, characterization, and application of melamine-based dendrimers supported on silica gel," J. Polym. Sci. Part A Polym. Chem., vol. 43, no. 1, pp. 168-177, 2005.

48. M. Douloudi, E. Nikoli, T. Katsika, M. Vardavoulias, and M. Arkas, “Dendritic Polymers as Promising Additives for the Manufacturing of Hybrid Organoceramic Nanocomposites with Ameliorated Properties Suitable for an Extensive Diversity of Applications," Nanomaterials, vol. 11, no. 1, p. 19, Dec. 2020.

49. T. H. Mourey, S. R. Turner, M. Rubinstein, J. M. J. Fréchet, C. J. Hawker, and K. L. Wooley, "Unique Behavior of Dendritic Macromolecules: Intrinsic Viscosity of Polyether Dendrimers," Macromolecules, vol. 25, no. 9, pp. 2401-2406, 1992.

50. L. M. Liz-Marzán, “Nanometals: Formation and color,” Materials Today, vol. 7, no. 2. pp. 26-31, Feb-2004.

51. S. Wunder, F. Polzer, Y. Lu, Y. Mei, and M. Ballauff, "Kinetic analysis of catalytic reduction of 4-nitrophenol by metallic nanoparticles immobilized in spherical polyelectrolyte brushes," J. Phys. Chem. C, vol. 114, no. 19, pp. 8814-8820, 2010. 
52. Pawlaczyk, M., Kurczewska, J., \& Schroeder, G. (2018). Nanomaterials Modification by Dendrimers-A Review. World Journal of Research and Review, 6(5), 262658.

53. Sadjadi, S., \& Sadjadi, S. (2018). Dendritic polymers for environmental remediation. In New Polymer Nanocomposites for Environmental Remediation (pp. 279-335). Elsevier. https://doi.org/10.1016/B978-0-12-811033-1.00013-5.).

54. Wazir, M. B., Daud, M., Ali, F., \& Al-Harthi, M. A. (2020). Dendrimer assisted dye-removal: A critical review of adsorption and catalytic degradation for wastewater treatment. Journal of Molecular Liquids, 113775. https://doi.org/10.1016/j.molliq.2020.113775.

55. M. Zhao and R. M. Crooks, "Homogeneous hydrogenation catalysis with monodisperse, dendrimer- encapsulated Pd and Pt nanoparticles," Angew. Chemie - Int. Ed., vol. 38, no. 3, pp. 364-366, 1999.

56. M. Zhao, L. Sun, and R. M. Crooks, "Preparation of Cu Nanoclusters within Dendrimer Templates," J. Am. Chem. Soc., vol. 120, no. 19, pp. 4877-4878, 1998.

57. K. Esumi, A. Suzuki, N. Aihara, K. Usui, and K. Torigoe, "Preparation of gold colloids with UV irradiation using dendrimers as stabilizer," Langmuir, vol. 14, no. 12, pp. 3157-3159, 1998.

58. Elia, M. C., Storer, R. D., McKelvey, T. W., Kraynak, A. R., Barnum, J. E., Harmon, L. S., ... \& Nichols, W. W. (1994). Rapid DNA degradation in primary rat hepatocytes treated with diverse cytotoxic chemicals: analysis by pulsed field gel electrophoresis and implications for alkaline elution assays. Environmental and molecular mutagenesis, 24(3), 181-191. https://doi.org/10.1002/em.2850240307.

59. Oglesby, L. A., Ebron-McCoy, M. T., Logsdon, T. R., Copeland, F., Beyer, P. E., \& Kavlock, R. J. (1992). In vitro embryotoxicity of a series of para-substituted phenols: Structure, activity, and correlation with in vivo data. Teratology, 45(1), 11-33. https://doi.org/10.1002/tera.1420450103.

60. Hayakawa, K., Yoshimura, T., \& Esumi, K. (2003). Preparation of gold-dendrimer nanocomposites by laser irradiation and their catalytic reduction of 4-nitrophenol. Langmuir, 19(13), 5517-5521. DOI: 10.1021/la0343391.

61. Kunio Esumi, Ryoko Isono, and Tomokazu Yoshimura Preparation of PAMAM- and PPI-Metal (Silver, Platinum, and Palladium) Nanocomposites and Their Catalytic Activities for Reduction of 4-Nitrophenol Langmuir 200420 (1), $237-243$ DOI: 10.1021/la035440t.

62. Bingwa, N., \& Meijboom, R. (2015). Evaluation of catalytic activity of Ag and Au dendrimer-encapsulated nanoparticles in the reduction of 4-nitrophenol. Journal of Molecular Catalysis A: Chemical, 396, 1-7. https://doi.org/10.1016/j.molcata.2014.09.019.

63. Feng, Z. V., Lyon, J. L., Croley, J. S., Crooks, R. M., Vanden Bout, D. A., \& Stevenson, K. J. (2009). Synthesis and catalytic evaluation of dendrimer-encapsulated $\mathrm{Cu}$ nanoparticles. An undergraduate experiment exploring catalytic nanomaterials. Journal of chemical education, 86(3), 368. https://doi.org/10.1021/ed086p368.

64. Johnson, J. A., Makis, J. J., Marvin, K. A., Rodenbusch, S. E., \& Stevenson, K. J. (2013). Size-dependent hydrogenation of pnitrophenol with Pd nanoparticles synthesized with poly (amido) amine dendrimer templates. The Journal of Physical Chemistry C, 117(44), 22644-22651. https://doi.org/10.1021/jp4041474.

65. Nemanashi, M., \& Meijboom, R. (2013). Synthesis and characterization of Cu, Ag and Au dendrimer-encapsulated nanoparticles and their application in the reduction of 4-nitrophenol to 4-aminophenol. Journal of colloid and interface science, 389(1), 260267. https://doi.org/10.1016/j.jcis.2012.09.012.

66. Noh, J. H., \& Meijboom, R. (2014). Catalytic evaluation of dendrimer-templated Pd nanoparticles in the reduction of 4-nitrophenol using Langmuir-Hinshelwood kinetics. Applied surface science, 320, 400-413. https://doi.org/10.1016/j.apsusc.2014.09.058.

67. Bingwa, N., \& Meijboom, R. (2014). Kinetic evaluation of dendrimer-encapsulated palladium nanoparticles in the 4-nitrophenol reduction reaction. The Journal of Physical Chemistry C, 118(34), 19849-19858. https://doi.org/10.1021/jp505571p.

68. Patala, R., Noh, J. H., \& Meijboom, R. (2018). Determination of maximum loading capacity of polyamidoamine (PAMAM) dendrimers and evaluation of $\mathrm{Cu}_{55}$ dendrimer-encapsulated nanoparticles for catalytic activity. International Journal of Chemical Kinetics, 50(10), 693-704. https://doi.org/10.1002/kin.21193.

69. Noh, J. H., \& Meijboom, R. (2015). Synthesis and catalytic evaluation of dendrimer-templated and reverse microemulsion Pd and Pt nanoparticles in the reduction of 4-nitrophenol: The effect of size and synthetic methodologies. Applied Catalysis A: General, 497, 107-120. https://doi.org/10.1016/j.apcata.2015.02.039.

70. Takeshi Endo, Tomokazu Yoshimura, Kunio Esumi, Synthesis and catalytic activity of gold-silver binary nanoparticles stabilized by PAMAM dendrimer, Journal of Colloid and Interface Science, Volume 286, Issue 2, 2005, Pages 602-609, https://doi.org/10.1016/j.jcis.2005.01.057.

71. Croley, J. S., \& Stevenson, K. J. Electroreduction of p-Nitrophenol at supported Mono-and Bimetallic Dendrimer Encapsulated Catalysts. UT-Austin 2007-2008 Beckman Scholars Final Report, 1-21.

72. Antonels, N. C., \& Meijboom, R. (2013). Preparation of well-defined dendrimer Encapsulated ruthenium nanoparticles and their evaluation in the reduction of 4-nitrophenol according to the Langmuir-Hinshelwood approach. Langmuir, 29(44), 13433-13442. https://doi.org/10.1021/la402885k.

73. Marvin, K. A., Thadani, N. N., Atkinson, C. A., Keller, E. L., \& Stevenson, K. J. (2012). Preparation and catalytic evaluation of ruthenium-nickel dendrimer encapsulated nanoparticles via intradendrimer redox displacement of nickel nanoparticles. Chemical Communications, 48(50), 6289-6291.

74. Gatard, S., Salmon, L., Deraedt, C., Ruiz, J., Astruc, D., \& Bouquillon, S. (2014). Gold Nanoparticles Stabilized by Glycodendrimers: Synthesis and Application to the Catalytic Reduction of 4-Nitrophenol. European Journal of Inorganic Chemistry, 2014(16), 2671-2677. https://doi.org/10.1002/ejic.201402067. 
75. Gatard, S., Salmon, L., Deraedt, C., Ruiz, J., Astruc, D., \& Bouquillon, S. (2014). Palladium nanoparticles stabilized by glycodendrimers and their application in catalysis. European Journal of Inorganic Chemistry, 2014(26), 4369-4375. https://doi.org/10.1002/ejic.201402457.

76. Li, N., Echeverria, M., Moya, S., Ruiz, J., \& Astruc, D. (2014). “Click” synthesis of nona-PEG-branched triazole dendrimers and stabilization of gold nanoparticles that efficiently catalyze p-nitrophenol reduction. Inorganic chemistry, 53(13), 6954-6961. https://doi.org/10.1021/ic500861f.

77. Liu, X., Ruiz, J., \& Astruc, D. (2018). Compared catalytic efficiency of click-dendrimer-stabilized late transition metal nanoparticles in 4-Nitrophenol reduction. Journal of In-organic and Organometallic Polymers and Materials, 28(2), 399-406. https://doi.org/10.1007/s10904-017-0666-x.

78. Tanaka, H., Hashimoto, T., Koizumi, S., Itoh, H., Naka, K., \& Chujo, Y. (2008). Control of self-assembling processes of polyamidoamine dendrimers and Pd nanoparticles. Macro-molecules, 41(5), 1815-1824. https://doi.org/10.1021/ma702034x.

79. Kannan, A., \& Rajakumar, P. (2015). Synthesis and catalytic application of glycodendrimers decorated with gold nanoparticlesreduction of 4-nitrophenol. RSC Advances, 5(58), 46908-46915. https://doi.org/10.1039/C5RA06375B.

80. Patil, N. G., Basutkar, N. B., \& Ambade, A. V. (2017). Copper and silver nanoparticles stabilized by bistriazole-based dendritic amphiphile micelles for 4-nitrophenol reduction. New Journal of Chemistry, 41(11), 4546-4554. https://doi.org/10.1039/C7NJ00605E.

81. Liu, X., Mu, S., Long, Y., Qiu, G., Ling, Q., Gu, H., \& Lin, W. (2019). Gold nanoparticles stabilized by 1, 2, 3-triazolyl dendronized polymers as highly efficient nanoreactors for the reduction of 4-nitrophenol. Catalysis Letters, $149(2)$, $544-551$. https://doi.org/10.1007/s10562-019-02662-5.

82. Liu, X., Liu, F., Wang, Y., \& Gu, H. (2019). Ferrocene-containing amphiphilic dendronized random copolymer as efficient stabilizer for reusable gold nanoparticles in catalysis. Reactive and Functional Polymers, 143, 104325. https://doi.org/10.1016/j.reactfunctpolym.2019.104325.

83. Liu, X., Liu, F., Astruc, D., Lin, W., \& Gu, H. (2019). Highly-branched amphiphilic organometallic dendronized diblock copolymer: ROMP synthesis, self-assembly and long-term Au and Ag nanoparticle stabilizer for high-efficiency catalysis. Polymer, 173, 1-10. https://doi.org/10.1016/j.polymer.2019.04.021.

84. Asharani, I. V., \& Thirumalai, D. (2012). Synthesis of Dendrimer-Encapsulated Silver Nanoparticles and Its Catalytic Activity on the Reduction of 4-Nitrophenol. Journal of the Chinese Chemical Society, 59(11), 1455-1460.

85. Gürbüz, M. U., \& Ertürk, A. S. (2018). Synthesis and Characterization of Jeffamine Core PAMAM Dendrimer-Silver Nanocomposites (Ag JCPDNCs) and Their Evaluation in The Reduction of 4-Nitrophenol. Journal of the Turkish Chemical Society Section A: Chemistry, 5(2), 885-894. http://dx.doi.org/10.18596/jotcsa.428572.

86. Murugan, E., \& Pakrudheen, I. (2015). Efficient amphiphilic poly (propylene imine) dendrimer encapsulated ruthenium nanoparticles for sensing and catalysis applications. Science of Advanced Materials, 7(5), 891-901. https://doi.org/10.1166/sam.2015.1906.

87. Liu, Y., Fan, Y., Yuan, Y., Chen, Y., Cheng, F., \& Jiang, S. C. (2012). Amphiphilic hyperbranched copolymers bearing a hyperbranched core and a dendritic shell as novel stabilizers rendering gold nanoparticles with an unprecedentedly long lifetime in the catalytic reduction of 4-nitrophenol. Journal of Materials Chemistry, 22(39), 21173-21182. DOI: 10.1039/C2JM34445A.

88. Gao, L., Nishikata, T., Kojima, K., Chikama, K., \& Nagashima, H. (2013). Water-and Organo-Dispersible Gold Nanoparticles Supported by Using Ammonium Salts of Hyperbranched Polystyrene: Preparation and Catalysis. Chemistry-An Asian Journal, 8(12), 3152-3163. https://doi.org/10.1002/asia.201300871.

89. Liu, Y., Xu, L., Liu, X., \& Cao, M. (2016). Hybrids of gold nanoparticles with core-shell hyperbranched polymers: Synthesis, characterization, and their high catalytic activity for reduction of 4-nitrophenol. Catalysts, 6(1), 3. https://doi.org/10.3390/catal6010003.

90. Redón, R., Ramírez-Crescencio, F., Gonzalez-Rodriguez, R., Coffer, J., \& Simanek, E. E. (2020). Ir (0) and Pt (0) nanoparticletriazine dendrimer composites. Journal of Coordination Chemistry, 73(4), $544-557$. https://doi.org/10.1080/00958972.2020.1738407.

91. Wang, L., Yang, Q., Cui, Y., Gao, D., Kang, J., Sun, H., ... \& Chen, S. (2017). Highly stable and biocompatible dendrimer-encapsulated gold nanoparticle catalysts for the re-duction of 4-nitrophenol. New Journal of Chemistry, 41(16), 8399-8406. https://doi.org/10.1039/C7NJ01567D.

92. Yang, D., Zhang, R., Zhao, T., Sun, T., Chu, X., Liu, S., ... \& Xu, X. (2019). Efficient re-duction of 4-nitrophenol catalyzed by 4carbo-methoxypyrrolidone modified PAMAM dendrimer-silver nanocomposites. Catalysis Science \& Technology, 9(21), 61456151. https://doi.org/10.1039/C9CY01655D.

93. Lim, J., Mintzer, M. A., Perez, L. M., \& Simanek, E. E. (2010). Synthesis of odd generation triazine dendrimers using a divergent, macromonomer approach. Organic letters, 12(6), 1148-1151. https://doi.org/10.1021/ol902669g.

94. Dai, Y., Yu, P., Zhang, X., \& Zhuo, R. (2016). Gold nanoparticles stabilized by amphiphilic hyperbranched polymers for cataly tic reduction of 4-nitrophenol. Journal of Catalysis, 337, 65-71. https://doi.org/10.1016/j.jcat.2016.01.014.

95. Dong, H., Dai, Y., Zhang, X., Zhang, Z., Fu, S., \& Zhong, Z. (2018). The influence of amine structures on the stability and catalytic activity of gold nanoparticles stabilized by amine-modified hyperbranched polymers. Nanotechnology, 29(5), 055705. https://doi.org/10.1088/1361-6528/aaa0fe.

96. Dai, Y., Zhang, X., \& Zhuo, R. (2016). Amphiphilic linear-hyperbranched polymer poly (ethylene glycol)-branched polyethylenimine-poly ( $\epsilon$-caprolactone): synthesis, self-assembly and application as stabilizer of platinum nanoparticles. Polymer International, 65(6), 691-697. https://doi.org/10.1002/pi.5118. 
97. Yang, P., Zhang, W., Du, Y., \& Wang, X. (2006). Hydrogenation of nitrobenzenes catalyzed by platinum nanoparticle corepolyaryl ether trisacetic acid ammonium chloride dendrimer shell nanocomposite. Journal of Molecular Catalysis A: Chemical, 260(1-2), 4-10. https://doi.org/10.1016/j.molcata.2006.06.045.

98. Zhang, W., Li, L., Du, Y., Wang, X., \& Yang, P. (2009). Gold/platinum bimetallic core/shell nanoparticles stabilized by a fréchettype dendrimer: preparation and cata-lytic hydrogenations of phenylaldehydes and nitrobenzenes. Catalysis letters, 127(3), 429436. https://doi.org/10.1007/s10562-008-9725-9.

99. Murugan, E., Rangasamy, R., \& Pakrudheen, I. (2012). Efficient amphiphilic poly (propyleneimine) dendrimer stabilized gold nanoparticle catalysts for aqueous phase re-duction of nitrobenzene. Science of Advanced Materials, 4(11), 1103-1110. https://doi.org/10.1166/sam.2012.1401.

100. Asharani, I. V., Thirumalai, D., \& Sivakumar, A. (2017, November). Dendrimer encapsulated silver nanoparticles as novel catalysts for reduction of aromatic nitro com-pounds. In IOP Conference Series: Materials Science and Engineering (Vol. 263, No. 2, p. 022010). IOP Publishing. https://doi.org/10.1088/1757-899X/263/2/022010.

101. Jiménez, V. A., Marrugo, K., Campos, C. H., Alderete, J. B., \& Torres, C. C. (2021). Copper metallic nanoparticles capped with PEGylated PAMAM-G3 dendrimers for the catalytic reduction of low solubility nitroarenes of pharmaceutical interest. Catalysis Today, 372, 27-35. https://doi.org/10.1016/j.cattod.2020.11.011.

102. Campos, C. H., Bustamante, T. M., Jiménez, V. A., Torres, C. C., \& Alderete, J. B. (2021). Efficient and recyclable gold nanoparticles as catalysts for the cleaner production of 4-morpholinoanilines used as pharmaceutical building blocks. Journal of Cleaner Production, 290, 125761. into a dendrimer layer without agglomeration https://doi.org/10.1016/j.jclepro.2020.125761.

103. Sanyal, M., \& Sharma, U. (2021). PAMAM (poly-amido amine) dendrimer supported copper nanoparticles for chemoselective nitro reduction. Journal of the Indian Chemical Society, 98(10), 100149. https://doi.org/10.1016/j.jics.2021.100149.

104. Murugan, E., Pakrudheen, I., \& Gomathi, G. (2011, November). Amphiphilic dendrimer stabilized Ag, Pd and Pt homogeneous nanoparticle catalysts and their catalysis for the reduction of methyl orange. In International Conference on Nanoscience, Engineering and Technology (ICONSET 2011) (pp. 35-39). IEEE.) DOI: 10.1109/ICONSET.2011.6167904.

105. Ilunga, A. K., Khoza, T., Tjabadi, E., \& Meijboom, R. (2017). Effective Catalytic Reduction of Methyl Orange Catalyzed by the Encapsulated Random Alloy Palladium-Gold Nanoparticles Dendrimer. ChemistrySelect, 2(30), 9803-9809. https://doi.org/10.1002/slct.201701631.

106. Ilunga, A. K., \& Meijboom, R. (2016). Synthesis of narrowly dispersed silver and gold nanoparticles and their catalytic evaluation for morin oxidation. Applied Catalysis A: General, 509, 17-29. https://doi.org/10.1016/j.apcata.2015.10.019.

107. Nemanashi, M., \& Meijboom, R. (2015). Catalytic behavior of different sizes of dendrimer-encapsulated au n nanoparticles in the oxidative degradation of Morin with H2O2. Langmuir, 31(33), 9041-9053. https://doi.org/10.1021/acs.langmuir.5b02020.

108. Ncube, P., Hlabathe, T., \& Meijboom, R. (2015). The preparation of well-defined dendrimer-encapsulated palladium and platinum nanoparticles and their catalytic evaluation in the oxidation of morin. Applied Surface Science, 357, 1141-1149 https://doi.org/10.1016/j.apsusc.2015.09.123.

109. Ilunga, A. K., \& Meijboom, R. (2016). Catalytic and kinetic investigation of the encapsulated random alloy (Pdn-Au110-n) nanoparticles. Applied Catalysis B: Environmental, 189, 86-98. https://doi.org/10.1016/j.apcatb.2016.02.040.

110. Xiao, H., Wang, R., Dong, L., Cui, Y., Chen, S., Sun, H., ... \& Wang, L. (2019). Biocompatible dendrimer-encapsulated palladium nanoparticles for oxidation of morin. ACS omega, 4(20), 18685-18691. https://doi.org/10.1021/acsomega.9b02606.

111. Wang, L., Zhang, J., Guo, X., Chen, S., Cui, Y., Yu, Q., ... \& Xie, D. (2018). Highly stable and biocompatible zwitterionic dendrimer-encapsulated palladium nanoparticles that maintain their cata-lytic activity in bacterial solution. New Journal of Chemistry, 42(24), 19740-19748. DOI: 10.1039/C8NJ04263B.

112. Ilunga, A. K., \& Meijboom, R. (2016). Catalytic oxidation of methylene blue by dendrimer encapsulated silver and gold nanoparticles. Journal of Molecular Catalysis A: Chemical, 411, 48-60. https://doi.org/10.1016/j.molcata.2015.10.009.

113. Ncube, P., Bingwa, N., Baloyi, H., \& Meijboom, R. (2015). Catalytic activity of palladium and gold dendrimer-encapsulated nanoparticles for methylene blue reduction: a kinetic analysis. Applied Catalysis A: General, 495, 63-71. https://doi.org/10.1016/j.apcata.2015.01.033.

114. Murugan, E., \& Rangasamy, R. (2010). Synthesis, characterization, and heterogeneous catalysis of polymer-supported poly (propyleneimine) dendrimer stabilized gold nanoparticle catalyst. Journal of Polymer Science Part A: Polymer Chemistry, 48(12), 2525-2532. https://doi.org/10.1002/pola.24028.

115. Dang, G., Shi, Y., Fu, Z., \& Yang, W. (2012). Polymer particles with dendrimer@SiO2-Ag hierarchical shell and their application in catalytic column. Journal of colloid and inter-face science, 369(1), 170-178. https://doi.org/10.1016/j.jcis.2011.11.054.

116. Chen, L., Cao, W., Quinlan, P. J., Berry, R. M., \& Tam, K. C. (2015). Sustainable catalysts from gold-loaded polyamidoamine dendrimer-cellulose nanocrystals. ACS Sustainable Chemistry \& Engineering, 3(5), 978-985. https://doi.org/10.1021/acssuschemeng.5b00110.

117. Wang, M. L., Jiang, T. T., Lu, Y., Liu, H. J., \& Chen, Y. (2013). Gold nanoparticles immobilized in hyperbranched polyethylenimine modified polyacrylonitrile fiber as highly efficient and recyclable heterogeneous catalysts for the reduction of 4-nitrophenol. Journal of Materials Chemistry A, 1(19), 5923-5933. https://doi.org/10.1039/C3TA10293A.

118. Hu, D., Huang, Y., Liu, H., Wang, H., Wang, S., Shen, M., ... \& Shi, X. (2014). The assembly of dendrimer-stabilized gold nanoparticles onto electrospun polymer nanofibers for catalytic applications. Journal of Materials Chemistry A, 2(7), $2323-2332$. https://doi.org/10.1039/C3TA13966B.

119. Li, H., Lü, J., Zheng, Z., \& Cao, R. (2011). An efficient and reusable silica/dendrimer sup-ported platinum catalyst for electron transfer reactions. Journal of colloid and interface science, 353(1), 149-155. https://doi.org/10.1016/j.jcis.2010.09.047. 
120. Ricciardi, R., Huskens, J., \& Verboom, W. (2015). Influence of the Au/Ag ratio on the catalytic activity of dendrimer-encapsulated bimetallic nanoparticles in microreactors. Journal of flow chemistry, 5(4), 228-233. https://doi.org/10.1556/1846.2015.00018.

121. Gaofei, D. A. N. G., Yan, S. H. I., Zhifeng, F. U., \& Wantai, Y. A. N. G. (2012). Fe3O4@ PS@ PAMAM-Ag magnetic nanocatalysts and their recoverable catalytic ability. Chinese Journal of Catalysis, 33(4-6), 651-658. https://doi.org/10.1016/S18722067(11)60369-0.

122. Kurtan, U., \& Baykal, A. (2014). Fabrication and characterization of Fe3O4@ APTES@ PAMAM-Ag highly active and recyclable magnetic nanocatalyst: Catalytic reduction of 4-nitrophenol. Materials Research Bulletin, 60, 79-87 https://doi.org/10.1016/j.materresbull.2014.08.016.

123. Ma, M., Yang, Y., Li, W., Feng, R., Li, Z., Lyu, P., \& Ma, Y. (2019). Gold nanoparticles sup-ported by amino groups on the surface of magnetite microspheres for the catalytic reduction of 4-nitrophenol. Journal of materials science, 54(1), 323-334. https://doi.org/10.1007/s10853-018-2868-1.

124. Sun, Z., Li, H., Cui, G., Tian, Y., \& Yan, S. (2016). Multifunctional magnetic core-shell dendritic mesoporous silica nanospheres decorated with tiny Ag nanoparticles as a highly active heterogeneous catalyst. Applied Surface Science, 360, $252-262$. https://doi.org/10.1016/j.apsusc.2015.11.013.

125. Rajesh, R., \& Venkatesan, R. (2012). Encapsulation of silver nanoparticles into graphite grafted with hyperbranched poly (amidoamine) dendrimer and their catalytic activity towards reduction of nitro aromatics. Journal of Molecular Catalysis A: Chemical, 359, 88-96. https://doi.org/10.1016/j.molcata.2012.04.001.

126. Ramezanpour, A., Karami, K., Kharaziha, M., Silvestru, C., \& Bayat, P. (2021). Synthesis and characterization of the ternary graphene oxide, $\mathrm{MnFe} 2 \mathrm{O} 4$ nanoparticles, and Polyamidoamine dendrons nanocomposite decorated with palladium as a heterogeneous catalyst for nitroaromatics reduction. Applied Organometallic Chemistry, e6329. https://doi.org/10.1002/aoc.6329.

127. Murugan, E., \& Vimala, G. (2013). Synthesis, characterization, and catalytic activity for hybrids of multi-walled carbon nanotube and amphiphilic poly (propyleneimine) dendrimer immobilized with silver and palladium nanoparticle. Journal of colloid and inter-face science, 396, 101-111. https://doi.org/10.1016/j.jcis.2012.12.074.

128. Murugan, E., Arumugam, S., \& Panneerselvam, P. (2016). New nanohybrids from poly (propylene imine) dendrimer stabilized silver nanoparticles on multiwalled carbon nano-tubes for effective catalytic and antimicrobial applications. International Journal of Polymeric Materials and Polymeric Biomaterials, 65(3), 111-124. https://doi.org/10.1080/00914037.2015.1038820.

129. Nemanashi, M., \& Meijboom, R. (2016). “Cat in a bag" recycling of dendrimer encapsulated Au nanoparticles by use of dialysis membrane bag in the reduction of 4-nitrophenol: proof of heterogeneous catalysis. Catalysis Communications, 83, 53-57. https://doi.org/10.1016/j.catcom.2016.05.007.

130. Pan, H., Liu, D., Hu, N., Shi, J., \& Liu, H. X. (2015). Hyperbranched polymer-protected gold nanoparticles well-dispersed in different organic solvents: preparation and their catalytic applications to 4-nitrophenol reduction. Colloid and Polymer Science, 293(7), 2017-2026. https://doi.org/10.1007/s00396-015-3591-y.

131. Liu, H., Wan, D., Du, J., \& Jin, M. (2015). Dendritic Amphiphile mediated one-pot preparation of 3D Pt nanoparticles-decorated PolyHIPE as a durable and well-recyclable catalyst. ACS applied materials \& interfaces, 7(37), 20885-20892. https://doi.org/10.1021/acsami.5b06283.

132. Wan, Y., Feng, Y., Wan, D., \& Jin, M. (2016). Polyamino amphiphile mediated support of platinum nanoparticles on polyHIPE as an over 1500-time recyclable catalyst. RSC advances, 6(110), 109253-109258. https://doi.org/10.1039/C6RA19013H.

133. Ye, Y., Jin, M., \& Wan, D. (2015). One-pot synthesis of porous monolith-supported gold nanoparticles as an effective recyclable catalyst. Journal of Materials Chemistry A, 3(25), 13519-13525. https://doi.org/10.1039/C5TA02925B.

134. Rajesh, R., Kumar, S. S., \& Venkatesan, R. (2014). Efficient degradation of azo dyes using Ag and Au nanoparticles stabilized on graphene oxide functionalized with PAMAM dendrimers. New Journal of Chemistry, 38(4), 1551-1558. DOI: 10.1039/C3NJ01050C.

135. Hao, B., Lu, G., Zhang, S., Li, Y., Ding, A., \& Huang, X. (2020). Gold nanoparticles standing on PEG/PAMAM/thiol-functionalized nanographene oxide as aqueous catalysts. Polymer Chemistry, 11(25), 4094-4104. DOI: 10.1039/D0PY00471E).

136. Ilunga, A. K., \& Meijboom, R. (2017). Random alloy nanoparticles of Pd and Au immobilized on reducible metal oxides and their catalytic investigation. Applied Catalysis B: Environmental, 203, 505-514. https://doi.org/10.1016/j.apcatb.2016.10.053.

137. Xaba, M. S., Noh, J. H., \& Meijboom, R. (2019). Catalytic activity of different sizes of Ptn/Co3O4 in the oxidative degradation of Methylene Blue with H2O2. Applied Surface Science, 467, 868-880. https://doi.org/10.1016/j.apsusc.2018.10.259.

138. Ramaraju, B., Imae, T., \& Destaye, A. G. (2015). Ag nanoparticle-immobilized cellulose nanofibril films for environmental conservation. Applied Catalysis A: General, 492, 184-189. https://doi.org/10.1016/j.apcata.2014.12.045.

139. Nabil, B., Morshed, M. N., Nemeshwaree, B., Christine, C., Julien, V., Olivier, T., \& Abdelkrim, A. (2019). Development of new multifunctional filter-based nonwovens for organics pollutants reduction and detoxification: High catalytic and antibacterial activities. Chemical Engineering Journal, 356, 702-716. https://doi.org/10.1016/j.cej.2018.08.166.

140. Morshed, M. N., Bouazizi, N., Behary, N., Guan, J., \& Nierstrasz, V. (2019). Stabilization of zero valent iron (Fe0) on plasma/dendrimer functionalized polyester fabrics for Fen-ton-like removal of hazardous water pollutants. Chemical Engineering Journal, 374, 658-673. https://doi.org/10.1016/j.cej.2019.05.162.

141. Morshed, M. N., Miankafshe, M. A., Persson, N. K., Behary, N., \& Nierstrasz, V. A. (2020). Development of a multifunctional graphene/Fe-loaded polyester textile: robust electrical and catalytic properties. Dalton Transactions, 49(47), 17281-17300. DOI: 10.1039/D0DT03291C. 
142. Morshed, M. N., Bouazizi, N., Behary, N., Vieillard, J., Thoumire, O., Nierstrasz, V., \& Azzouz, A. (2019). Iron-loaded amine/thiol functionalized polyester fibers with high cata-lytic activities: a comparative study. Dalton Transactions, 48(23), 8384-8399. DOI: 10.1039/C9DT00937J.

143. Murugan, E., \& Shanmugam, P. (2016). Surface grafted hyper-branched polyglycerol stabilized Ag and AuNPs heterogeneous catalysts for efficient reduction of Congo red. Journal of nanoscience and nanotechnology, 16(1), 426-438. https://doi.org/10.1166/jnn.2016.10655.

144. Shanmugam, P., Rajakumar, K., Boddula, R., Ngullie, R. C., Wei, W., Xie, J., \& Murugan, E. (2019). Heterogeneous form of poly (4-vinyl pyridine) beads based dendrimer stabilized Ag, Au and PdNPs catalyst for reduction of trypan blue. Materials Science for Energy Technologies, 2(3), 532-542. https://doi.org/10.1016/j.mset.2019.05.006.

145. Murugan, E., Jebaranjitham, J. N., Raman, K. J., Mandal, A., Geethalakshmi, D., Kumar, M. D., \& Saravanakumar, A. (2017). Insoluble dendrimer-grafted poly (vinylimidazole) microbeads stabilized with mono/bimetallic nanoparticle catalysts for effective degradation of malachite green. New Journal of Chemistry, 41(19), 10860-10871. DOI: 10.1039/C7NJ01054K.

146. Nemanashi-Maumela, M., Nongwe, I., Motene, R. C., Davids, B. L., \& Meijboom, R. (2017). Au and Ag nanoparticles encapsulated within silica nanospheres using dendrimers as dual templating agent and their catalytic activity. Molecular Catalysis, 438 , 184-196. https://doi.org/10.1016/j.mcat.2017.06.003.

147. Arkas, M., Kithreoti, G., Boukos, N., Kitsou, I., Petrakli, F., \& Panagiotaki, K. (2018). Two completely different biomimetic reactions mediated by the same matrix producing inorganic/organic/inorganic hybrid nanoparticles. Nano-Structures \& Nano-Objects, 14, 138-148.https://doi.org/10.1016/j.nanoso.2018.01.009.

148. Onisuru, O. R., Oseghale, C. O., \& Meijboom, R. (2020). In situ replacement of Cu-DEN: an approach for preparing a more noble metal nanocatalyst for catalytic use. New Journal of Chemistry, 44(46), 20322-20333. DOI: 10.1039/d0nj04381h.

149. Murugan, E., \& Jebaranjitham, J. N. (2015). Dendrimer grafted core-shell Fe3O4-polymer magnetic nanocomposites stabilized with AuNPs for enhanced catalytic degradation of Rhodamine B-a kinetic study. Chemical Engineering Journal, 259, 266-276. https://doi.org/10.1016/j.cej.2014.07.121.

150. Malinga, S. P., Arotiba, O. A., Krause, R. W. M., Mapolie, S. F., Diallo, M. S., \& Mamba, B. B. (2013). Composite polyester membranes with embedded dendrimer hosts and bimetallic $\mathrm{Fe} / \mathrm{Ni}$ nanoparticles: synthesis, characterisation and application to water treatment. In Nanotechnology for Sustainable Development (pp. 47-61). Springer, Cham. https://doi.org/10.1007/978-3-31905041-6_4.

151. Sivasankar, V., Nkonde, M. A., Govender, P., Omine, K., Kuvarega, A. T., Prabhakaran, M., \& Msagati, T. A. (2018). Dendrimer supported $\mathrm{Fe} / \mathrm{Ni}$ bimetallic composites immobilized in polyether-sulfone membranes for effective degradation of arginine containing microcystins. European Polymer Journal, 98, 456-467. https://doi.org/10.1016/j.eurpolymj.2017.11.049.

152. Vlotman, D. E., Ngila, J. C., Ndlovu, T., Doyle, B., Carleschi, E., \& Malinga, S. P. (2019). Hyper-branched polymer membrane for catalytic degradation of polychlorinated biphenyl-153 (PCB-153) in water. Reactive and Functional Polymers, 136, 44-57. https://doi.org/10.1016/j.reactfunctpolym.2018.12.019.

153. Wang, X. X., Chen, T., \& Wang, J. P. (2016). Degradation of Synthetic Reactive Dye Wastewater Based on Amine-Functionalized Polyacrylonitrile Fiber. In Key Engineering Materials (Vol. 671, pp. 425-430). Trans Tech Publications Ltd. https://doi.org/10.4028/www.scientific.net/KEM.671.425.

154. Aldana, A. A., Strumia, M. C., \& Martinelli, M. (2015). The cooperative effect in dendronized chitosan microbeads. Australian Journal of Chemistry, 68(12), 1918-1925. https://doi.org/10.1071/CH15102.

155. Hassan, S. A., Darwish, A. S., Gobara, H. M., Abed-Elsatar, N. E., \& Fouda, S. R. (2017). Interaction profiles in poly (amidoamine) dendrimer/montmorillonite or rice straw ash hybrids-immobilized magnetite nanoparticles governing their removal efficiencies of various pollutants in wastewater. Journal of Molecular Liquids, 230, 353-369. https://doi.org/10.1016/j.molliq.2017.01.060.

156. Kitsou, I., Panagopoulos, P., Maggos, T., Arkas, M., \& Tsetsekou, A. (2018). Development of SiO2@ TiO2 core-shell nanospheres for catalytic applications. Applied Surface Science, 441, 223-231. https://doi.org/10.1016/j.apsusc.2018.02.008.

157. Kitsou, I., Arkas, M., \& Tsetsekou, A. (2019). Synthesis and characterization of ceria-coated silica nanospheres: Their application in heterogeneous catalysis of organic pollutants. SN Applied Sciences, 1(12), 1-12. https://doi.org/10.1007/s42452-019-1613-y.

158. Yu, D., Ni, H., Wang, L., Wu, M., \& Yang, X. (2018). Nanoscale-confined precursor of CuFe2O4 mediated by hyperbranched polyamide as an unusual heterogeneous Fenton catalyst for efficient dye degradation. Journal of Cleaner Production, 186, 146154. https://doi.org/10.1016/j.jclepro.2018.03.134.

159. Kabel, K. I., Mady, A. H., \& Rabie, A. M. (2021). Novel preparation of ferromanganese oxide based on hyperbranched polymer for peroxymonosulfate activation as a robust catalyst for the degradation of organic pollutants. Environmental Technology \& Innovation, 22, 101435. https://doi.org/10.1016/j.eti.2021.101435.

160. M Brazkova, M Gerginova, I Gitsov, A Krastanov Microbes in the Spotlight: Recent Progress in the Understanding of Beneficial and Harmful Microorganisms. (2016) 45-51. Edited by A. Mendez-Vilas. Brown Walker Press. Boca Raton Florida. USA.

161. Soozanipour, A., Taheri-Kafrani, A., Razmjou, A., \& Asadnia, M. (2021). Hyaluronidase enzyme conjugated polyamidoamine dendrimer: An efficient and stable nanobiocatalyst for enzymatic degradation of hyaluronic acid. Journal of Molecular Liquids, 118111. https://doi.org/10.1016/j.molliq.2021.118111.

162. Fujishima, A., \& Honda, K. (1972). Electrochemical photolysis of water at a semiconductor electrode. nature, 238(5358), 37-38. https://doi.org/10.1038/238037a0.

163. Nakanishi, Y., \& Imae, T. (2005). Synthesis of dendrimer-protected TiO2 nanoparticles and photodegradation of organic molecules in an aqueous nanoparticle suspension. Journal of colloid and interface science, 285(1), 158-162. https://doi.org/10.1016/j.jcis.2004.11.055. 
164. Nakanishi, Y., \& Imae, T. (2006). Preparation of siloxy focal dendron-protected TiO2 nanoparticles and their photocatalysis. Journal of colloid and interface science, 297(1), 122-129. https://doi.org/10.1016/j.jcis.2005.10.017.

165. Lei, Y., Zhang, C., Lei, H., \& Huo, J. (2013). Visible light photocatalytic activity of aromatic polyamide dendrimer/TiO2 composites functionalized with spirolactam-based molecular switch. Journal of colloid and interface science, 406, 178-185. https://doi.org/10.1016/j.jcis.2013.05.063.

166. Ghanem, A. F., Badawy, A. A., Ismail, N., Tian, Z. R., Rehim, M. A., \& Rabia, A. (2014). Photocatalytic activity of hyperbranched polyester/TiO2 nanocomposites. Applied Catalysis A: General, 472, 191-197. https://doi.org/10.1016/j.apcata.2013.12.023Get.

167. Kim, L. J., Jang, J. W., \& Park, J. W. (2014). Nano TiO2-functionalized magnetic-cored dendrimer as a photocatalyst. Applied Catalysis B: Environmental, 147, 973-979. https://doi.org/10.1016/j.apcatb.2013.10.024.

168. Jung, J. J., Jang, J. W., \& Park, J. W. (2016). Effect of generation growth on photocatalytic activity of nano TiO2-magnetic cored dendrimers. Journal of Industrial and Engineering Chemistry, 44, 52-59. https://doi.org/10.1016/j.jiec.2016.08.007.

169. Mahmood, A., \& Park, J. W. (2019) TiO2/CdS nanocomposite stabilized on a magnetic-cored dendrimer for enhanced photocatalytic activity and reusability. Journal of colloid and interface science, 555, 801-809. https://doi.org/10.1016/j.jcis.2019.08.036.

170. Xiao, S. R., Huang, B. Q., Chen, Q. H., Xue, H., Qian, Q. R., Xiao, L. R., ... \& Xu, J. (2015). Photocatalysis Activity of TiO2Based/Dendrimer Phthalocyanine Nanocomposite Photocatalyst. In Applied Mechanics and Materials (Vol. 703, pp. 86-89). Trans Tech Publications Ltd. https://doi.org/10.4028/www.scientific.net/AMM.703.86.

171. Monzavi, A., Montazer, M., \& Malek, R. M. A. (2017). A novel polyester fabric treated with nanoclay/nano TiO 2/PAMAM for discoloration of reactive red 4 from aqueous solution under UVA irradiation. Journal of Polymers and the Environment, 25(4), 1321-1334. https://doi.org/10.1007/s10924-016-0905-1.

172. Nzaba, S. K., Nyoni, H. H., Mamba, B. B., \& Kuvarega, A. T. (2019). Comparative Study of Dendrimer-Templated NitrogenPlatinum Co-Doped TiO2 for the Photocatalytic Degradation of Azo Dyes in Contaminated Water. Chemistry Select, 4(41), 12156-12163. https://doi.org/10.1002/slct.201903170.

173. Chronopoulos, D. D., Karousis, N., Zhao, S., Wang, Q., Shinohara, H., \& Tagmatarchis, N. (2014). Photocatalytic application of nanosized CdS immobilized onto functionalized MWCNTs. Dalton Transactions, 43(20), 7429-7434. DOI: 10.1039/C3DT53338G.

174. Wang, Q., Xiang, Y., Li, X., Zhang, W., Huang, X., \& Qian, X. (2021). Stable construction of layered reduced grapheme oxide/copper sulfide composites on cellulose fibers with hyperbranched polyamide-amine for efficient photocatalytic degradation of organic dyes. Industrial Crops and Products, 170, 113695. https://doi.org/10.1016/j.indcrop.2021.113695.

175. Mousavi, S., Shahraki, F., Aliabadi, M., Haji, A., Deuber, F., \& Adlhart, C. (2019). Nano-fiber immobilized CeO2/dendrimer nanoparticles: An efficient photocatalyst in the visible and the UV. Applied Surface Science, 479, 608-618. https://doi.org/10.1016/j.apsusc.2019.02.119.

176. Kutz, A., Mariani, G., Schweins, R., Streb, C., \& Groehn, F. (2018). Self-assembled polyoxometalate-dendrimer structures for selective photocatalysis. Nanoscale, 10(3), 914-920. DOI: 10.1039/C7NR07097G.

177. Mohammadi, A., \& Shahmirzaei, M. (2022). Polyamidoamine Dendrimers-MoS2 Nano-composites for Photocatalytic Degradation of Chlorpyrifos and Glyphosate Pesticides. Analytical and Bioanalytical Chemistry Research, 9(1), 21-31. https://doi.org 10.22036/abcr.2021.271647.1595.

178. Shaku, K. M., Dlamini, L. N., \& Malinga, S. P. (2020). Highly efficient photocatalytic hyperbranched polyethyleneimine/bismuth vanadate membranes for the degradation of triclosan. International Journal of Environmental Science and Technology, 17(6), 3297-3312. https://doi.org/10.1007/s13762-020-02699-9.

179. Guo, B., Zhang, B., Cong, Q., Ma, L. W., He, X. C., Gao, M. J., ... \& Li, G. (2016). Surface Modification of Low-Dimensional Heterostructured Functional Materials with Dendrimers and their Properties of Organic-Inorganic Nanocomposites. In Materials Science Forum (Vol. 847, pp. 299-307). Trans Tech Publications Ltd. https://doi.org/10.4028/www.scientific.net/MSF.847.299.

180. Ghanem, A. F., Badawy, A. A., Mohram, M. E., \& Abdelrehim, M. H. (2019). Enhance-ment the photocatalytic and biological activity of nano-sized $\mathrm{ZnO}$ using hyperbranched polyester. Journal of Inorganic and Organometallic Polymers and Materials, 29(3), 928-938. https://doi.org/10.1007/s10904-018-01067-y.

181. Krishnakumar, B., \& Imae, T. (2014). Chemically modified novel PAMAM-ZnO nano-composite: synthesis, characterization and photocatalytic activity. Applied Catalysis A: General, 486, 170-175. https://doi.org/10.1016/j.apcata.2014.08.010.

182. Duarah, R., \& Karak, N. (2019). Hyperbranched polyurethane/reduced carbon dot-zinc oxide nanocomposite-mediated solarassisted photocatalytic degradation of organic contaminant: an approach towards environmental remediation. Chemical Engineering Journal, 370, 716-728. https://doi.org/10.1016/j.cej.2019.03.248.

183. Yang, J., Chu, S., Guo, Y., Luo, L., Kong, F., Wang, Y., \& Zou, Z. (2012). Hyperbranched polymeric N-oxide: a novel kind of metal-free photocatalyst. Chemical Communications, 48(29), 3533-3535. DOI: 10.1039/C2CC30308F. 